University of Rhode Island

DigitalCommons@URI

Open Access Dissertations

1993

\title{
The Transtheoretical Model Applied to Safer Sex Behavior Among University Students: A Cross-Sectional Investigation
}

Colleen A. Redding

University of Rhode Island

Follow this and additional works at: https://digitalcommons.uri.edu/oa_diss

\section{Recommended Citation}

Redding, Colleen A., "The Transtheoretical Model Applied to Safer Sex Behavior Among University Students: A Cross-Sectional Investigation" (1993). Open Access Dissertations. Paper 1120.

https://digitalcommons.uri.edu/oa_diss/1120

This Dissertation is brought to you for free and open access by DigitalCommons@URI. It has been accepted for inclusion in Open Access Dissertations by an authorized administrator of DigitalCommons@URI. For more information, please contact digitalcommons-group@uri.edu. 
THE TRANSTHEORETICAL MODEL APPLIED TO

SAFER SEX BEHAVIOR AMONG UNIVERSITY STUDENTS:

A CROSS-SECTIONAL INVESTIGATION

BY

COLLEEN A. REDDING

A DISSERTATION SUBMITTED IN PARTIAL FULFILLMENT OF THE REQUIREMENTS FOR THE DEGREE OF DOCTOR OF PHILOSOPHY

IN

PSYCHOLOGY 


\begin{abstract}
This study applied the transtheoretical model of behavior change to safer sex adoption in a cross-sectional sample of 352 college students. The transtheoretical model has received empirical support in other areas of health behavior change and has important implications for intervention development. Variables assessed include the stages of change, decisional balance, confidence, temptation, processes of change, perceived risk, perceived severity, social desirability, and behavioral variables. Where possible, the sample was split randomly to conduct exploratory and confirmatory analyses. The Pros and Cons of safer sex were best represented by a 4 -factor model instead of the usual 2 -factor model. The new factors described concerns for self and relationship in safer sex decision making. Confidence in safer sex and Temptation for unsafe sex both revealed 5 lower-order situational factors: sexual arousal, perceived low risk, negative affect, substance use, and partner pressure. Processes of safer sex adoption analyses revealed all ten hypothetical processes of change, and one less common process, interpersonal systems control.
\end{abstract} MANOVAs and discriminant function analyses examined stage and gender differences. Different subsets of variables (transtheoretical model, demographics, and health beliefs model) were entered into several discriminant function analyses in order to predict AIDS risk group. The combination which best predicted AIDS risk group included variables from all sources, supporting theoretical eclecticism. Finally, a large cross-sectional structural equations model was developed using all model-based constructs. These constructs were used to predict behavioral constructs, risky and safer sexual behavior, which were intercorrelated $\underline{r}=-.323$. Reducing this large structural model to include only significant paths left 3 transtheoretical constructs accounting for nearly $31 \%$ of the variance in risky sexual 
behavior and $11 \%$ of the variance in safer sexual behavior. These three variables were: experiential processes, behavioral processes, and confidence in safer sex.

Results support the application of the transtheoretical model to safer sex adoption, as well as supporting model-based predictions about construct relationships in this area, with specific content-related differences between safer sex and other problem areas emerging for each scale. These results have important implications for AIDS risk reduction intervention development. 


\section{ACKNOWLEDGMENTS}

One cannot devote as much time as is necessary to a dissertation without a lot of support. There are many people to whom I am grateful for supporting me both academically and emotionally as I earned my degree. In my mind, their names arise in time sequence, not in order of importance, and that is how I will list them. Some of these friends and colleagues I met by chance, for example, the rest of my class: Sherri Nelson Fitts, Tony Giuliano, Pam Gibson, Ellen Kenner, and Terry Fitzgerald. There are many other friends and colleagues, to whom I am equally grateful: Pam Deiter, Chris Fiore Lerner, Dena Rosenbloom, Bob Porter, Mary Liz Callaway, Jeff Bellis, Sue Rossi, Matt Snow, Chris Dunstan, Judy Goldman, and Linelle Blais, among others. I have grown during the discussion, informal and formal supervision, and experience with each of them. My many supervisors have each supported me in different and helpful ways: Harriet Singer, Frank Sparadeo, Hanoch Livneh, Larry Grebstein, Allan Berman, Jim Prochaska, Trish Morokoff, Roger Mitchell, and Judith Lubiner from RI. From California, I feel grateful to Lorraine Sterman, Jean Holroyd, David Wellisch, Mary Neal, Deborah Cresswell, Val Herman, Fran Rockwell, Tom Kennon, Fawzy Fawzy, and Julia Schwartz: Almost all the URI Psychology department faculty have taught me in one course or another, and to them I am grateful, especially to Wayne Velicer, Lisa Harlow, John Stevenson, Al Lott, Jerry Cohen, Paul Florin, Charlie Collyer, Dom Valentino, Kat Quina, and those already listed. Many URI staff members have also been helpful, chiefly: Jean Mayer, Elaine Taylor, and Terri Hodson.

The Cancer Prevention Research Center, a.k.a. the Self Change Lab, has obviously has a strong influence on me, teaching me research methodology and critical thinking in both health and clinical psychology. I am grateful to "the lab" 
for providing a rigorous intellectual environment which has continually challenged me, as well as for financial support and collegiality.

My committee members have been quite patient and helpful, chief among them, of course, my major professor, Joe Rossi, who has served as mentor, role model, friend, and advisor since 1988. Our weekly breakfast meetings have been a great means to informally consider important questions and ideas.

I am grateful to my family members who have each been supportive in their own ways. Finally, I feel grateful to Christian Vye for all the extra chores he took care of when I was too busy, for moving with me to California, and for encouraging me. 


\section{PREFACE}

This dissertation is organized in manuscript format as follows: a general introduction to the area of safer sex adoption and AIDS; the first manuscript describing the Pros and Cons of Safer Sex; the second manuscript describing Confidence in Safer Sex and Temptation for Unsafe Sex; a third manuscript describing the Processes of Safer Sex, a fourth manuscript describing validation of the Stages of Change for Safer Sex; a fifth manuscript describing all the measures developed in this dissertation and their relationships to sexual behavior and AIDS risk; and finally, a general discussion of the implications of all this work taken together. This varies slightly with the format for a manuscript style dissertation recommended by the graduate school, however, my major professior and I agreed that it makes good sense in terms of logical progression, and ease of understanding for the committee. Portions of the Processes of safer sex paper were presented at the annual meeting of the Society of Behavioral Medicine in San Francisco, CA in March, 1993, and at the meeting of the American Psychological Association in Washington, D.C. in August, 1992. Portions of the Self Efficacy paper were submitted and are pending for presentation at the upcoming Association for the Advancement of Behavior Therapy conference in Atlanta, GA. 


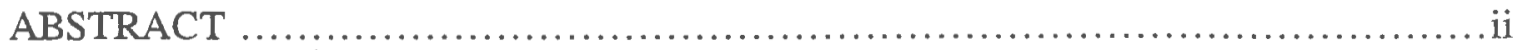

ACKNOWLEDGMENTS .................................................... iv

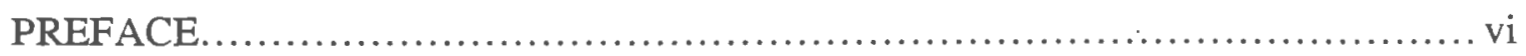

TABLE OF CONTENTS ................................................. vii

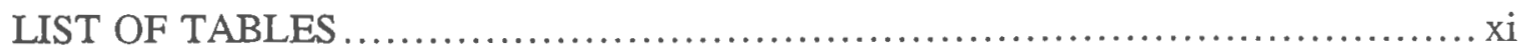

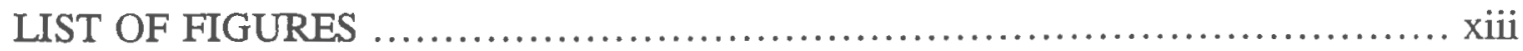

LIST OF ABBREVIATIONS ............................................ xiv

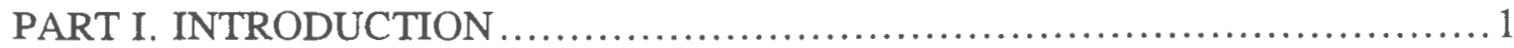

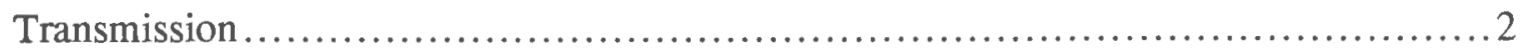

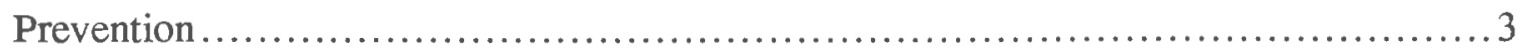

Knowledge \& Behavior ......................................................... 6

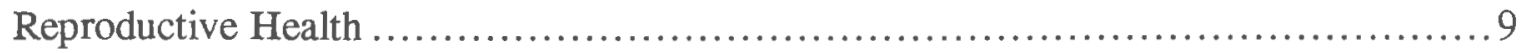

AIDS Risk in Heterosexuals ................................................... 11

College Student Populations .................................................. 11

The Transtheoretical Model .................................................... 15

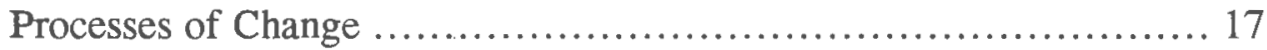

Decisional Balance ............................................. 18

Self-Efficacy ............................................... 19

PART II. PROS AND CONS OF SAFER SEX ............................... 25

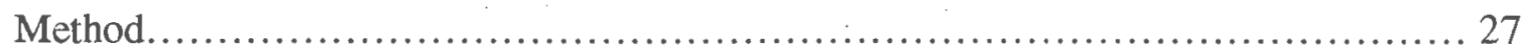

Subjects ................................................. 27

Measurement Development ..................................... 28

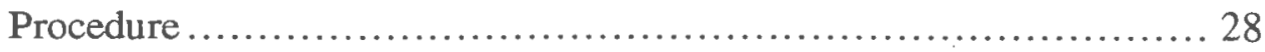

Analysis .......................................................... 28 
Results

Exploratory Analyses ......................................... 29

Confirmatory Analyses .......................................... 30

Model Validation ............................................. 34

Discussion ................................................................. 36

References..................................................................... 40

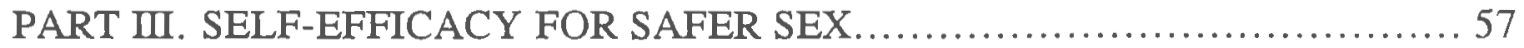

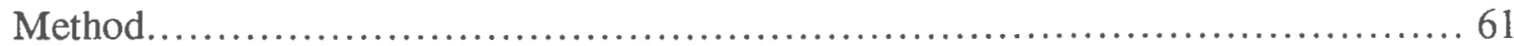

Subjects .................................................. 61

Procedure ....................................................... 61

Questionnaire Development.................................... 61

Results ....................................................................... 62

Questionnaire Development and Testing ......................... 62

Cross-validation and Model Testing .............................. 64

Hierarchical Models for Confidence and Temptation ................ 66

Stage X Self-Efficacy Analyses ................................. 68

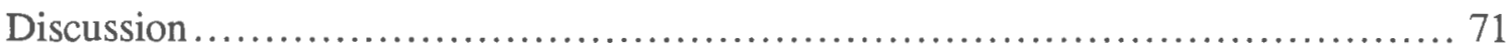

References.................................................................... 75

PART IV. PROCESSES OF SAFER SEX ADOPTION ........................... 97

Method..................................................................... 99

Subjects ................................................... 99

Procedure ...................................................... 99

Questionnaire Development.................................... 99

Results ....................................................................... 101

Questionnaire Development and Testing ........................ 101 
Model Testing................................................ 104

Hierarchical Model Testing ................................... 106

Stage By Process Analyses ..................................... 108

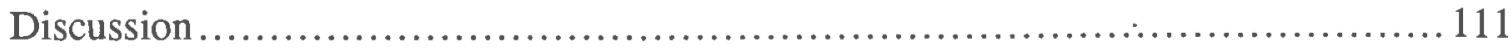

References...................................................................... 115

PART V. STAGES OF CHANGE FOR SAFER SEX $\ldots \ldots \ldots \ldots \ldots \ldots \ldots \ldots \ldots \ldots 14$

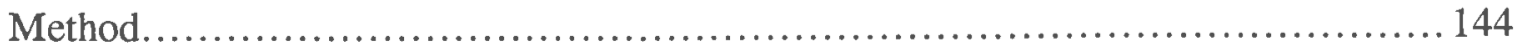

Subjects ..................................................... 144

Measures........................................................ 145

Procedure ...................................................... 145

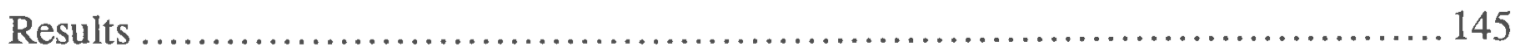

Stages of Change .............................................. 146

Validating Behavioral Data .................................... 148

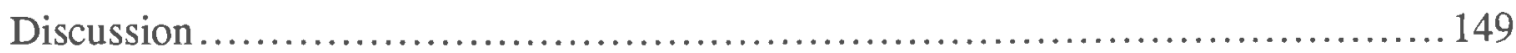

References.............................................................. 151

PART VI. PREDICTORS OF AIDS RISK, RISKY SEXUAL BEHAVIORS, AND

SAFER SEX BEHAVIORS ................................................... 161

Method..................................................................... 162

Subjects ..................................................... 163

Procedure ....................................................... 163

Measures..................................................... 163

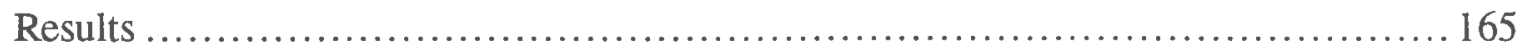

Discriminant Function Analyses.............................. 166

Structural Models Predicting Risky and Safer Sex Behaviors.......... 168

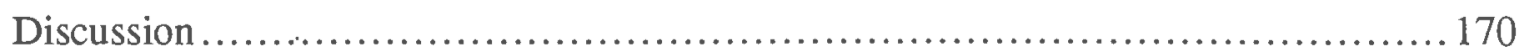


References.............................................................. 173

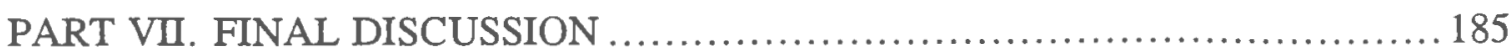

College Student Health ..................................................... 185

The Transtheoretical Model .................................................. 186

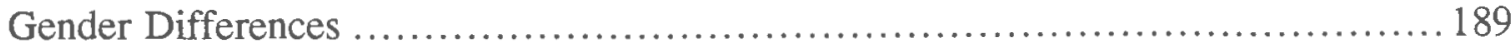

Recommendations for Future Research ...................................... 191

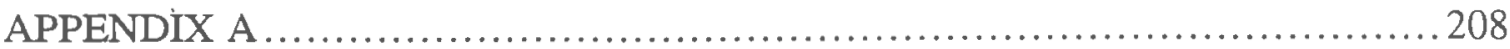

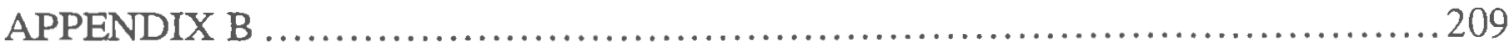

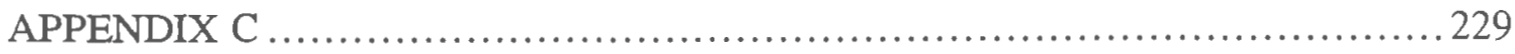

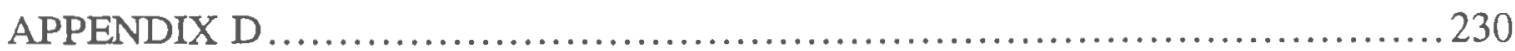

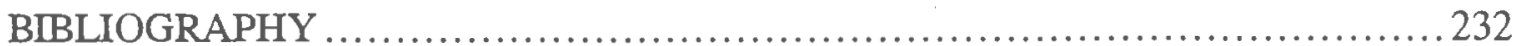




\section{LIST OF TABLES}

Table

1-1 Transtheoretical model-based applications ................................ 22

2-1 Decisional balance items and maximum likelihood factor loadings ............ 47

2-2 Decisional balance scale statistics and coefficient alphas ..................... 48

2-3 Decisional balance structural model fit indices............................. 49

2-4 Decisional balance subscale MANOVA results by Stage of Change............ 51

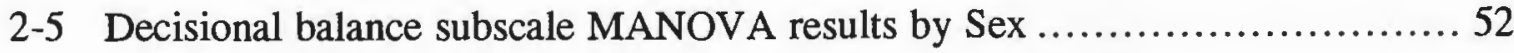

3-1 Confidence in safer sex maximum likelihood factor loadings.................. 84

3-2 Temptation for unsafe sex maximum likelihood factor loadings............... 85

3-3 CSS and TUS subscale statistics and coefficient alphas..................... 86

3-4 CSS and TUS structural model fit indices ................................. 87

3-5 Confidence in safer sex MANOVA results by Stage of Change ............... 88

3-6 Confidence in safer sex MANOVA results by sex............................ 89

3-7 Temptation for unsafe sex MANOVA results by Stage of Change.............. 90

3-8 Temptation for unsafe sex MANOVA results by sex ...................... 91

4-1 Processes of safer sex general definitions................................. 124

4-2 Processes of safer sex items and maximum likelihood factor loadings ......... 126

4-3 Processes of safer sex scale statistics and coefficients alphas ................ 130

4-4 Processes of safer sex structural model fit indices ............................ 131

4-5 Processes of safer sex MANOVA results by Stage of Change.................. 132

4-6 Processes of safer sex MANOVA results by sex.......................... 134

4-7 Group centroids and DFA results predicting Stage of Change

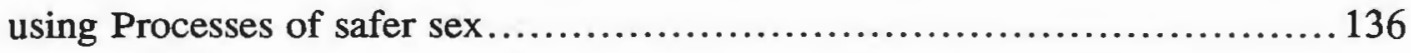

5-1 Number of methods of safer sex chosen by subjects ...................... 156 
5-2 Stages of Change distributions.

5-3 Sexual behavior MANOVA results by Stages of Change

5-4 Group centroids and DFA results predicting Stage of Change using Behavioral Variables

6-1 Group centroids and DFA results predicting AIDS risk group using HBM variables 176

6-2 Group centroids and DFA results predicting AIDS risk group using TTT variables 177

6-3 Group centroids and DFA results predicting AIDS risk group using all variables 179

6-4 Maximum likelihood factor correlations among all variables 182

7-1 Demographic information on the entire sample 192

7-2 Sexual behavior frequencies on the entire sample 196

7-3 Sexual behaviors MANOVA by Stages of Change 198

7-4 Sexual behaviors MANOVA by Sex. 200

7-5 Numbers of sexual partners during different time periods.... 202

7-6 Relationships characteristics of subjects in a relationship..... 203

7-7 Reasons for primary abstinence among sexually abstinent subjects 205 


\section{LIST OF FIGURES}

Figure $\quad$ Page

2-1 Decisional balance 2 hierarchical factor structural model .................... 54

2-2 Decisional balance 4 hierarchical factor structural model .................... 55

2-3 Decisional balance subscale T-scores across the Stages of Change. ........... 56

3-1 Confidence in safer sex structural model loadings $\ldots \ldots \ldots \ldots \ldots \ldots \ldots \ldots \ldots . \ldots 9$

3-2 Temptation for unsafe sex structural model loadings...................... 94

3-3 Confidence in safer sex subscales by Stage of Change..................... 95

3-4 Temptation for unsafe sex subscales by Stage of Change.................... 96

4-1 Processes of safer sex structural model loadings........................... 138

4-2 Behavioral processes of safer sex by Stage of Change ..................... 139

4-3 Experiential processes of safer sex by Stage of Change ...................... 140

6-1 Significant predictors of risky and safer sex behavior.................... 184

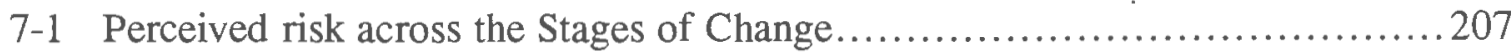




\section{LIST OF ABBREVIATIONS}

AIDS - acquired immune deficiency syndrome

ARRM - AIDS risk reduction model (Catania, Kegeles, \& Coates, 1990)

BBI - Bentler \& Bonnet fit index (Bentler \& Bonett, 1980)

CAX - component analysis extended (Velicer, Zwick, Harrop, \& Fava, 1993)

CDC - Centers for Disease Control and Prevention

CFI - comparative fit index (Bentler, 1990)

CSS - Confidence in Safer Sex

ECA - exploratory component analysis

GFI - goodness of fit index (Jöreskog \& Sörbom, 1984)

HIV - human immunodeficiency virus

HPV - human papillomavirus

HSV - herpes simplex virus

IAI - insertive anal intercourse

IFI2 $\left(\chi^{2}\right)$ - incremental fit index, type 2 (Mulaik et al., 1989)

IV - intravenous

IVDU - intravenous drug user

LISREL - linear structural equations modeling program

(Jöreskog \& Sörbom, 1984)

MAP - minimum average partial (Velicer, 1976)

NSFG - National Survey of Family Growth

PCA - principal component analysis

PSS - Processes of Safer Sex

PWA - people with AIDS

RAI - receptive anal intercourse 
RDD - random digit dial

RMR - root mean square residual (Jöreskog \& Sörbom, 1984)

STD - sexually transmitted disease

TLI - Tucker - Lewis fit index (Tucker \& Lewis, 1973)

TUS - Temptation in Unsafe Sex

WHO - World Health Organization

US - United States of America

USDHHS - US Department of Health and Human Services 
PART I

INTRODUCTION

Recent reports indicate that 210,000 people are currently diagnosed with acquired immune deficiency syndrome (AIDS) in this country with incidence rates still rising (CDC, 1992). Approximately 20-25\% of the currently reported AIDS cases are in the 20-29 year age group, and an even larger percentage are between 30-39 years old. Due to the decade long incubation period of human immunodeficiency virus (HIV) many of these cases must have become infected with the virus during their teens and twenties (CDC, 1992). Again, due to this 8-10 year latency period between HIV exposure and AIDS diagnosis, the numbers of those already infected, but currently asymptomatic have been estimated to be as high as 1 million people in the US alone. Because these individuals are asymptomatic and likely unaware of their HIV seropositive status, there is potential for even more viral transmission to even greater numbers of people. The numbers of those indirectly affected by AIDS through bereavement are, of course, much larger (Fawzy, Fawzy, \& Pasnau, 1991; Martin \& Dean, 1993). In this country the AIDS situation is somewhat unique, since the disease first appeared among homosexual/bisexual men and intravenous (IV) drug users. On a global basis, the majority of AIDS cases are heterosexually transmitted, and the World Health Organization (WHO) estimates that by the year $2000,90 \%$ of all HIV infections will be transmitted heterosexually (Aral \& Holmes, 1991). Unfortunately, although medical research has extended the life span of people with AIDS (PWAs) somewhat, five year fatality rates for those with an AIDS diagnosis approach $100 \%$. While continuing medical research designed to improve prognosis for PWA's is important, primary prevention efforts at the other end of the disease trajectory, targeting those who may not yet be 
infected with HIV is equally compelling. In fact, since there is no known medical cure for HIV infection, behavioral prevention is currently the only means to halt the virus' spread.

\section{Transmission}

HIV is transmitted through direct exposure to body fluids rich with T-4 lymphocytes, i.e. blood, semen, and vaginal secretions (Hatcher, Stewart, Trussel, Kowal, Guest, Stewart, \& Cates, 1990). Exposure can occur perinatally if the mother is infected with HIV. In all other cases, exposure to these fluids occurs primarily through sexual contact and/or inoculation with infected blood from: intravenous (IV) needle sharing; blood transfusion; accidental needle stick; and/or injection with an unsterilized needle (e.g., tatoo, acupuncture). These modes of transmission are strongly influenced by the lifestyle and habitual behaviors of the individuals at risk. Several potential modes of HIV transmission are no longer considered risks: exposure to nasal secretions, sweat, tears, feces, urine, or vomitus, unless any of these also contain blood. The risk of salivary transmission of HIV is remote, although salivary transmission was documented in at least one case (Valdiserri, 1989). Salivary transmission would be difficult to evaluate however, since it is rarely the only means of sexual expression. Further, HIV is not transmitted by casual contact with PWA's (e.g., shaking hands, hugging, dry kissing, sneezing, coughing, sharing eating/drinking utensils, sharing toilets or kitchens, swimming in a pool) or by insect bites (Hatcher et al., 1990).

HIV transmission is ultimately a function of the infectivity of the donor (which varies over the course of HIV infection), the vulnerability of the host, and the type and frequency of sex acts between the donor and host (Catania, Gibson, 
Chitwood, \& Coates, 1990). Even when one partner is HIV positive and unprotected vaginal, anal, and/or oral sex occurs repeatedly, not all "hosts" seroconvert (Valdisseri, 1989). Because of the fluid dynamics of vaginal intercourse, women are at increased risk for a variety of sexually transmitted diseases (STD), including AIDS, compared to men. For example, a woman is twice as likely to become infected with gonorrhea after having unprotected sex once with an infected partner compared to a man (Hatcher et al., 1990). These fluid dynamics also apply to anal sex, such that receptive anal intercourse (RAI) is considered much more risky than insertive anal intercourse (IAI) for a man (Valdisseri, 1989): Also, anal sex is considered more risky than vaginal sex, it was thought, because of its relative lack of lubrication, which could result in many small tissue wounds inside the rectum which would then be exposed to semen. More recent evidence suggests that HIV can directly infect the cells lining the lower rectum (Valdisseri, 1989). Generally, oral sex is considered a lower risk activity than anal or vaginal sex, however, again, this is difficult to assess since it is rarely the sole means of sexual expression. In general, different sex acts carry somewhat different risk, however a precise risk assessment of each act in isolation would not be possible due to the clustering of sex acts. Any unprotected vaginal, anal, or oral sex is considered risky, unless the serostatus of both participants is definitely HIV negative (Hatcher et al., 1990; Valdisseri, 1989).

\section{Prevention}

Behavioral prevention of HIV and other STD exposure is currently a high national priority (PHS, 1991; Rugg, 1990). Reducing the rates of IV drug use and the prevalence of needle sharing will serve to protect IV drug users (IVDU) from 
inoculation with infected blood. Increasing the sterile precautions taken in medical and dental settings will reduce incidental transmission to both patients and health care workers through health care settings, although needle-sticks are still bound to occur (Hatcher et al., 1990). There are disagreements about the best recommendations to prevent sexual exposure to HIV. These disagreements have strong sociocultural roots in our culture, which have been evidenced historically during other STD outbreaks (Brandt, 1988; Fineberg, 1988). Some argue that only sexual abstinence is $100 \%$ effective, and therefore that sexual abstinence or "just say no" is the best recommendation. Often hidden in this argument is the view that sexual activity is inherently "bad" and should be punished. This position is often promoted by fundamentalist religious and/or moralistic groups (e.g., "gonna play, gotta pay"). Also apparent is the fear that promoting condom use or educating young people about sexuality will increase their sexual activity, in spite of evidence to the contrary (Hatcher et al., 1990). A different, more pragmatic view counters that sexual abstinence is unrealistic for most people, that "just say no" has not worked well to reduce drug use, and therefore, that promoting use of latex condoms will diminish public health risk over time (Valdiserri, 1989). To complicate matters further, condoms are imperfect protection, since they can slip off or break and are often used incorrectly (e.g., put on too late) (Catania et al., 1992). Condom contraceptive failure rates during the first year of use ranged from 4-14\%, although the most common error is failure to use it at all. The additional use of a spermacide containing nonoxynol-9 increases contraceptive effectiveness from $88 \%$ to $99 \%$ (Hatcher et al., 1990). It remains unclear to what extent contraceptive effectiveness translates into STD or HIV prevention effectiveness. "Condom use is beneficial in 
reducing the cumulative risk, though if the prevalence of infection in the population of prospective partners is sufficiently high, even consistent condom use may not afford an adequate measure of protection over the long term. The benefit gained from use of condoms is more substantial moving from half-time to every-time use than in moving from no use to half-time use." (Fineberg, 1988, p. 239) This disagreement has unfortunately been fueled by political and religious agenda creating more heat than light, which has only further obscured an already complex issue (see Brandt, 1988; Fineberg, 1988; or Valdisseri, 1989 for more discussion on this). Safer sexual activities, i.e. those which limit direct contact with body fluids (e.g. massage, mutual masturbation, kissing, oral, anal, and vaginal sex using latex barriers) and reducing exposure to multiple sexual partners have been promoted. If public health officials with scientific advisors have had difficulty deciding on accurate AIDS prevention information to provide to the public, then one can only imagine the ambiguity and confusion in the public mind regarding AIDS risk and prevention. Unfortunately, these conditions provide the public with fertile ground for confusion, denial, and minimization of risk. Ultimately, this will only hinder the public health promotion of safer sex adoption and maintenance (Kraus, Siegel, \& Godfrey, 1993; Valdisseri, 1989).

During the 1980 's the warning to the sexually active family planning clinic clients, as well as to gay men, was to "know your partner" (Hatcher et al., 1990; Valdisseri, 1990), in spite of the fact that many sexual relationships occur between people who do not know each other well. Being more selective about sexual partners could be partly effective if the rate of infection in the population is low (Fineburg, 1988), however, it could also be spuriously comforting since one cannot 
tell even by asking whether someone has been exposed to HIV. Many people may not be willing, even when asked directly, to admit to risky behavior, especially in the early stages of a relationship when pressure to impress one's partner is greatest (Cochran \& Mays, 1989) and when any such admissions might limit the development of the relationship at all. Now, the admonition to the sexually active has become, "know your (HIV) serostatus" (Hatcher et al., 1990).

For heterosexuals, there are some generally agreed upon safer sexual guidelines, however. Sexual abstinence is the safest sexual practice. If one is going to be sexually active, however, condoms should be used for all sex acts involving genital secretions with all sexual partners. If the relationship is sexually exclusive, neither partner uses IV drugs, and both partners have tested HIV negative (preferably, twice 6 months apart), then condom use can be stopped safely, assuming contraception is not also an issue (Fineberg, 1988; Hatcher et al., 1990; Valdisseri, 1989). These are the guidelines for safer sex adopted in this study. Knowledge $\underline{\&} \underline{\text { Behavior }}$

Public information and awareness of AIDS has increased dramatically since its introduction to the medical literature in 1981 (Becker \& Joseph, 1988; Fineburg, 1988). Recently CDC reported that nationwide, only $47 \%$ of school districts required HIV education for 9 th -12 th grade students, in spite of rates of risky sexual activity which would support more education/ skills training (CDC, 1992). San Francisco adolescents knew that sexual intercourse or IV drug use could lead to HIV infection and $73 \%$ of them were afraid of getting AIDS. In spite of this, $61 \%$ responded that they "were not the kind of person at risk" for AIDS (DiClemente, Zorn, \& Temoshok, 1986). Similarly, $54 \%$ of Massachusetts youths (Strunin \& 
Hingson, 1987) stated that they were not concerned about getting AIDS. Several misconceptions about HIV transmission (e.g. via kissing, shaking hands, toilet seats, working with a PWA, that you can tell by looking if someone has AIDS, etc.) remain apparent as well (St. Lawrence, 1993). Importantly, such misunderstandings could lead to ineffective efforts to prevent exposure to $\mathrm{HIV}$, not to mention scapegoating and victimization of PWA's (DiClemente et al., 1986). Several studies have found high rates of AIDS knowledge in the general public, but no relationship between AIDS knowledge and preventive behaviors (Baldwin \& Baldwin, 1988; DiClemente, Lanier, Horan, \& Lodico, 1991; DiClemente, Durbin, Siegel, Krasnovsky, Lazarus, \& Comacho, 1992; Fineberg, 1988).

In one study, of the $15 \%$ who indicated that they had changed their sexual behavior in response to AIDS, only $20 \%$ were doing so in effective ways (i.e. $10 \%$ abstinent and 10\% using condoms reliably) (Strunin \& Hingson, 1987). The majority $(60 \%)$ of those who said they had changed their behavior in response to AIDS were being more selective/careful about their sexual partners. Increasing selectiveness of sexual partners could be partly effective if the rate of infection in the population is low (Fineburg, 1988), however, it could also be erroneously comforting since one cannot tell even by asking if someone has been HIV exposed (Cochran \& Mays, 1989).

In a San Francisco clinic-based sample that was followed for one year, only $2 \%$ of females and $8 \%$ of males reported that they use condoms every time they had intercourse (Kegeles, Adler, \& Irwin, 1988). More hopefully, another group (Hingson, Strunin, Berlin, \& Heeren, 1990) found that $31 \%$ of their teenage sample endorsed using condoms every time they had intercourse. Unfortunately, subjects 
with more sexual partners were actually less likely to use condoms than their counterparts with fewer sexual partners (Hingson et al., 1990). That subjects engaging in higher risk activities are actually less likely to use condoms has been found repeatedly (Biglan, Metzler, Wirt, Ary, Noell, Ochs, French, \& Hood, 1990; DiClemente et al., 1991; 1992). In fact, Biglan et al. (1990) found that sexual risk behaviors for AIDS were significantly related to other health risk behaviors such as cigarette smoking, alcohol use, and drug use. A different group found a relationship between not wearing seatbelts and having risky sex (Baldwin \& Baldwin, 1988). Others have noted this clustering of risk behaviors or multiple risk factors among adolescents and young adults (Dryfoos, 1991; St. Lawrence, 1993).

In summary, research has revealed that many young adults are aware of the most important behaviors which are risky, but they are confused about other potential modes of transmission, that they apply protective strategies unsystematically, that they evaluate their risk in terms of their perceived similarity/ dissimilarity to risk group stereotypes instead of by assessing which risk behaviors they have engaged in, and that those engaging in the highest risk activities may actually be the least likely to apply preventive strategies (Biglan et al., 1990; DiClemente et al., 1986; 1991; 1992; Fisher, 1988; Price, Desmond, \& Kukulka, 1985; Siegel \& Gibson, 1988; Strunin \& Hingson, 1987). Although studies of AIDS awareness and prevention are relatively new to the literature, research on reproductive health, i.e., contraception, STD prevention, and pregnancy prevention, are also relevant (Brandt, 1988; CDC, 1992; Hatcher et al., 1990). 
Reproductive Health

Literature on adolescent pregnancy compiled by the National Survey of Family Growth (NSFG) found that $60 \%$ of females and $75 \%$ of males had had intercourse by their 19th birthdays (Brooks-Gunn, Boyer, \& Hein, 1988; Hayes, 1987). Slightly different recent figures are that $51 \%$ of females and $57 \%$ of males in grades 9-12 reported ever having had sexual intercourse (CDC, 1992). Within the NSFG sample, only $52 \%$ had used any contraception at all the first time they had intercourse. Of those that do use contraception, only half cite condoms as their main method, while slightly less than a quarter cite "withdrawal" (Hayes, 1987). Although teen sexual activity in the US is comparable to estimates from other Western democracies, effective contraceptive use is considerably lower (Jones et al., 1986). Increasing safer sexual practices (i.e. use of condoms, secondary abstinence, etc.) would serve to reduce the risk of contracting AIDS, along with other STDs, and potentially, to reduce the relatively high rate of unwanted pregnancy in this country as well (CDC, 1992; Hatcher et al, 1990; Torres \& Forrest, 1985; Ventura, Taffel, \& Mosher, 1988).

Educational efforts directed at increasing contraceptive use, while costly and intensive, have not appeared to significantly decrease the rates of teenage pregnancy (Marsiglio \& Mott, 1986), although there are exceptions (Vincent, Clearie, \& Schluchter, 1987). Studies of knowledge acquisition reveal that a significant proportion of teens have had formal sex and contraceptive education by age 18, and, as with other health behaviors, although education does improve contraceptive knowledge, it is insufficient to predict contraceptive behavior (Dawson, 1986). 
One estimate of the incidence of unprotected sex in college aged subjects is the rate of abortion in this age group. Of the 2.5 million pregnancies which occurred in 1983 to US women between $18-24$ years old, $31.5 \%(793,000)$ of them resulted in abortions (Ventura, Taffel, \& Mosher, 1988). This is an underestimate of unwanted pregnancies in this age group, since some women elect to continue an unintended pregnancy. Some pregnancies resulted from contraceptive failures, while others resulted from lack of contraceptive use. Although exact figures were not available on the same data, estimates from other data collected in 1979 are that $69 \%$ did not use contraception when they became pregnant (Hayes, 1987, p. 56). Another study found that one-third of sexually active college students were using an unreliable method (e.g. withdrawal) or no contraception at all at their last intercourse (Strassberg \& Mahoney, 1988). Either figure suggests a high rate of unprotected sex for 18-24 year olds, and a consequent risk of HIV exposure.

Individuals under 25 years old account for the majority of STD cases. "STDs are getting worse in both magnitude and severity; syphilis and antibiotic resistant strains of gonorrhea are at decade high levels" (Hatcher et al., 1990, p. 91). The term, "sexually transmitted disease," is a relatively new one, replacing the older and more pejorative, "venereal disease." Whereas venereal diseases traditionally referred to bacterial infections (e.g., syphilis, gonorrhea, etc.), sexually transmitted diseases (STDs) today include more than 20 organisms and syndromes, including both bacterial and viral infections (e.g., chlamydia trachomatis, herpes simplex virus (HSV), human papillomavirus (HPV), HIV, etc.). The consequences of STDs (excluding HIV) include pelvic inflammatory disease, genital cancers, infertility, perinatal transmission, and ultimately if untreated, dementia and/or death (Hatcher 
et al., 1990). In addition, some STDs (HSV, canchroid, gonorrhea, etc.) increase the likelihood of infection with HIV by causing cervical or genital skin ulcerations and are, therefore, considered co-factors (Aral \& Holmes, 1991; Catania et al., 1990).

\section{$\underline{\text { AIDS }}$ Risk in Heterosexuals}

A recent large-scale national random digit dial (RDD) study of risky sexual behavior shed some light on how much risk the U.S. heterosexual adult population may be exposed to for HIV (Catania, Coates, Stall, Turner, Peterson, Hearst, Dolcini, Hudes, Gagnon, Wiley, \& Groves, 1992). In general, between 15 and 41 percent of about 10,000 heterosexuals reported at least one risk factor associated with HIV (multiple sexual partners, risky sexual partner(s), or blood transfusion recipient). Of those at risk, between 10-17 percent were using condoms all the time. Analyses of demographic predictors found that respondents were more likely to report multiple sexual partners if they were: educated beyond high school (vs. not), single (vs. cohabiting or married), male (vs. female), African-American or white (vs. Hispanic), and aged in their 20's (vs. 30's, 40's, 50's or 60's). This certainly implicates college-aged populations as at increased risk on almost all counts.

\section{College Student Populations}

Although most interventions to date have targeted the highest risk groups, gay men, IVDU's, hemophiliacs, prostitutes, and their partners, there are many good reasons to target college-aged heterosexuals to reduce risk of HIV exposure. Rates of AIDS have grown fastest in those between 20-30 years old, and with the 8- 
10 years between exposure to HIV and the development of AIDS, most of these likely contracted the virus during their teens and 20's (CDC, 1992; Severn, 1990).

College students have generally had more sexual experience than their high school counterparts. A survey of 390 male and female college students found that $81 \%$ of them had engaged in vaginal sex (Redding, Rossi, Velicer, \& Prochaska, 1989). Other surveys of college students have found roughly similar percentages (81.5\% of $\underline{\mathrm{N}}=851$, Baldwin \& Baldwin, $1988 ; 96.2 \%$ of $\underline{\mathrm{N}}=599$, Severn, 1990 ; $71 \%$ of $\underline{\underline{N}}=248$, Sacco, Levine, Reed, \& Thompson, $1991 ; 87 \%$ of $\underline{N}=109$, Grimley, Riley, Bellis, \& Prochaska, 1993), although some studies targeting only women have found slightly smaller percentages $(61 \%$ of $\underline{N}=339$, Paxton \& Quina, 1989).

One study found the average age of first intercourse among college students to be 17 years old, and that students averaged 2 sexual partners per year during college (Baldwin \& Baldwin, 1988). Consistent condom use was reported for only $13 \%$ of this sample. Again, in this study, AIDS knowledge was unrelated to condom use (Baldwin \& Baldwin, 1988).

For many young people, college may be the first time they are away from home and out from under parental supervision and authority. This coincides with ample social opportunities on most college campuses, as well as opportunities to experiment with alternative lifestyle and identity choices (e.g., alcohol, drugs, sexuality, religious groups, political groups, etc.) (Baldwin \& Baldwin, 1988; Severn, 1990). Developmentally, young people are asking themselves the question, "Who am I, apart from my family? and Who do I want to become?" At the same 
time, if they have not already engaged in sexual intercourse, they may feel freer as well as more prepared to try it now.

Peer influences are strong in college (Biglan et al., 1990; Fisher, 1988; Fisher \& Fisher, 1992; Manning, Balson, Barenberg, \& Moore, 1989). The perception that "everybody else is doing it" may pressure some young people to initiate risky behaviors that they would not otherwise have participated in, especially in some subgroups such as fraternities or sororities. Weinstein $(1983,1984)$ has studied risk assessment among several samples, including but not limited to college students, and found a systematic underestimation of risk for a number of illnesses, including venereal diseases, relative to peers. He termed this phenomenon "optimistic bias." This bias was more apparent for diseases which subjects felt they could control through their personal actions, lifestyle, and psychological factors. Optimistic bias was not apparent for diseases for which subjects ascribed causality to either heredity or the environment.

The Health Beliefs Model (Becker, 1974; Cummings, Jette, \& Rosenstock, 1978; Maiman, Becker, Kirscht, Haefner, \& Drachman, 1977) posits assessment of personal susceptibility (risk) as vital to subsequent preventive action, and this model has received empirical support in the area of AIDS risk reduction (Hingson et al., 1990). Others have noted the sense of invulnerability in this age group (Baldwin \& Baldwin, 1988; Manning et al., 1989; Severn, 1990). Some have postulated that sensation-seeking or risk-seeking is a trait level variable which underlies many findings (Earleywine \& Finn, 1991; Wyatt, 1990).

Several studies have found an empirical relation between substance use and sexual behavior (Buffam, 1988; Clapper \& Lipsitt, 1991; Earleywine \& Finn, 1991; 
Flavin \& Frances, 1988; Hingson, Strunin, Berlin, \& Heeren, 1990; Kegeles, Adler, \& Irwin, 1988; Leigh, 1990; Martin; 1990; Mott \& Haurin, 1988; Nagy, Hunt, \& Adcock, 1990; Rosenbloom, 1991; Stall, McKusick, Wiley, Coates, \& Ostrow, 1986). In spite of physiological evidence to the contrary, there is a public perception that substance use increases sexual arousal (Leigh, 1990). This is explained through sexual disinhibition secondary to substance use. An alternative explanation is that sensation-seeking is the third variable accounting for the observed relationship between behavioral disinhibition and alcohol consumption (Earleywine \& Finn, 1991; Leigh, 1990). In addition, alcohol and certain drugs are part of the "dating scene," and are therefore, inextricably tied to sexual relationship formation and development (Leigh, 1990).

Sexual behavior change studies have been largely epidemiological, focusing on sociodemographic predictors of who is at highest risk for HIV exposure, AIDS, and other STD's. Epidemiological research has been very useful for quickly identifying geographic areas of highest risk and modes of transmission, the appropriate first priorities of public health officials in dealing with a relatively new disease. However, this approach has also led to a focus on risk groups as opposed to risk behaviors, among not only the general population, but clinicians and researchers as well. This descriptive empirical work has produced a set of demographic "marker" variables, i.e. variables which do not cause STD's (e.g. race), but which, due to both their strong relationship to a causal third variable (e.g. poverty, risky behaviors, lack of education) and their ease of measurement, emerge as significant predictors. These "marker" variables are somewhat useful, but they may not identify the underlying causal factors which increase risk among certain 
individuals or groups, nor do they help us develop means of intervention or prevention. Demographic variables are not amenable to intervention. This is where psychological theories of health behavior change can be most useful. These are only a few of the reasons why public health officials and researchers have called upon psychologists for more rigorous assessment of how knowledge and attitudes are related to risk reduction efforts, along with a theoretical model which would explain why some people do not modify their sexual behavior despite adequate education (Becker \& Joseph, 1988; Catania, Kegeles, \& Coates, 1990; Fisher \& Fisher, 1992; Flora \& Thoreson, 1989; Kelly \& Murphy, 1992). The transtheoretical model is one such model for sexual behavior change.

\section{The Transtheoretical Model}

Although the transtheoretical model was originally developed within the context of psychotherapy (Prochaska \& DiClemente, 1982, 1984), most empirical support for this model has been found investigating the addictive behaviors (Prochaska \& DiClemente, 1985, 1986a, in press; Prochaska, DiClemente, \& Norcross, 1992a; 1992b; Prochaska \& Prochaska, in press a, in press b), especially smoking cessation (DiClemente, Prochaska, Fairhurst, Velicer, Velasquez, \& Rossi, 1991; Prochaska \& DiClemente, 1983, 1984b; Prochaska, DiClemente, Velicer, \& Rossi, in press). Table 1-1 illustrates the numbers of different empirical applications of the Model to quite different behaviors.

Insert Table 1-1 about here 
The Transtheoretical Model can serve as an integrative theme for accelerating change across a broad range of problem behaviors, as Table 1-1 demonstrates. However, there may be important differences between problem areas as well, which the model must accommodate. The objective of the proposed project is to extend and validate the trantheoretical model to the problem of AIDS risk reduction among college students.

Interventions designed to change lifestyle risk factors have frequently been less successful than expected, possibly because many programs are implicitly designed for individuals who are ready to take action, that is, ready to change their lifestyle behaviors (DiClemente et al., 1991). Yet, especially in newer problem areas, most people may not be ready to take action to reduce their risk. Results of the few studies to date on heterosexual practices reveals that only a small proportion of people are actually modifying their behavior as a precautionary step to decrease the risk of AIDS (Catania et al., 1992; Hingson et al., 1990; Kegeles, Adler, \& Irwin, 1988; Strunin \& Hingson, 1987). In addition, significant proportions continue to feel that they are at little or no risk for contracting AIDS (Price, Desmond, \& Kukulka, 1985; Strunin \& Hingson, 1987). If we are to accelerate the rate of behavior change efforts with this population, interventions will have to be developed that are targeted not only for those who are ready to take action, but also for a significant proportion who are only considering changing their behavior (contemplators) and even those who are not intending to change their behavior (precontemplators).

Research on how people change behavior in the natural environment (selfchange) as well as through intervention programs reveals that people progress 
through a series of stages, from precontemplation to contemplation to preparation to action and into maintenance (DiClemente et al., 1991; Prochaska \& DiClemente, 1983, 1984, 1986). These stages apply both to the cessation of unhealthful behaviors, such as cigarette smoking, and to the acquisition of more healthful behaviors, such as regular exercise. However, progression through the stages is only rarely linear. For most health behavior problems, the majority of people relapse and recycle back to the precontemplation or contemplation stage several times, before they succeed in their efforts to modify the problem behavior. Current applications of the Transtheoretical Model to AIDS risk reduction efforts have not yet used the preparation stage due, in part, to the difficulty of choosing an adequate behavioral criterion (Grimley et al., 1992; Redding et al., 1989; Prochaska et al., 1990). More recent work on the preparation stage in the area of smoking cessation has suggested that the intention to change within the next 30 days is more important to defining the preparation stage than the recent quit attempt (Tsoh, Rossi, \& Prochaska, 1992).

\section{Processes of Change}

Smoking cessation and exercise adoption interventions which have been tailored to participants' stage of change have been more successful in modifying problem behaviors, than traditional action-oriented programs (Marcus, Banspach et al., 1992; Prochaska, Velicer et al., in press). The amount of progress people make in their efforts at self-change or as a result of professional intervention tends to be a function of the stage they are in at the start of treatment. One current prospective study of smoking cessation has found that helping people progress just one stage can double the chances that the participants will take action on their own in the near 
future (Prochaska et al., in press). It has been found that individuals apply different strategies or techniques (processes of change) as they progress through the different stages of change (Prochaska, Velicer, Guadagnoli, Rossi, \& DiClemente, 1991). Individuals who mismatch processes to stages are more likely to fail in their action attempts (Fitzgerald \& Prochaska, 1990; Prochaska, DiClemente, Velicer, Ginpil, \& Norcross, 1985).

\section{Decisional Balance}

Part of the decision to move to action is based on the relative weight given to the pros and cons of changing behavior so as to reduce risk. The pros represent positive aspects of changing behavior, and may be thought of as facilitators of change. The cons represent the negative aspects of changing behavior, and may be thought of as barriers to change. Importantly, the subject rates these possible attitudes in terms of their importance or salience to the subject's own decision making. The decisional balance inventory has been very successful in predicting action for smoking cessation (Velicer, DiClemente, Prochaska, \& Brandenburg, 1985), weight control (O'Connell \& Velicer, 1988), exercise adoption (Marcus et al., 1992), and psychological distress (Penney, 1988). In addition, longitudinal studies of smokers suggest that the positive aspects of changing a problem behavior begin to outweigh the negative aspects of change early in the contemplation stage (Prochaska et al., 1991).

The functional relationship of pros and cons across the stages of change has been replicated across twelve different problem behaviors (Prochaska, Velicer, Rossi, Goldstein, Marcus, Rakowski, Fiore, Harlow, Redding, Rosenbloom, \& Rossi, in press) and has led to the development of general principles of behavioral 
change (Prochaska, in press). This functional relationship has been found in preliminary studies of AIDS risk reduction (Redding, Rossi, Velicer, \& Prochaska, 1989) and studies of contraceptive behavior (Grimley, Riley, Bellis, \& Prochaska, in press) among college students, and in two community samples at high-risk for HIV exposure (Grimley, Riley, Prochaska, Redding, Ruggiero, Velicer, \& Rossi, 1992; Prochaska, Harlow, Redding, Snow, Rossi, \& Velicer, 1990). In these samples, the pros accounted for more of the variance in the movement through the stages, while the cons of safer sex or condom use remained relatively stable across the stages of change. This suggests that increasing the pros of change may be more effective in helping subjects move towards action than attempting to decrease the cons of change.

\section{Self-Efficacy}

Self-efficacy has become a nearly standard variable in the prediction of behavior, since its inception as part of Social Learning Theory (Bandura, 1977; 1982). The self-efficacy construct employed in the transtheoretical model integrates the model of self-efficacy proposed by Bandura $(1977,1982)$, and the coping models of relapse and maintenance described by Shiffman $(1982,1986$; Velicer et al., 1990). Independent investigations have found self-efficacy evaluations to predict AIDS risk reduction behaviors in different subject groups (Freeman, Cohn, Corby, \& Wood, 1991; Kelly et al., 1990; Grimley et al., 1992; Goldman \& Harlow, 1990; Prochaska et al., 1990; Schnell, Galavotti, \& O'Reilly, in press).

Self efficacy is an important mediating variable within the transtheoretical model, where it has been operationalized as both confidence in the new, healthful behavior and temptation to engage in the problem behavior, across a variety of 
problematic situations (Velicer et al., 1990). Confidence and temptation both vary across the stages of change, with confidence rising and temptation diminishing across longitudinal profiles of smokers (Prochaska et al., 1991). Confidence is typically lowest in the precontemplation stage, since individuals have little performance feedback and/or little interest in change. Confidence is higher during contemplation, outperforming other demographic variables in its ability to predict movement into Preparation and Action (DiClemente et al., 1991; Velicer et al., 1990). Confidence and temptation function inversely across the stages, although temptation predicts relapse better (Redding, Rossi, Fava, Snow, Rossi, Prochaska, Velicer, \& DiClemente, 1989). Even in the maintenance stage where subjects have successfully altered the problem behavior for at least six months, temptation is one or the best predictors of relapse and recycling to earlier stages of change. In longitudinal studies of smokers, some were quit for long periods of time, but still had moderate levels of temptation. With two independent populations at high risk for HIV exposure, self-efficacy (confidence) to use condoms significantly differentiated persons in precontemplation from those in contemplation, action, and maintenance stages for condom use (Grimley et al., 1992; Prochaska et al., 1990). These results suggest that the tailoring of self-efficacy interventions to the stage of change may accelerate progress through the stages and thus increase adoption of safer sex, as well as improve adherence. Such stage-targeted interventions have been useful for both smoking cessation and exercise adoption (Marcus et al., 1992; Prochaska, DiClemente, Velicer, \& Rossi, in press).

This cross-sectional study of college students will proceed in the following separate manuscript format parts: Pros and Cons of safer sex; Self-efficacy for safer 
sex; Processes of safer sex; Stages of change and validating behavioral data; modelbased predictors of AIDS risk group, and risky and safer sexual behavior; and finally, an overall discussion of these papers taken together. 
Table 1-1

Applications of the Transtheoretical Model

adolescent

delinquent behavior

AIDS risk reduction

alcohol use

cocaine use

contraception

\& condom use

dietary fat reduction

exercise adoption
Fiore-Lerner (1990)

Redding, Rossi et al. (1989)

Prochaska, Harlow et al. (1990)

Begin (1989)

DiClemente \& Hughes (1990)

Norcross, Prochaska, \& Hambrecht (1991)

Snow (1991)

Snow, Prochaska, \& Rossi (in press)

Rosenbloom (1991)

Martin, Rossi et al. (1992)

Grimley, Riley et al. (1992)

Grimley, Riley et al. (in press)

Rossi, Rossi, \& Prochaska (1990)

Curry, Kristal, \& Bowen (1992)

Greene, Rossi et al. (1992)

Rossi (1993)

Sonstroem $(1987 ; 1988)$

Marcus, Banspach et al. (199.2)

(Table 1-1 continues on next page) 
(Table 1-1 continued)

mammography

psychological distress

psychotherapy

radon exposure

smoking cessation
Marcus, Rakowski, \& Rossi (1992)

Marcus, Selby et al. (1992)

Marcus, Rossi et al. (1992)

Rakowski, Dube et al. (1992)

McConnaughy, Prochaska, \& Velicer (1983)

Norcross \& Prochaska (1986a; 1986b)

Norcross, Prochaska, \& DiClemente (1986)

McConnaughy, DiClemente et al. (1989)

O'Connell (1988)

Medeiros (1989)

Prochaska, Rossi, \& Wilcox (1991)

Bellis (1993)

Rossi (1990a)

Prochaska \& DiClemente (1983; 1984b)

Prochaska, DiClemente et al. (1985)

Velicer, DiClemente et al. (1.985)

Prochaska, Velicer et al. (1988)

Rossi, Prochaska, \& DiClemente (1988)

Fitzgerald \& Prochaska (1990)

Gottlieb, Galavotti et al. (1990)

Pallonen, Murray et al. (1990)

(Table 1-1 continues on next page) 
(Table 1-1 continued)

$\begin{array}{ll} & \text { Velicer; DiClemente et al. (1990) } \\ & \text { DiClemente, Prochaska et al. (1991) } \\ & \text { Prochaska, Velicer et al. (1991) } \\ & \text { Ahijevych \& Wewers (1992) } \\ & \text { Pallonen, Fava et al. (1992) } \\ & \text { Velicer, Hughes et al. (1992) } \\ & \text { Velicer, Prochaska et al. (1992) } \\ & \text { Velicer, Rossi et al. (1992) } \\ & \text { Kristeller, Rossi et al. (1992) } \\ & \text { Prochaska, DiClemente et al. (in press) } \\ & \text { Velicer, Prochaska et al. (in press) } \\ & \text { Stern, Prochaska et al. (1987) } \\ & \text { Elder, DeMoor et al. (1990) } \\ \text { smoking acquisition } & \text { Rossi (1989a; 1989b; 1990a) } \\ \text { O'Connell, \& Velicer (1988) } \\ \text { Clark, Abrams et al. (1991) } \\ \text { Prochaska, Norcross et al. (1992) } \\ \text { weight control }\end{array}$

Note: This is not intended as a complete list of Transtheoretical model based publications. Citations with more than 3 authors have been abbreviated. See bibliography for more complete citations. 
PART II

\section{PROS AND CONS OF SAFER SEX}

Recent reports are that 210,000 people are currently diagnosed with AIDS in this country with incidence rates still rising (CDC, 1992a). As AIDS has become an increasing public health concern, so primary and secondary prevention efforts have escalated, especially those targeting adolescents and young adults (Becker \& Joseph, 1988; Brooks-Gunn, Boyer, \& Hein, 1988; Flora \& Thoresen, 1988; Hingson, Strunin, Berlin, \& Heeren, 1990; Kegeles, Adler, \& Irwin, 1988; Strunin \& Hingson, 1987). To accelerate this process, researchers have called for the application of theoretical models from other areas of health behavior change (CDC, 1992b; Fisher \& Fisher, 1992; Flora \& Thoresen, 1988; Kelly \& Murphy, 1992; Valdisseri, 1989) .

The transtheoretical model (Prochaska \& DiClemente, 1983, 1984, 1986; Prochaska, DiClemente, \& Norcross, 1992) is a general model of health behavior change which has been successfully applied in several areas of health behavior change and risk reduction. The most fundamental aspect of this model describes a continuum of readiness to change called the stages of change: Precontemplation (not considering change or denying the need for it), Contemplation (seriously thinking about changing within the next 6 months), Action (has met some behavioral criterion for some minimal amount of time), and Maintenance (has maintained the change for at least 6 months). The stages of change describe whether or not sexual behavior has been changed in order to avoid the risk of AIDS transmission, how recently the change has occurred, or whether such change is intended in the near future. 
A second important component of the trantheoretical model which helps predict early stage movement is the concept of decisional balance. Generally, the process of decision making is conceived as one of weighing pros (positive attitudes, advantages, or facilitators) and cons (negative attitudes, disadvantages, or barriers) of behavior change. This concept was originally developed by Janis and Mann $(1968,1977)$ who hypothesized four components each for the pros and cons. For the pros, these include gains for self, gains for others, approval from self, and approval from others. Correspondingly for the cons, these hypothetical components include losses for self, losses for others, disapproval from self, and disapproval from others. Independent researchers have found attitudes towards condoms to be important predictors of both intention to use condoms and condom use (Abraham, Sheeran, Spears, \& Abrams, 1992; Sacco, Levine, Reed, \& Thompson, 1991; St. Lawrence, 1993).

In the area of smoking cessation, the pros and cons have been most useful in predicting movement from the precontemplation to contemplation stage of change (Prochaska, DiClemente, Velicer, Ginpil, \& Norcross, 1985; Prochaska, Velicer, Guadagnoli, Rossi, \& DiClemente, 1991), Decisional balance has important implications for intervention, since the relative weighting of pros and cons predicts early stage movement. Generally, in longitudinal studies, the pros of change exceed the cons of change until contemplation/preparation, when they are nearly equally weighted. This near equal weighting of pros and cons reflects subjects' ambivalence about change, and is the source of the term, decisional balance. As subjects prepare for action, the pros of change exceed the cons by greater degrees. Since most 
interventions are action-oriented, the pros and cons give valuable information for targeting stage-based interventions for precontemplators and contemplators.

At least 12 different decisional balance measures have been developed and validated (Prochaska, Velicer, Rossi, Goldstein, Marcus, Rakowski, Fiore, Harlow, Redding, Rosenbloom, \& Rossi, in press) for such areas as smoking cessation (Velicer, DiClemente, Prochaska, \& Brandenburg, 1985), weight control (O'Connell \& Velicer, 1988), safer sex (Redding, Rossi, Velicer, \& Prochaska, 1989), condom use (Grimley, Riley, Bellis, \& Prochaska, in press; Prochaska, Harlow, Redding, Snow, Rossi, \& Velicer, 1990), psychological distress (Penney, 1988), exercise adoption (Marcus, Rakowski, \& Rossi, 1992) and mammography screening (Rakowski, Dube, Marcus, Prochaska, Velicer, \& Abrams, 1992). Other decisional balance measures are currently being developed in other areas of behavioral risk, for example, sunscreen use (Rossi, 1990), dietary fat reduction (Rossi, 1993), and contraceptive behavior (Grimley, Riley, Prochaska, Redding, Ruggiero, Velicer, \& Rossi, 1992; Grimley et al., in press). The purpose of this study is to extend the stages of change and the pros and cons into the area of safer sex adoption and to examine the model-based relationships among these variables.

Method

\section{Subjects}

Subjects were 305 male and female, sexually active students attending a midsize, northeastern state university. Approximately $54 \%$ of the subjects were female, $91 \%$ were Caucasian, $99 \%$ were single, and $98 \%$ identified themselves as heterosexual. Modal age was 19 years (34\%), and modal year in college was freshman (47\%). 
Measurement Development

The development of the Pros and Cons of Safer Sex Questionnaire followed the sequential method of scale development (Comrey, 1988; Jackson, 1970). An initial pool of 34 items was developed to represent both pros and cons of safer sex. Some of these items had been tested previously (Prochaska, Harlow, Redding, Snow, Rossi, \& Velicer, 1990; Redding, Rossi, Velicer, \& Prochaska, 1989). Items were written so as to apply to homosexual, bisexual, or heterosexual subjects and either gender. Items were screened for face validity, to ensure breadth of construct, and to reduce item complexity by a research group already familiar with the model and other decisional balance measures. Items were also included to assess subjects' stage of change and demographic variables.

Procedure

Subjects were recruited from within their undergraduate classes or labs. Participation was anonymous and voluntary, and questionnaires took about 30 minutes to complete. Passive informed consent was obtained from all subjects. Some subjects completed questionnaires in a large auditorium during free time, while others took questionnaires with them, which were returned in postage-paid envelopes. Consistent with other decisional balance measures, subjects rated how important each item was to their own sexual decision-making using a Likert format, ranging from 1 (least important) to 5 (most important).

Analysis

The original subject pool $(\underline{\mathrm{N}}=305)$ was randomly divided into two subgroups, one for exploratory analyses $(\underline{N}=144)$ and the other for crossvalidation analyses $(\underline{N}=139)$. Careful inspection of demographic variables for 
these two subgroups revealed that they were nearly equivalent. Results of exploratory and confirmatory analyses will be reported separately. Finally, analyses on the entire sample examining the transtheoretical model based predictions regarding the relationship between Pros and Cons and stages of change will be presented.

\section{Results}

Exploratory Analyses

Initial principal components analyses (PCA) were conducted using $\mathrm{CAX}$ (Velicer, Zwịck, Harrop, \& Fava, 1993) and BMDP4M (Dixon, Brown, Engelman, Hill, \& Jennrich, 1988) on the 34-item scale using the exploratory half of the sample $(\underline{n}=144)$. Different indices suggested a range of component solutions. Specifically, parallel analysis (Horn, 1965) identified 4 components, while the Minimum Average Partial (MAP) technique (Velicer, 1976) identified 5 components. The four component solution broke the pros and cons into 2 components each, one reflecting concerns for self and the other reflecting relationship/partner concerns. The five component solution was nearly identical to the four factor solution, except that 2 items about pregnancy separated from the rest to form their own factor. Evidence from other studies (Grimley et al., 1992; Grimley et al., in press; Prochaska, Harlow et al., 1990) supports separating pregnancy concerns from AIDS risk reduction concerns. Not enough items were originally included to fully represent a pregnancy concerns factor, so the five factor solution was abandoned in favor of the four factor solution.

Further item selection based on simple structure of the four factor solution using DQUART from BMDP4M produced four three-item scales reflecting the pros 
and cons of safer sex for both self and relationship. These four factors accounted for $53.2 \%$ of the variance in the original 34 items and $72.0 \%$ of the variance in the reduced 12-item set. Scale items and component loadings are presented in Table 21. Pros for self and pros for relationship were correlated $\underline{r}=.50$. Cons for self and cons for relationship were correlated $\underline{r}=.63$. The pro and con factors were allowed to correlate also, although the correlation was minimal $(\underline{r}=.06)$. Scale statistics and alphas for all 4 scales are reported in Table 2-2.

Insert Tables 2-1 \& 2-2 about here

Confirmatory Analyses

Complete data on the 12 items were available for 139 subjects from the crossvalidation sample. To avoid confirmation bias, and as a further test of the adequacy of the model derived from sample 1, several alternative models representing different conceptualizations of the structure of the Pros and Cons of Safer Sex were allowed to compete to best describe the data.

Null Model. The Null Model suggests that there are no latent factors, and that the items are completely independent. This model is not meant as a serious representation of the data, but rather is useful as a baseline against which other models may be compared.

One Factor Model. This model posits the existence of a single general decision- making factor for safer sex. Support for this model would suggest that subjects view pros and cons of safer sex as opposite sides of the same coin. 
Two Uncorrelated Factors Model. This model suggests that subjects are able to discriminate between the pros and cons and that these factors are best represented as independent dimensions of change. There is some theoretical support for this model based on previous decisional balance applications.

Two Correlated Factors Model. This model is similar to the previous model except that the pros and cons are allowed to be correlated. Based on the results from previous model-based applications of decisional balance (Grimley et al., in press; Marcus et al., 1992; O'Connell \& Velicer, 1988; Penney, 1988; Prochaska et al., 1990; Prochaska et al., in press; Rakowski et al., 1992; Redding et al., 1989; Velicer et al., 1985), this model was originally considered the most plausible.

Two Factors (Nested). This model is similar to a four factor model except that the pros and cons subscales are fixed to be fully correlated, essentially equating it with a two factor model. This model tests for mathematical model specification biases and was not considered theoretically meaningful.

Four Uncorrelated Factors Model. This model suggests that subjects are able to discriminate among 4 factors: 2 pros (self and other) and 2 cons (self and other) and that these factors are best represented as independent dimensions of change. There is some empirical support for this model based on the exploratory PCA's described above and some theoretical support for this model based on Janis and Mann's original conception of the importance of self and other independent dimensions.

Four Correlated Factors Model. This model is similar to the previous model except that the 4 pros and cons factors for self and other are allowed to be fully 
correlated. Based on the exploratory PCA results, this model is considered quite plausible.

Two Hierarchical Factors Model - Self/Other. This model is similar to the previous model since the 4 factor distinction is preserved, except that correlations between each set of pro and con factors is expressed through one higher order factor, self or other. This solution would suggest that the distinction between self and other is more important to subjects than the distinction between pros and cons, and is, therefore, considered somewhat improbable.

Two Hierarchical Factors Model - Pro/Con. This model is similar to the previous model since the original 4 factors are preserved, except that the correlations between the each set of self and other factors is expressed through one higher order factor, pros or cons. This solution would provide a resolution between the previous model-based applications of decisional balance and the exploratory PCA results in this study.

Four Hierarchical Factors Model - Pro/Con and Self/Other. This model is similar to the two previous models since the original 4 factors are preserved. The correlations between each set of pros and cons and each set of self and other subfactors is expressed through two higher order factors, pros or cons and self or other. Figure 2-2 describes these relationships visually.

The adequacy of the competing models was assessed by maximum likelihood confirmatory factor analysis using the LISREL VI program (Jöreskog \& Sörbom, 1984). Because a general consensus has not yet emerged on which of the many different measures of model adequacy provides the best evaluation of model fit, several different measures were computed for each model. These measures 
represent a wide variety of conceptual approaches to the problem of assessing model adequacy, thus providing some protection against the possibility of model misspecification and sampling error (Marsh, Balla, \& McDonald, 1988). The asymptotic maximum likelihood chi-square statistic, while problematic in itself, is useful as a basis for the computation of other fit indices. The Comparative Fit index (CFI; Bentler, 1990), the Tucker-Lewis index (TLI; Tucker \& Lewis, 1973), and the incremental chi-square fit index, type 2 (IFI2 $\left(\chi^{2}\right)$; Mulaik et al., 1989) are all indices of relative model fit, as compared to the null model. For these indices, higher values indicate better fit, with 1.00 representing a perfect fit to the data and 0 representing a complete lack of fit. While no firm guidelines for interpretations have been established, values of about .90 are generally considered to indicate excellent model fit. The goodness-of-fit index (GFI) and root mean square residual (RMR) are provided by the LISREL VI program (Jöreskog \& Sörbom, 1984) and are indices of absolute model fit (i.e., without reference to a null model). Both indices range from 0 to 1.00 . Better fitting models are indicated by higher GFI values and by lower RMR values.

Insert Table 2-3 about here

The competing models are evaluated and compared in Table 2-3. Across all comparative measures of model adequacy, the Two Hierarchical Factors Model Pros/Cons provided the best fit to the data, as opposed to the two factor correlated model. In this model, pros and cons higher-order factors were only slightly correlated $(\underline{r}=.06)$. Maximum likelihood factor loadings for the 12 items are 
presented in Figure 2-1 and are similar to the exploratory PCA results. Scale means, standard deviations, and alpha coefficients for the 4 factors are reported in Table 2-2. In general, results for sample 2 are very similar to those based on sample 1, thus cross-validating the structure of the Pros and Cons of Safer Sex. Scale correlations with the Jackson social desirability scale (Jackson, 1967) were low: $\underline{r}=.10$ for cons-relationship, $\underline{r}=.15$ for cons-self, $\underline{r}=-.15$ for pros-self, and $\underline{r}=-.16$ for pros-relationship. Factor correlations are presented in Figure 2-1 for the 2 factor hierarchical mode and in Figure 2-2 for the 4 factor hierarchical model.

Insert Figure 2-1 and 2-2 about here

\section{Model Validation}

Sexually active subjects $(\underline{N}=305)$ were assigned to their respective stages of change based on their responses to five items included in the battery. Subjects who indicated that they had not changed their sexual behavior in response to AIDS and were not considering doing so were placed in the precontemplation stage $(\underline{\mathrm{n}}=19$, $6.5 \%)$ group. Subjects who indicated that they were considering changing their sexual behavior were placed in the contemplation stage $(\underline{\mathrm{n}}=54,18.6 \%)$ group. Subjects who indicated that they had changed their sexual behavior in response to AIDS with consistency, but for less than 6 months were placed in an action stage group $(\underline{n}=49,16.8 \%)$. finally, subjects who indicated that they had changed their sexual behavior in response to AIDS with consistency, but for 6 months or more were placed in a maintenance stage group $(\underline{\mathrm{n}}=169,58.1 \%)$. 
A multivariate analysis of variance (MANOVA) of Pros and Cons subscale T-scores (standardized scores with $\mathrm{M}=50$ and $\mathrm{SD}=10$ ) by stage $(\mathrm{PC}, \mathrm{C}, \mathrm{A}, \mathrm{M}$ ) and sex revealed a nonsignificant stage by sex interaction, Wilks' $\lambda=.962$, approximate $\underline{\mathrm{F}}(12,741.1)=0.89, \quad \mathrm{p}>.05$, and significant main effects for both stage, Wilks' $\lambda=.732$, approximate $\underline{\mathrm{F}}(12,741.1)=7.74, \underline{\mathrm{p}}<.001$, multivariate $\eta^{2}=.099$, and sex, Wilks' $\lambda=.850, \underline{\mathrm{F}}(4,280)=12.35, \mathrm{p}<.001$, multivariate $\eta^{2}=.15$. Results for stages of change are presented in Table 2-4. Follow-up univariate analyses of variance (ANOVA's) on separate pros and cons subscales found significant differences between stage groups on pros-self, $\underline{F}(3,283)=12.45$, $\mathrm{p}<.01, \eta^{2}=.117$, pros-relationship $\underline{\mathrm{F}}(3,283)=12.55, \mathrm{p}<.01, \eta^{2}=.117$, and cons-self, $\underline{\mathrm{F}}(3,283)=9.05, \underline{\mathrm{p}}<.01, \eta^{2}=.088$, but not for cons-relationship, $\underline{F}(3,192)=1.33, \underline{p}>.05$.

Insert Table 2-4 about here

Follow-up Tukey tests demonstrated that the precontemplation group was significantly $(\mathrm{p}<.05)$ lower than all other stages on the pros-self and prosrelationship subscales. Contemplators were also significantly lower than the action and maintenance stage groups on the pros-relationship subscale. For cons-self subscale, maintenance stage subjects' scores were significantly lower than scores of precontemplators and contemplators. These stage relationships are presented graphically in Figure 2-3. 
Insert Figure 2-3 about here

Results for sex differences are presented in Table 2-5. Follow-up univariate analyses of variance (ANOVA's) on pros and cons subscales found significant differences between males and females on pros-self, cons-self, and consrelationship, but not pros-relationship. Females rated the pros-self significantly higher than males, while males rated both cons-self and cons-relationship significantly higher than females.

Insert Table 2-5 about here

\section{Discussion}

Figure 2-3 demonstrates strong support for transtheoretical model-based predictions about the functional relationship between stages of change and decisional balance. Further, model-based predictions about the magnitude of those relationships are supported, with both the pros increasing about one standard deviation from precontemplation to action, and the cons-for-self decreasing about one half a standard deviation across the same stages (Prochaska, in press). Stage variability accounted for $10 \%$ of the variance in the pros and cons, mostly due to precontemplators, who regarded both the pros of safer sex as less important than any other group, and who regarded the cons-for-self as more important than those in maintenance. Safer sexual decision making can be well characterized as weighing the salience of positive and negative safer sex attitudes. This 6 factor hierarchical 
model fit the data well, and the same model cross-validated in the confirmatory subsample. This provides strong independent support for several transtheoretical model-based predictions for decisional balance applied to safer sex.

Contrary to previous applications of decisional balance to condom use, safer sex, and other health behaviors, 4 factors were found to best describe the data: both pros and cons indicating concerns for self and concerns for the partner and/or relationship. This has intuitive appeal given the relational nature of sexuality, in general, and safer sex decision making, in specific. It makes sense that subjects are concerned with the impact of safer sex decisions on their partner and their relationships. The lower-order factors were moderately correlated to each other, not surprisingly. This is not viewed as a serious departure from the 2 factor decisional balance model, since the 4 lower-order factors were hierarchically organized in two higher-order factors, the Pros and Cons of safer sex.

Other previous applications of decisional balance have found that a two factor, orthogonal or nearly orthogonal solution best described the data, as opposed to the Janis and Mann hypothetical eight factor solution. Although several previous decisional balance measures have included items reflecting all eight hypothetical Janis and Mann categories, a two factor (pros and cons) solution fit the data best in each case (Velicer et al., 1985; O'Connell \& Velicer, 1988; Redding et al., 1989; Rosenbloom, 1991; Rossi, 1990). In some other cases, a two factor solution was assumed a priori (Prochaska et al., 1990; Grimley et al., 1992; Grimley et al., in press), and so cannot fully test the Janis and Mann model. These data partially confirm the original Janis and Mann idea of a self/other distinction important to decision making. 
There was some suggestion in the factor analyses of these data that concerns about pregnancy are separate from concerns about safer sex. Subsequent work has verified this finding and separate decisional balance scales for both contraception and condom use have been developed and tested (Grimley et al, 1992; in press).

Previous model-based applications of decisional balance to both safer sex and condom use failed to find differences between stage groups on the cons (Grimley et al, 1992; in press; Redding et al., 1989). This study failed to find differences between stage groups on only one of the cons lower-order factors, that is, consrelationship. This could be a partial explanation for the lack of previous findings, in other words, that since self and relationship items were scored together on one scale in previous applications, this obscured stage differences found here on the cons-self subscale. Further, findings from previous applications have been interpreted to suggest that the Pros of condom use or safer sex may be more amenable to change than the Cons of safer sex or condom use. These findings call into question that interpretation, and suggest that the cons-self may be more amenable to intervention across the stages of change than the cons-relationship. In other words, subjects may view the negative impact of safer sex on their partner or relationship as relatively unchangeable, whereas they may learn for themselves, as they progress through the stages of safer sex adoption, that the cons-self are not so bad or so important to them. Of course, this is a longitudinal interpretation based on cross-sectional findings, and this caveat should be kept in mind. However, model-based crosssectional results for smoking cessation and exercise adoption have replicated longitudinally. This supports the efforts of future researchers to look at longitudinal 
changes in safer sex decision making, and to replicate these suggestive crosssectional findings.

Some comments about the sex differences are warranted. Females rated the pros-self as more important to their safer sex decision making than did males. Similarly, males rated cons-self and cons-relationship as significantly more important to their safer sex decision making than females did. These findings are consistent with previous work in this area (Grimley et al., in press), and with gender-role stereotypes (Lott, 1987). These differences did not however, spur females to progress through the stages of change differently than males, which would have resulted in a significant stage by sex interaction. Interestingly, males and females did not differ on their ratings of the importance of the pros-relationship to their safer sex decision making. Taken together, these findings suggest that new interventions, such as an expert system (Velicer et al., in press) for safer sex, which compare individuals' scores to group mean scores (normative feedback), should consider gender group means independently. 


\section{References}

Abraham, C., Sheeran, P., Spears, R., Abrams, D. (1992). Health beliefs and promotion of HIV-preventive intentions among teenagers: A Scottish perspective. Health Psychology, 11, 363-370.

Becker, M.H., \& Joseph, J.G. (1988). AIDS and behavioral change to reduce risk:

A review. American Journal of Public Health, 78, 394-410.

Bentler, P.M. (1990). Comparative fit indexes in structural models. Psychological Bulletin, 107, 238-246.

Bentler, P.M., \& Bonett, D.G. (1980). Significance tests and goodness of fit in the analysis of covariance structures. Psychological Bulletin, $\underline{88}, 588-606$.

Brooks-Gunn, J., Boyer, C.B., \& Hein, K. (1988). Preventing HIV infection and AIDS in children and adolescents. American Psychologist, 43, 958-964.

CDC. (1992a). HIV/AIDS Surveillance Report, October, 1-18.

CDC. (1992b). A conceptual framework for evaluating behavior change. HIV/AIDS Prevention Newsletter, $\underline{3}(4), 2-3$.

Comrey, A.L. (1988). Factor-Analytic methods of scale development in Personality and Clinical Psychology. Journal of Consulting and Clinical Psychology, 56, 754-761.

Dixon, W.J., Brown, M.B., Engelman, L., Hill, M.A., \& Jennrich, R.I. (1988). BMDP Statistical Software Manual. Los Angeles, CA: The Regents of the University of California.

Fisher, J.D., \& Fisher, W.A. (1992). Changing AIDS-risk behavior. Psychological Bulletin, 111, 455-474. 
Fitzgerald, T.E., Snow, M.G., \& Prochaska, J.O. (1988, July). A health behavior model of risk reduction for AIDS. Poster presented at the NIMH-VCPPP Conference on Psychological Approaches to the Treatment of AIDS, Burlington, VT.

Flora, J.A., \& Thoresen, C.E. (1988). Reducing the risk of AIDS in adolescents. American Psychologist, 43, 965-970.

Grimley, D., Riley, G.E., Prochaska, J.O., Redding, C.A., Ruggiero, L., Velicer, W.F., \& Rossi, J.S. (1992). Application of the transtheoretical model to contraceptive and condom use in high-risk women. Technical Report submitted to the Centers for Disease Control and Prevention (CDC) contract grant \#CSA-92-109.

Grimley, D., Riley, G.E., Bellis, J.M., \& Prochaska, J.O. (in press). Accessing decision-making and contraceptive use of men and women for the prevention of pregnancy and sexually transmitted diseases. Health Education Quarterly.

Horn, J.L. (1965). A rationale and test for the number of factors in factor analysis. Psychometrika, $\underline{30}, 179-185$.

Hingson, R.W., Strunin, L., Berlin, B.M., \& Heeren, T. (1990). Beliefs about AIDS, use of alcohol and drugs, and unprotected sex among Massachusetts adolescents. American Journal of Public Health, 으, 295-299.

Janis, I.L., \& Mann, L. (1968). A conflict theory approach to attitude and decision making. In A. Greenwald, T. Brook, and T. Ostrom (Eds.) Psychological Foundations of Attitudes. New York: Academic Press.

Janis, I.L., \& Mann, L. (1977). Decision making: A psychological analysis of conflict, choice and commitment. New York: Free Press. 
Jackson, D.N. (1970). A sequential system for personality scale development. In C.D. Spielberger (Ed.), Current topics in clinical and community psychology (Vol. 2, pp. 61-96). New York: Academic Press.

Jöreskog, K.G., \& Sörbom, D. (1984). LISREL VI: Analysis of linear structural relationships by the method of maximum likelihood (User's guide). Mooresville, IN: Scientific Software, Inc.

Kegeles, S.M., Adler, N.E., \& Irwin, C.E. (1988). Sexually active adolescents and condoms: Change over one year in knowledge, attitudes and use. American Journal of Public Health, $\underline{78}, 460-461$.

Kelly, J.A., \& Murphy, D.A. (1992). Psychological interventions with AIDS and HIV: Prevention and treatment. Journal of Consulting and Clinical Psychology, 60, 576-585.

Marcus, B.H., Rakowski, W., \& Rossi, J.S. (1992). Assessing motivational readiness and decision making for exercise. Health Psychology, 11, 257-261. Marsh, H.W., Balla, J.R., \& McDonald, R.P. (1988). Goodness of fit indexes in confirmatory factor analysis: The effect of sample size. Psychological Bulletin, 103, 391-410.

Mulaik, S.A., James, L.R., Van Alstine, J., Bennett, N., Lind, S., \& Stilwell, C.D. (1988). Evaluation of goodness-of-fit indices for structural equation models. Psychological Bulletin, 105, 430-445.

O'Connell, D., \& Velicer, W.F. (1988). A decisional balance measure and the Stages of Change Model for weight loss. The International Journal of the Addictions, 23, 729-750. 
Penney, D. (1988). A comparison of psychotherapy-changers and self-changers in a naturalistic environment. Unpublished doctoral dissertation, University of Rhode Island, Kingston, RI.

Prochaska, J.O. (in press). Common principles for progression from precontemplation to action based on twelve problem behaviors. Health Psychology.

Prochaska, J.O., \& DiClemente, C.C. (1983). Stages and processes of self-change in smoking: Towards an integrative model of change. Journal of Consulting and Clinical Psychology, 51, 390-395.

Prochaska, J.O., \& DiClemente, C.C. (1984). The transtheoretical approach:

Crossing the traditional boundaries of therapy. Homewood, IL: Dow Jones/Irwin

Prochaska J.O., DiClemente, C.C., \& Norcross, J.C. (1992). In search of how people change: Applications to the addictive behaviors. American Psychologist, 47, 1102-1114.

Prochaska, J.O., DiClemente, C.C., Velicer, W.F., Ginpil, S., \& Norcross, J.C. (1985). Predicting change in smoking status for self-changers. Addictive Behaviors, 10, 395-406.

Prochaska, J.O., \& DiClemente, C.C. (1986). Toward a comprehensive model of change. In W. Miller \& N. Heather (Eds.), Treating addictive behaviors (pp. 3-27). New York: Plenum Press. 
Prochaska, J.O., Harlow, L.L., Redding, C.A., Snow, M.G., Rossi, J.S., \& Velicer, W.F. (1990). Stages of Change, Self Efficacy, and Decisional Balance of condom use in a high HIV risk sample. Technical report to the Centers for Disease Control, contract grant \# 0-4115-002.

Prochaska, J.O., Velicer, W.F., Guadagnoli, E., Rossi, J.S., \& DiClemente, C.C. (1991). Patterns of change: Dynamic typology applied to smoking cessation. Multivariate Behavioral Research, 26, 83-107.

Prochaska, J.O., Velicer, W.F., Rossi, J.S., Goldstein, M.G., Marcus, B.H., Rakowski, W., Fiore, C., Harlow, L., Redding, C.A., Rosenbloom, D., \& Rossi, S.R. (in press). Stages of change and decisional balance for twelve problem behaviors. Health Psychology.

Rakowski, W., Dube, C.E., Marcus, B.H., Prochaska, J.O., Velicer, W.F., \& Abrams, D.B. (1992). Assessing elements of women's decisions about mammography. Health Psychology, 11, 111-118.

Redding, C.A., Rossi, J.S., Velicer, W.F., \& Prochaska, J.O. (1989, August). The pros and cons of safer sex: A measurement model. Poster presented at the 97th annual convention of the American Psychological Association, New Orleans, LA.

Rossi, J.S. (1990, August). Radon and ultraviolet light: Emerging cancer risk factors. In J.O. Prochaska (Chair), Stages of change: Extensions to new areas of behavior change. Symposium presented at the 98th annual convention of the American Psychological Association, Boston, MA. 
Rossi, S.R. (1993). Application of the Transtheoretical Model of behavior change to dietary fat reduction in a naturalistic population. Unpublished doctoral dissertation, University of Rhode Island, Kingston, RI.

Sacco, W.P., Levine, B., Reed, D.L., \& Thompson, K. (1991). Attitudes about condom use as an AIDS-relevant behavior: Their factor structure and relation to condom use. Psychological Assessment, $\underline{3}, 265-272$.

Snow, M.G., Fitzgerald, T.E., \& Prochaska, J.O. (1988, November). A conceptual framework for the prevention of AIDS-related behaviors. Poster presented at the Annual Meeting of the Society of Public Health Education, Boston.

SPSS Inc. (1988). SPSS-X User's Guide, 3rd Edition. Chicago, IL: SPSS Inc.

St. Lawrence, J.S. (1993). African-American adolescents' knowledge, health-related attitudes, sexual behavior, and contraceptive decisions: Implications for the prevention of adolescent HIV infection. Journal of Consulting and Clinical

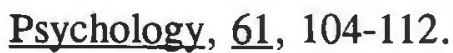

Strunin, L. \& Hingson, R. (1987). Acquired immunodeficiency syndrome and adolescents: Knowledge, beliefs, attitudes, and behaviors. Pediatrics, $\underline{79}$, 825-882.

Tucker, L.R., \& Lewis, C. (1973). A reliability coefficient for maximum likelihood factor analysis. Psychometrika, $\underline{38}, 1-10$.

Velicer, W.F. (1976). Determining the number of components from the matrix of partial correlations. Psychometrika, 41, 321-327.

Velicer, W.F., DiClemente, C.C., Prochaska, J.O., \& Brandenburg, N. (1985). A decisional balance measure for assessing and predicting smoking status. Journal of Personality and Social Psychology, 48, 1279-1289. 
Velicer, W.F., Zwick, W., Harrop, J., \& Fava, J. (1993). Component Analysis Extended (CAX). Unpublished computer program for component analysis and the application of the Minimum Average Partial (MAP) technique. 
Table 2-1

Exploratory Principal Components Loadings

Other

$\underline{\text { Pros }}$

1. I would feel safer.

.61

5. I would feel more responsible.

.63

9. I would fear sexually transmitted diseases, like AIDS, less.

3. It would build trust in our relationship. .79

7. My partner would feel respected. .80

11. It would promote trust. .83

$\underline{\text { Cons }}$

2. Sex would be less exciting. .83

8. Sex would be less enjoyable. .86

12. Sex would feel less natural. .83

4. My partner would feel insulted. .71

6. My partner would be upset. .86 10. My partner would object. .72

$\underline{\text { Note: }} \underline{\underline{N}}=144$ with complete item data. Dashes indicate that off-target loadings are less than .30 . 
Table 2-2

Scale Statistics and Alpha Coefficients

Scale

Mean

S.D.

Alpha

Exploratory Subsample

$(\underline{\mathrm{N}}=.156)$

$\begin{array}{llll}\text { Pros - S } & 4.47 & 0.88 & .63 \\ \text { Pros - R } & 4.03 & 1.11 & .85 \\ \text { Cons -S } & 2.58 & 1.19 & .87 \\ \text { Cons -R } & 2.17 & 1.20 & .80\end{array}$

Confirmatory Subsample

$(\underline{\mathrm{N}}=146)$

$\begin{array}{lllr}\text { Pros - S } & 4.40 & 0.65 & .55 \\ \text { Pros - R } & 3.89 & 1.02 & .88 \\ \text { Cons -S } & 2.63 & 1.15 & .89 \\ \text { Cons -R } & 2.14 & 0.94 & .83\end{array}$


Table 2-3

Comparative Fit Indices for Alternative Models

Model

Null

One Factor

Two Factors -

correlated

Two Factors -

Uncorrelated

Two Factors (Nested)

Four Factors -

correlated

65.64

32

.934

.047

$.959 \quad .916$

.961

Four Factors -

Uncorrelated

2 Hierarchical Factors
- Self/Other

2 Hierarchical Factors

- Pro/Con

4 Hierarchical Factors

- Pro/Con and

Self/Other $65.64 \quad 18$

$\begin{array}{llllll}18 & .934 & .047 & .943 & .790 & .946\end{array}$

$142.22 \quad 35$

.934

.047

$.871 \quad .756$

.875

$\begin{array}{lllllll}65.64 & 35 & .934 & .047 & .963 & .930 & .964\end{array}$

$\begin{array}{lllllll}195.11 & 54 & .838 & .234 & .829 & .792 & .832\end{array}$

Note: $\underline{N}=139 ; \mathrm{df}=$ degrees of freedom; GFI $=$ Goodness of fit index

( Table 2-3 continues on next page) 
Table 2-3 continued

(Jöreskog \& Sörbom, 1984); RMR = root mean square residual (Jöreskog \& Sörbom, 1984); CFI = Comparative Fit Index (Bentler, 1990); TLI = TuckerLewis index (Tucker \& Lewis, 1973); IFI2 $\left(\chi^{2}\right)=$ incremental chi-square fit index, type 2 (Mulaik et al., 1989). 
Table 2-4

Pros and Cons T-Score Means, S.D. 's and MANOVA Results for Stages of Change Stage of Change

$\begin{array}{lcccccc}\text { Scale } & \text { PC } & \mathrm{C} & \mathrm{A} & \mathrm{M} & \underline{\mathrm{F}}(3,283) & \eta^{2} \\ \text { Pros - } & 37.91 & 50.04 & 51.43 & 50.93 & 12.45^{*} & .12 \\ \text { Self } & (16.4) & (9.0) & (9.6) & (8.6) & & \\ \text { Pros - } & 40.53 & 45.96 & 51.26 & 51.99 & 12.54 * & .12 \\ \quad \text { Relationship } & (13.5) & (10.8) & (8.5) & (8.7) & & \\ \text { Cons - } & 54.62 & 53.52 & 50.88 & 48.10 & 9.05^{*} & .09 \\ \text { Self } & (13.4) & (10.0) & (8.1) & (9.6) & & \\ \text { Cons - } & 47.81 & 49.03 & 51.24 & 50.20 & 0.60 & - \\ \quad \text { Relationship } & (8.8) & (8.5) & (8.7) & (10.9) & & \end{array}$

Note: Standard deviations are given in parentheses. $\mathrm{PC}=$ Precontemplation $(\underline{\mathrm{N}}=$ 19); $\mathrm{C}=$ Contemplation $(\underline{\mathrm{N}}=54) ; \mathrm{A}=\operatorname{Action}(\underline{\mathrm{N}}=49) ; \mathrm{M}=$ Maintenance $(\underline{\mathrm{N}}$ $=169$ ); $\eta^{2}=$ effect size (proportion of variance accounted for); $*$ indicates $\underline{\mathrm{F}}$ test is significant $(\mathrm{p}<.05)$. 
Table 2-5

Pros and Cons of Safer Sex T-Score Means, S.D. 's and MANOVA Results for Sex

$\begin{array}{lcccc}\underline{\text { Scale }} & \begin{array}{c}\text { Females } \\ (\underline{\mathrm{N}}=160)\end{array} & \begin{array}{c}\text { Males } \\ (\underline{\mathrm{N}}=139)\end{array} & \underline{\mathrm{F}}(1,283) & \eta^{2} \\ \text { Pros - } & 52.80 & 46.87 & 18.11^{*} & .06 \\ \quad \text { Self } & (8.2) & (10.8) & & \\ \text { Pros - } & 51.04 & 49.03 & 1.69 & - \\ \text { Relationship } & (10.9) & (8.7) & & .10 \\ \text { Cons - } & 47.10 & 53.28 & 31.45^{*} & \\ \quad \text { Self } & (9.6) & (9.4) & & .04 \\ \text { Cons - } & 47.22 & 53.18 & 12.52^{*} & \\ \quad \text { Relationship } & (8.7) & (10.4) & & \end{array}$

Note: Standard deviations are given in parentheses; $\eta^{2}=$ effect size (proportion of variance accounted for $) ;{ }^{*}$ indicates $\underline{F}$ test is significant $(\mathrm{p}<.05)$. 


\section{$\underline{\text { Figure Captions }}$}

Figure 2-1. Decisional balance for safer sex 2 hierarchical factor structural model.

Figure 2-2. Decisional balance for safer sex 4 hierarchical factor structural model.

Figure 2-3. The pros and cons of safer sex subscale T-scores across the stages of change. 


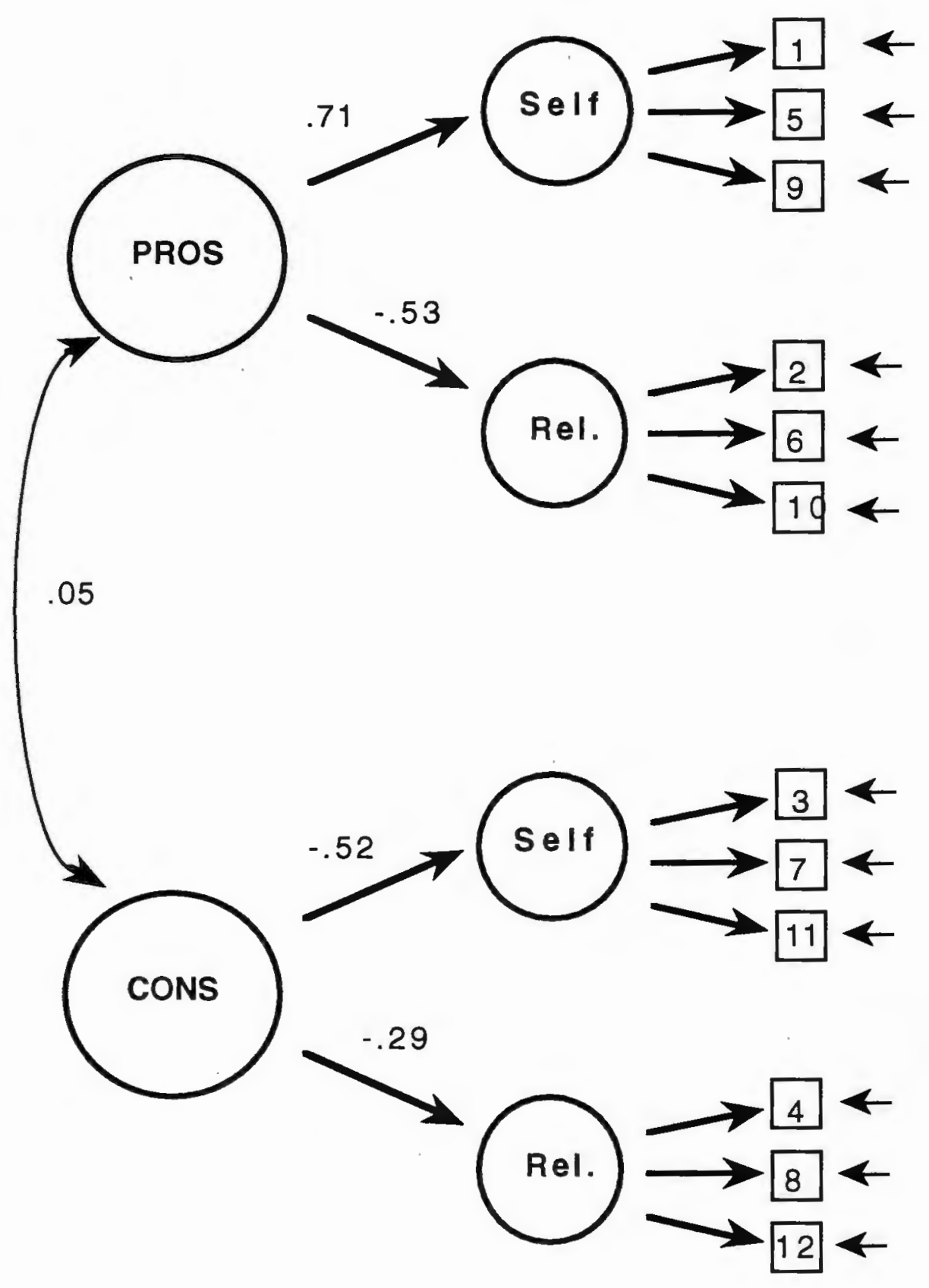




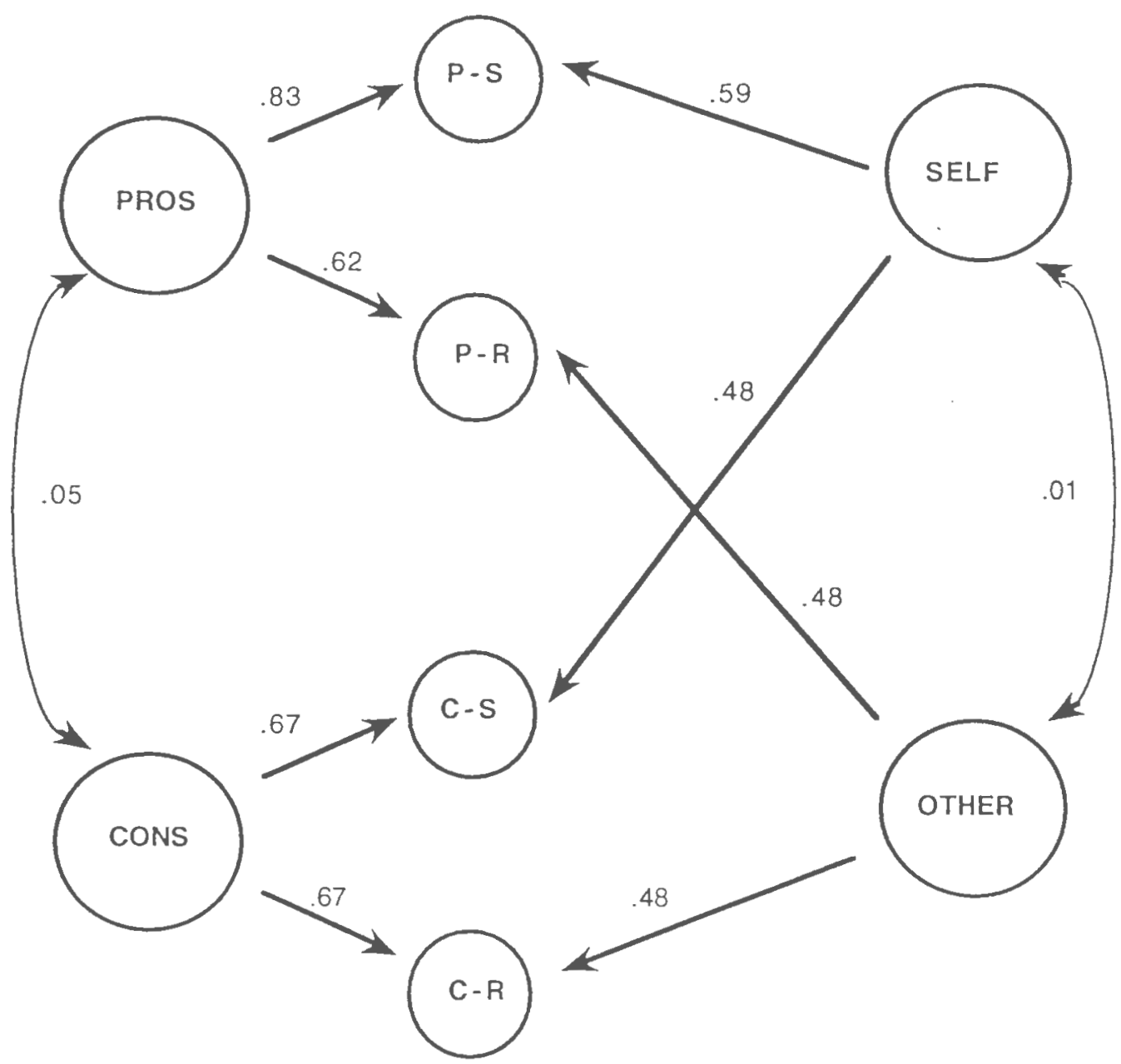


Decisional Balance Subscales by Stage

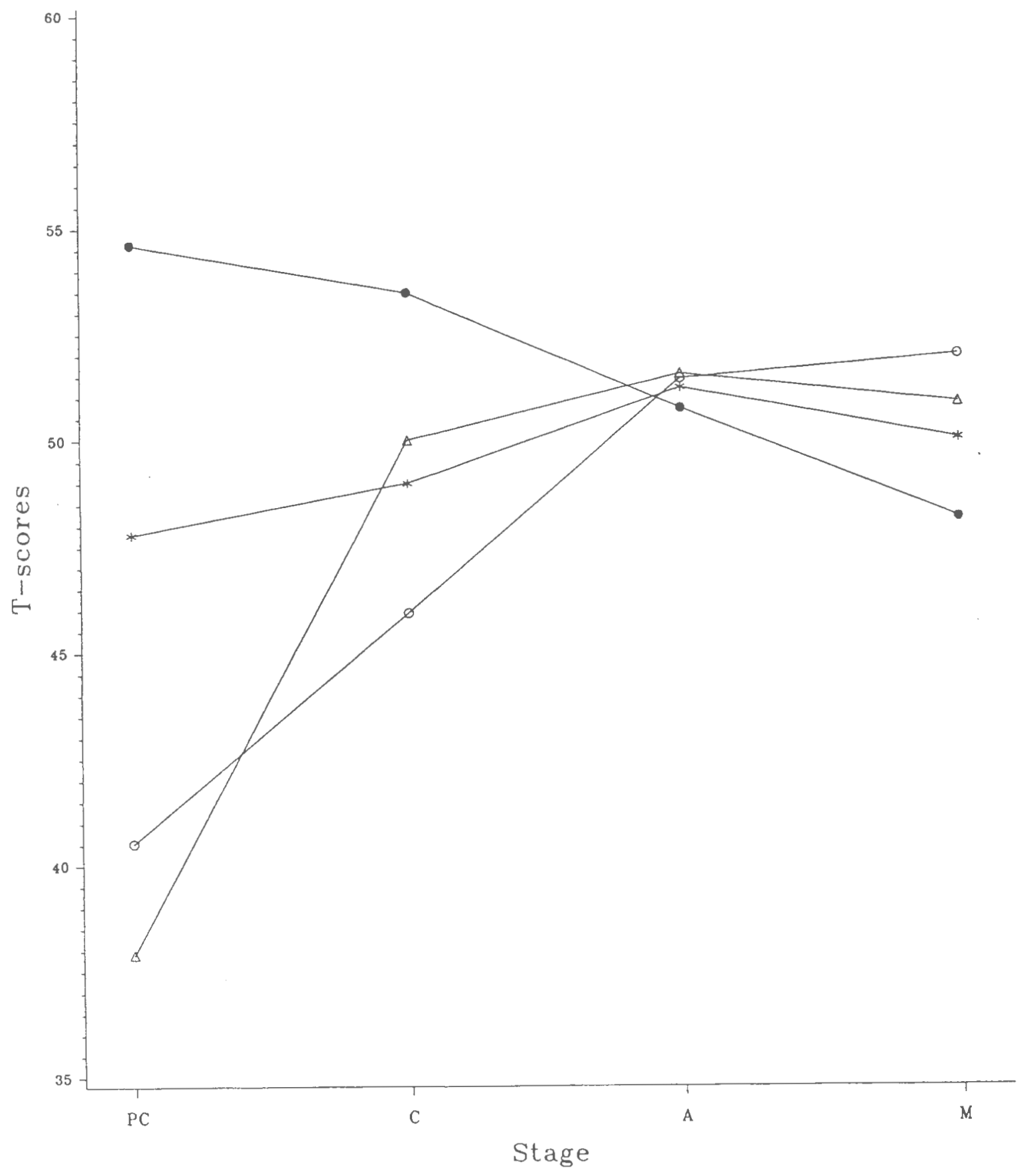

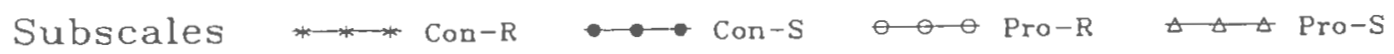




\section{PART III \\ SELF-EFFICACY FOR SAFER SEX}

Practicing safer sex would prevent a variety of sexually transmitted diseases, including but not limited to Acquired Immune Deficiency Syndrome (AIDS), Human Immunodeficiency Virus (HIV) infection, and other health conditions (e.g., unintended pregnancy) (Hatcher et al., 1990). Since the benefits of safer sex are clear, health researchers and clinicians are faced with two main challenges: how to get individuals to initiate safer sexual activity, and how to get them to maintain their safer sexual activity.

Self-efficacy has become a nearly standard variable in the prediction of behavior, since its inception as part of Social Learning Theory (Bandura, 1977; 1982). The self-efficacy construct employed in the transtheoretical model integrates the model of self-efficacy proposed by Bandura $(1977,1982)$, and the coping models of relapse and maintenance described by Shiffman $(1982,1986$; Velicer, DiClemente, Rossi, \& Prochaska, 1990). Although self-efficacy has generally been conceptualized as unidimensional, independent investigations have found global self-efficacy ratings to predict AIDS risk reduction behaviors in different subject groups (Freeman, Cohn, Corby, \& Wood, 1991; Kelly et al., 1990; Grimley, Riley, Prochaska, Redding, Ruggiero, Velicer, \& Rossi, 1992; Goldman \& Harlow, 1990; Prochaska, Harlow, Redding, Snow, Rossi, \& Velicer, 1990; Schnell, Galavotti, \& O'Reilly, in press; St. Lawrence, 1993).

Intervention studies to increase the practice of safer sexual activities among gay men have found disturbing relapse rates (Kelly \& Murphy, 1992; Fisher \& Fisher, 1992; Schnell, Galavotti, \& O'Reilly, in press), and little is known about relapse to unsafe sex. Relapse is usually considered within the context of addictive 
behavior problems, but, applies equally well to safer sex. If the pattern of relapse to unsafe sex proves similar to the negatively accelerated relapse curve often seen in addictive behaviors (Hunt, Barnett, \& Branch, 1971), then public health will clearly suffer. What is known about other health acquisition behaviors such as exercise adoption? For exercise adoption, approximately $50 \%$ of individuals who join an exercise program will drop out during the first three to six months (Carmody, Senner, Manilow, \& Matarazzo, 1980; Dishman, 1988). The similarity between relapse rates of different cessation and acquisition behavior changes is important since research has documented common processes involved in adopting positive behaviors such as safer sex (Redding, 1993) and exercise (Marcus, Rossi, Selby, Niaura, \& Abrams, 1992) and stopping unhealthful behaviors such as smoking, substance abuse, and overeating (Prochaska \& DiClemente, 1983, 1985; Prochaska, DiClemente, Velicer \& Fava, 1988; Rossi, 1992). In fact, within this context the traditional distinction between addictive and non-addictive behaviors has become less clear. What are some of the best predictors of relapse from other health behavior areas, which may prove useful for the prediction of relapse to unsafe sex?

The Trantheoretical model (Prochaska, DiClemente, \& Norcross, 1992; DiClemente, Prochaska, Fairhurst, Velicer, Velasquez, \& Rossi, 1991; Prochaska \& DiClemente, 1983; Velicer et al., 1990; 1992) has investigated and sought to better understand how people change problem behaviors. This model has found that people engaging in a new behavior (acquisition) or stopping an old behavior (cessation) move through a series of stages of change: Precontemplation, Contemplation, Preparation, Action and Maintenance. Stage movement is usually cyclical, rather than linear, since most individuals make several attempts at change 
before reaching maintenance. One important mediating variable in this model is self-efficacy, which has been operationalized as confidence in the new, healthful behavior and temptation to engage in the problem behavior, across a variety of problematic situations (Velicer et al., 1990). Confidence and temptation both vary across the stages of change, with confidence rising and temptation diminishing across longitudinal profiles of smokers (Prochaska et al., 1991). Confidence is typically lowest in the precontemplation stage, since individuals have little performance feedback and/or little interest in change. Confidence is higher during contemplation, outperforming other demographic variables in its ability to predict movement into Preparation and Action (DiClemente et al., 1991; Velicer et al., 1990). Confidence and temptation functioned inversely across the stages, although temptation predicted relapse better (Redding, Rossi, Fava, Snow, Rossi, Prochaska, Velicer, \& DiClemente, 1989). Even in the maintenance stage where subjects have successfully altered the problem behavior for at least six months, temptation is one of the best predictors of relapse and recycling to earlier stages of change. In longitudinal studies of smokers, some were quit for long periods of time, but still had moderate levels of temptation. With a population at high risk for HIV exposure, self-efficacy (confidence) to use condoms significantly differentiated persons in precontemplation from those in contemplation, action, and maintenance stages for condom use (Prochaska et al., 1990). These results suggest that the tailoring of self-efficacy interventions to the stage of change may accelerate progress through the stages and thus increase adoption of safer sex, as well as improve adherence. Such stage-targeted interventions have been useful for both smoking 
cessation and exercise adoption (Marcus et al., 1992; Prochaska, DiClemente, Velicer, \& Rossi, in press).

The trantheoretical model has been applied to a wide range of health behaviors, especially the addictions (Prochaska \& DiClemente, 1985; Prochaska, Harlow et al., 1990; Prochaska, Norcross, Fowler, Follick, \& Abrams, 1991; Prochaska, Redding, Harlow, Rossi, \& Velicer, 1992; Rakowski et al., 1992; Rosenbloom, 1991; Rossi, 1989, 1990a; Rossi et al., 1991; Snow, 1991; Tejero, Trujols, \& Hernández, 1991). AIDS prevention researchers (CDC, 1992; Fisher \& Fisher,1992; Kelly \& Murphy ,1992; Valdisseri, 1989) have independently cited the transtheoretical model as an example of a health behavior change model which has important implications for AIDS prevention. Researchers have called for a shift from a reliance on epidemiologic models to the use of process models which can improve our understanding of mediating mechanisms of behavior change (Becker \& Joseph, 1988; Coates, 1990; Catania, Kegeles, \& Coates, 1990; Rugg, 1990). This study was designed to examine the application of the stages of change model to safer sex behavior. Specific aims were to develop scales to measure both confidence and temptation for safer sex behavior change, to explore the underlying structure of these scales, and to determine the functional relationship between these variables and the stages of change. How this model is adapted to safer sex behavior change will have important ramifications for understanding how to better address the two major challenges to the field: getting more people to adopt safer sex activities and getting adopters to maintain their behavior changes. 
Method

Subjects

Subjects were 305 male and female, sexually active students attending a midsize, northeastern state university. Approximately $54 \%$ of the subjects were female, $91 \%$ were Caucasian, $99 \%$ were single, and $98 \%$ identified themselves as heterosexual. Modal age was 19 years (34\%), and modal year in college was freshman (47\%).

\section{Procedure}

Subjects were recruited from within their classrooms. Participation was anonymous and voluntary. Study participants provided informed consent and completed questionnaires about their sexual behavior and demographic information within about 30 minutes.

Questionnaire Development

The development of the Confidence in Safer Sex (CSS) and Temptation for Unprotected Sex (TUS) Questionnaires followed the sequential method of scale development (Comrey, 1988; Jackson, 1970). An initial pool of 20 items for each questionnaire was generated based on previous data investigating situational confidence for condom use (Harlow, Prochaska et al., 1993; Prochaska et al., 1990) using the transtheoretical model. Many of these items were adapted and revised for safer sex from those used by Velicer et al. (1990) for smoking cessation. Care was taken to make sure that items were constructed to be relevant for subjects of either gender and any sexual orientation. Content validity was established by having three doctoral level judges classify the items according to conceptual definitions of areas considered important potential mediators of self-efficacy: negative affect; perceived 
low risk; sexual arousal; substance use; and partner pressure. Subjects were instructed to rate their level of confidence in having safer sex or temptation to have unsafe sex on a five-point Likert scale $(1=$ Not at all confident/tempted to $5=$ very confident/tempted).

Four questions designed to assess current stage of safer sex behavior were also administered to all subjects. Four stages were hypothesized based on previous work in the area of smoking cessation (Prochaska \& DiClemente, 1983; Velicer et al., 1992) and earlier HIV prevention studies (Prochaska, Harlow, Redding et al., 1990): 1) Precontemplation included subjects who did not practice safer sex and did not intend to start in the next six months; 2) Contemplation included subjects who did not practice safer sex, but did intend to start in the next six months; 3) Action included subjects who practiced safer sex regularly, for less than six months; 4) Maintenance included subjects who had been practicing safer sex regularly for six months or more. The validity of this classification scheme for sexual behaviors and intentions has been established in previous studies (Grimley et al., 1992, 1993; Prochaska et al., 1990; Redding, Rossi, Velicer, \& Prochaska, 1989).

Results

Questionnaire Development and Testing

The sample was randomly split in half for initial development (sample 1) and cross-validation (sample 2) analyses of the questionnaires. The goals of these analyses were to study the measurement structure and psychometric properties of the CSS and TUS, and to produce two brief, reliable questionnaires for measuring confidence and temptation. 
Initial item analysis was based on an examination of the distributions for each set of 20 items, resulting in no elimination of items because of skewed distributions. The extremity bias reported by Velicer et al. (1990) for smoking cessation was not found in these data.

Measurement analyses of remaining items were conducted using the BMDP principal components analysis program (P4M) and the LISREL VI structural modeling computer program (Jöreskog \& Sörbom, 1984). Horn's (1965) parallel analysis of the CSS and TUS suggested that 2 component solutions would best represent the item space. The minimum average partial (MAP) technique (Velicer, 1976) suggested a 6 component solution for the TUS and a 3 component solution for the CSS. Each possible solution was considered for both scales. The goal was to develop two scales with comparable items and components, since this has been useful in the area of smoking cessation (Velicer et al., 1990). Loadings on different component solutions and diagnostic indicators provided by the structural modeling analyses were used to detect poorly functioning items. One item with a low loading (less than .50) on its designated (target) factor was deleted. Further item deletions were accomplished through a restricted specification search (MacCallum, 1986; Silvia \& MacCallum, 1988) using modification indices, normalized residuals, and first-order derivatives. Complex items were detected in this fashion and eliminated. The goal of item deletion was to reduce the number of items per factor to three, the minimum scale length which still ensures reliability of component patterns (Velicer \& Fava, 1987). After poorly functioning items were deleted, additional (and otherwise well functioning) items were eliminated by emphasizing breadth of construct, and comparable fit using similar items for both confidence and 
temptation. These procedures ultimately reduced the number of items from 20 to 15 , three items for each of the 5 lower order factors of both confidence and temptation.

Final measurement analyses for the exploratory sample were conducted on the 15 remaining items, based on complete item data from 144 subjects. Maximum likelihood factor loadings for each item are displayed in Tables 3-1 and 3-2. Scale means, standard deviations, and internal consistency (alpha) coefficients for each of the 5 scales are given in Tables 3-3.

Insert Tables 3-1, 3-2, and 3-3 About Here

Cross-validation and Model Testing

Complete data on the 15 items were available for 139 subjects from the crossvalidation sample. To avoid confirmation bias, and as a further test of the adequacy of the model derived from sample 1, several alternative models representing different conceptualizations of the structure of the CSS and TUS were allowed to compete to best describe the data.

Null Model. The Null Model suggests that there are no latent factors, and that the CSS or TUS items are completely independent. This model is not meant as a serious representation of the data, but rather is useful as a baseline against which other models may be compared.

One Factor Model. This model posits the existence of a single general confidence or temptation factor for safer sex. Support for this model would suggest 
that subjects do not or cannot differentiate among the situations in their attempts at safer sex behavior change.

Five Uncorrelated Factors Model. This model suggests that subjects are able to discriminate among the 5 situational factors and further that these factors are best represented as independent dimensions.

Five Correlated Factors Model. This model is similar to the previous model except that the 5 factors are allowed to be correlated. Based on the results from sample 1, as well as results obtained in previous studies for other types of problem behaviors (Clark, Abrams, Niaura, Eaton \& Rossi, 1991; Prochaska \& DiClemente, 1985; Rossi et al., 1991; Velicer et al., 1990), this model was considered most plausible.

One Hierarchical Factor Model. In this model the correlations among the 5 lower order factors are expressed as a single hierarchical factor, representing a generalized tendency to feel confident about safer sex (CSS) or to feel tempted to engage in unsafe sex (TUS). This model differs from the previously described One Factor Model in that the distinction among the 5 lower order factors is preserved. This model will be discussed more fully in the next section.

The adequacy of the competing models was assessed by maximum likelihood confirmatory factor analysis using the LISREL VI program (Jöreskog \& Sörbom, 1984). Because a general consensus has not yet emerged on which of the many different measures of model adequacy provides the best evaluation of model fit, several different measures were computed for each model. These measures represent a wide variety of conceptual approaches to the problem of assessing model 
adequacy, thus providing some protection against the possibility of model misspecification and sampling error (Marsh, Balla, \& McDonald, 1988).

The competing models are evaluated and compared in Table 3-4. Across all measures of model adequacy, the One Hierarchical Factor Model provided the best fit to the data. Maximum likelihood factor loadings for all items on both exploratory and confirmatory sub samples (see Tables 3-1 and 3-2) are quite similar. In addition, scale means, standard deviations, and alpha coefficients for the 5 factors (see Table 3-3) are also similar. Subscale correlations with Jackson social desirability (Jackson, 1967) were low, averaging about $\underline{r}=-.20$ for confidence subscales and $\underline{r}=.20$ for temptation subscales. In general, results for the confirmatory subsample cross-validate the structure of the CSS and TUS well.

\section{Insert Table 3-4 About Here}

Hierarchical Models for Confidence and Temptation

Velicer et al. (1990) found that for smoking cessation, self-efficacy was organized into one higher-order (hierarchical) factor each for both confidence and temptation. Both confidence and temptation were each comprised of the same three lower-order factors: habit strength, negative affect, and positive social situations. Similarly, Clark et al. (1991) found a hierarchical organization with 5 lower-order factors for the area of weight control, including: negative emotions, (food) availability, social pressure, physical discomfort, and positive activities. Based on these previous results (Clark et al., 1991; Prochaska \& DiClemente, 1985; Velicer 
et al., 1990), the one hierarchical factor model was tested within the cross-validation subsample here.

Indeed, confidence in safer sex and temptation for unsafe sex appear to be adequately described as hierarchical models, in other words, that subjects meaningfully differentiate between the lower-order situational subfactors, in addition to viewing the construct as homogeneous at the higher-order level. This lends support to other studies which have only looked at self-efficacy as one unitary construct, i.e. at the higher-order level.

The question remains, however, are confidence and temptation redundant? Do they really measure different constructs or are they merely measuring opposite ends of one spectrum (i.e., bipolar)? In the area of smoking cessation, confidence and temptation are reported to be correlated at $\underline{r}=-.60$ (Velicer et al., 1990). To address these questions for safer sex, a multi-trait multi-method matrix was constructed with all confidence and temptation items, which allowed all identical item pairs to have correlated error terms. This would allow the true construct variances to correlate, with some of the artifactual measurement error removed. Results of this analysis revealed that the higher-order constructs, confidence and temptation, were correlated, $\underline{r}=-.66$. When like lower-order subscales were also allowed to correlate, the correlation between higher-order constructs dropped somewhat to $\underline{r}=-.60$. This reveals that the correlation between confidence and temptation higher-order constructs is $\underline{r}=-.60$, even when the shared method variance created by using identical situational items is statistically accounted for. This supports the distinction between the confidence and temptation constructs. Further support for their distinction is likely to emerge from clinical intervention 
applications, based on our experience with smoking cessation. Standardized maximum likelihood parameter estimates for the structural relations among the 5 factors and the one hierarchical factor for the CSS and TUS are shown in Figures 31 and 3-2.

Insert Figures 3-1 \& 3-2 About Here

Stage X Self-Efficacy Analyses

Further model testing was conducted by investigating the relationship between the stages of change and confidence and temptation. According to the stages of change model, confidence and temptation vary differentially for subjects in the various stages of change. Such results have been obtained consistently in the area of smoking cessation (DiClemente et al., 1991; Prochaska \& DiClemente, 1983; Prochaska et al., 1991) and exercise adoption (Marcus, Rossi, Selby, Niaura, \& Abrams, 1992). To determine if similar results would also be obtained for safer sex adoption, two two-way multivariate analyses of variance (MANOVA) were conducted using sex and stage of change as the independent variables and confidence or temptation subscale scores as dependent variables. T-scores were determined by calculating the summed ratings for the items representing each factor and standardizing them $(M=50, S D=10)$. Subjects were placed in one of four stages of safer sex behavior change using a short series of questions, as described in the Method section. Only sexually active subjects with complete data on all 15 CSS and 15 TUS items were retained for the analysis $(\underline{N}=288)$. The resulting distribution 
among the stages of change was: Precontemplation $(\underline{\mathrm{N}}=18,6.3 \%)$; Contemplation $(\underline{\mathrm{N}}=50,17.4 \%)$; Action $(\underline{\mathrm{N}}=50,17.4 \%)$; and Maintenance $(\underline{\underline{N}}=170,59.0 \%)$.

For confidence, the stage by sex MANOVA revealed a nonsignificant interaction term, Wilks $\Lambda=.917$, approximate $\underline{F}(15,756.79)=1.60, \underline{p}>.05$, and significant main effects for both stage of change, Wilks $\Lambda=.813$, approximate $\underline{F}(15,756.79)=3.93, \underline{p}<.001$, multivariate $\eta^{2}=.067$, and sex, Wilks $\Lambda=$ .922 , exact $\underline{F}(5,274)=4.66, \underline{p}<.001$, multivariate $\eta^{2}=.078$. Results for stages of change are reported in Table 3-5. Follow-up univariate analyses of variance were conducted for each subscale and all were statistically significant ' $(\underline{p}<$ .001). The effects of stage of change were generally medium to large in magnitude, with proportions of variance accounted for $\left(\eta^{2} s\right)$ ranging from .06 to .16 (mean $=$ $.11) .1$ Follow-up comparisons for each scale as a function of stage of change were conducted using Tukey tests. In general, these results revealed that Precontemplators felt substantially less efficacious about having safer sex than subjects in all other stages of change. 
Results for sex are reported in Table 3-6. Follow-up univariate analyses of variance were conducted for each subscale and four out of five were statistically significant $(\mathfrak{p}<.001)$. The effects of sex were generally small to medium in magnitude, with proportions of variance accounted for $\left(\eta^{2} s\right)$ ranging from .01 to .06 $($ mean $=.04) .1$ Interestingly, the CSS situational subscales with the largest sex differences were partner pressure and negative affect. No sex differences were found for the CSS subscale, substance use.

For temptation, the stage by sex MANOVA revealed a nonsignificant interaction term, Wilks $\Lambda=.938$, approximate $\underline{\mathrm{F}}(15,751.27)=1.16, \underline{\mathrm{p}}>.05$, and significant main effects for both stage of change, Wilks $\Lambda=.891$, approximate $\underline{\mathrm{F}}(15,751.27)=2.14, \mathrm{p}<.01$, multivariate $\eta^{2}=.038$, and sex, Wilks $\Lambda=.903$, exact $\underline{F}(5,272)=5.84, \underline{p}<.01$. Results for stages of change are reported in Table 3-7. Follow-up univariate analyses of variance were conducted for each subscale and all were statistically significant $(\underline{p}<.05)$. The effect sizes were slightly smaller than for confidence, with proportions of variance accounted for $\left(\eta^{2} s\right)$ ranging from .03 to .06 (mean $=.05$ ). Follow-up comparisons for each subscale as a function of stage of change were conducted using Tukey tests and no significant differences between stage groups were revealed.

\section{Insert Tables 3-7 and 3-8 About Here}

Results for sex are reported in Table 3-8. Follow-up univariate analyses of variance were conducted for each subscale and all were statistically significant $(p<.05)$. The effect sizes were slightly larger than for confidence, with proportions 
of variance accounted for $\left(\eta^{2} s\right)$ ranging from .03 to .09 (mean $\left.=.06\right)$. Males rated their temptation for unsafe sex significantly higher than females across all 5 situational categories. The largest sex differences in subscale scores were for partner pressure, negative affect, and perceived low risk.

Discussion

The present study demonstrates how the stages of change model can be applied to the study of self-efficacy and safer sex. In their efforts at modifying sexual behavior, participants estimated their confidence in practicing safer sex and their temptations to have unsafe sex differentiating between five situational categories: negative affect, sexual arousal, perceived low risk, partner pressure, and substance use. These subscales were organized in an hierarchical fashion, consisting of one higher-order construct which may be globally characterized as confidence or temptation, respectively. Ratings of each subscale were highly related to subjects' stage of change and to subjects' gender. Precontemplators rated each confidence subscale significantly lower than subjects in other stages of change. Males rated all 5 temptation situational subscales significantly higher than did females. Conversely, females' ratings of 4 out of 5 confidence situational subscales were significantly higher than males'. Finally, this study has resulted in the development of two brief, reliable instruments for assessing self-efficacy for safer sex adoption and maintenance.

The results of this study are similar in many ways to the model-based results previously reported for smoking cessation (DiClemente et al., 1991; Prochaska \& DiClemente, 1983; Prochaska et al., 1991; Velicer et al., 1990), for exercise adoption (Marcus, Selby et al., 1992), and for weight control (Clark et al, 1991), 
with the exception of the item content of the situational subscales. The distinction among situations has proven useful in the area of smoking cessation, especially for intervention purposes (Velicer, Prochaska, Bellis, DiClemente, Rossi, Fava, \& Steiger, in press), where situational confidence and temptation scores are used to provide subjects with normative and ipsative feedback and suggestions for bolstering confidence and/or resisting temptations in particularly troublesome situations.

College-aged males rated their temptation in unsafe sex higher than females did across all 5 situational categories, and for 4 out of 5 situations, females rated their confidence in safer sex higher than males did. These differences are consistent with gender-role stereotypes and previous results (Goldman \& Harlow, 1990). The differences in confidence and temptation apparently do not result in gender differences in stage progression, which would have been demonstrated by a significant stage by sex interaction. These findings do suggest, however, that development of an expert system (Velicer et al., in press) for safer sex should keep male and female group differences separate. Some of these findings appear counterintuitive. For example, that females exceeded males in their ratings of confidence in their ability to practice safer sex across 4 out of 5 situational categories is important information. This could reflect females greater experience with negotiating contraception and protecting themselves sexually. Research investigating the development of this capacity in males and females would be particularly interesting. That college males, in general, had greater situational temptation and lower situational self-efficacy than college females suggests that they are an undertargeted group for efficacy-based intervention. 
Several studies have found an empirical relation between substance use and risky sexual behavior (Buffam, 1988; Clapper \& Lipsitt, 1991; Earleywine \& Finn, 1991; Flavin \& Frances, 1988; Hingson, Strunin, Berlin, \& Heeren, 1990; Kegeles, Adler, \& Irwin, 1988; Leigh, 1990; Martin, 1990; Mott \& Haurin, 1988; Nagy, Hunt, \& Adcock, 1990; Rosenbloom, 1991; Stall, McKusick, Wiley, Coates, \& Ostrow, 1986). In spite of some physiological evidence to the contrary, there is a public perception that substance use increases sexual arousal (Leigh, 1990). This is explained through sexual disinhibition secondary to substance use. An alternative explanation is that sensation seeking is a third variable accounting for the observed relationship between behavioral disinhibition and alcohol consumption (Earleywine \& Finn, 1991; Leigh, 1990). In addition, alcohol and certain drugs have become part of the "dating scene," and are therefore, inextricably bound up with sexual relationship formation and development (Leigh, 1990). It is also possible that substance use decreases self-efficacy for safer sex and/or increases temptation to have unsafe sex. This instrument provides one means to test this hypothesis. Interestingly, males and females did not differ significantly in their ratings of selfefficacy for safer sex after using substances, although males did rate substance use situations as significantly more tempting than females. This, in combination with data suggesting higher rates of substance use among college-aged males suggests that this is an important area to target for intervention.

One obvious limitation of this study should be noted. Specifically, this research was based on a cross-sectional sample using self-report data. This limitation was partly necessitated by sample size and by the desire to begin model development in the area of safer sex along lines similar to those that have proven 
useful for other health behaviors (Prochaska \& DiClemente, 1983; 1985; Prochaska et al., 1992). Although it should be noted that for smoking cessation, crosssectional results have been replicated in longitudinal studies (Prochaska et al., 1991). This underscores the need for longitudinal research in the area of sexual behavior change, in part to replicate interesting cross-sectional findings such as these.

The results of this study have clinical implications for sexual behavior change. Subjects differentiate among at least 5 situational factors in their estimates of confidence in their ability to have safer sex and ratings of their degree of temptation to have unsafe sex. Both stage of readiness to adopt safer sex and gender have important effects on subjects' ratings of situational confidence and temptation. This suggests that clinicians, by measuring and understanding individuals' situational confidence and temptations, may be assisted in designing and targeting situationspecific interventions to help individuals improve their confidence or manage their temptation. Such situation-specific targeting should help individuals better prepare to adopt safer sex practices, and help them to better maintain these practices once they have adopted them. Development of more successful interventions, in turn, will help to reach the goal of decreasing the level of risky sexual activity in the United States and attaining the health objectives that have been established for the year 2000 (USDHHS, 1991), as the incidence and prevalence of STD's, unwanted pregnancy, HIV infection, and AIDS decrease. 
References

Bandura, A. (1977). Self-efficacy: Toward a unifying theory of behavioral change. Psychological Review, 84, 191-215.

Bandura, A. (1982). Self-efficacy mechanism in human agency. American Psychologist, $\underline{37}, 122-147$.

Bandura, A. (1986). Social foundations of thought and action: A social cognitive theory. Prentice Hall, Inc.: New Jersey.

Bentler, P.M., \& Bonett, D.G. (1980). Significance tests and goodness of fit in the analysis of covariance structures. Psychological Bulletin, $\underline{88}, 588-606$.

Bollen, K.A. (1989). Structural equations with latent variables. New York: Wiley. Buffam, J. (1988). Substance abuse and high-risk sexual behavior: Drugs and sex -the dark side. Journal of Psychoactive Drugs, 20, 165-168.

Clapper, R.L. \& Lipsitt, L.P. (1991). A retrospective study of risk-taking and alcohol-mediated unprotected intercourse. Journal of Substance Abuse, $\underline{3}, 91$ 96.

Clark, M.M., Abrams, D.B., Niaura, R.S., Eaton, C.A., \& Rossi, J.S. (1991). Self-efficacy in weight management. Journal of Consulting and Clinical Psychology, 59, 739-744.

Cohen, J. (1977). Statistical power analysis for the behavioral sciences (rev. ed.). New York: Academic Press.

Comrey, A.L. (1988). Factor-analytic methods of scale development in personality and clinical psychology. Journal of Consulting and Clinical Psychology, $\underline{56}$, 754-761. 
DiClemente, C.C. (1986). Self-efficacy and the addictive behaviors. Journal of Social and Clinical Psychology, 4, 302-315.

DiClemente, C.C., Prochaska, J.O., Fairhurst, S.K., Velicer, W.F., Velasquez, M.M., \& Rossi, J.S. (1991). The process of smoking cessation: An analysis of precontemplation, contemplation and preparation stages of change. Journal of Consulting and Clinical Psychology, 59, 295-304.

Dishman, R. K. (1982). Compliance/adherence in health-related exercise. Health Psychology, 1, 237-267.

Dixon, W.J., Brown, M.B., Engelman, L., Hill, M.A., \& Jennrich, R.I. (1988). BMDP Statistical Software Manual. Los Angeles, CA: The Regents of the University of California.

Dryfoos, J.G. (1991). Preventing high-risk behavior. American Journal of Public Health, $\underline{81}, 157-158$.

Dwyer, J.H. (1983). Statistical models for the social and behavioral sciences. New York: Oxford University Press.

Earleywine, M., \& Finn, P.R. (1991). Sensation seeking explains the relation between behavioral disinhibition and alcohol consumption. $\underline{\text { Addictive }}$ Behaviors, 16, 123-128.

Ekstrand, M.L., \& Coates, T.J. (1990). Maintenance of safer sexual behaviors and predictors of risky sex: The San Francisco men's health study. American Journal of Public Health, $\underline{80}$, 973-977.

Fisher, J.D., \& Fisher, W.A. (1992). Changing AIDS-risk behavior. Psychological Bulletin, 111, 455-474. 
Flavin, D.K., \& Frances, R.J. (1987). Risk-taking behavior, substance abuse disorders, and the Acquired Immune Deficiency Syndrome. Advances in Alcohol \& Substance Abuse, $\underline{6}, 23-32$.

Flora, J.A., \& Thoreson, C.E. (1989). Reducing the risk of AIDS in adolescents. American Psychologist, 43, 965-970.

Freeman, A., Cohn, D., Corby, N., and Wood, R. (1991). Patterns of sexual behavior change among homosexual/bisexual men: Selected U.S. sites, 19871990. Morbidity and Mortality Weekly Report, 40(46), 792-794.

Gladis, M.M., Michela, J.L., Walter, H.J., \& Vaughan, R.D. (1992). High school students' perceptions of AIDS risk: Realistic appraisal or motivated denial? Health Psychology, 11, 307-316.

Goldman, J.A., \& Harlow, L.L. (1990, August). Psychological variables mediating AIDS preventive behavior: A preliminary study. Paper presented at the 98th annual meeting of the American Psychological Association, Boston, MA.

Harlow, L.L., Prochaska, J.O., Redding, C.A., Snow, M.G., Rossi, J.S., Velicer, W.F., Rhodes, F., Schnell, D., \& Galavotti, C. (1993). Self-efficacy for condom use in a high HIV-risk sample. Manuscript in preparation.

Horn, J.L. (1965). A rationale and test for the number of factors in factor analysis. Psychometrika, $\underline{30}, 179-185$.

Hingson, R.W., Strunin, L., Berlin, B.M., \& Heeren, T. (1990). Beliefs about AIDS, use of alcohol and drugs, and unprotected sex among Massachusetts adolescents. American Journal of Public Health, 스, 295-299.

Hunt, W.A., Barnett, L.W. \& Branch, L.G. (1971). Relapse rates in addictions programs. Journal of Clinical Psychology, 27, 455-456. 
Jackson, D.N. (1970). A sequential system for personality scale development. In C.D. Spielberger (Ed.), Current topics in clinical and community psychology (Vol. 2, pp. 61-96). New York: Academic Press.

Jöreskog, K.G., \& Sörbom, D. (1984). LISREL VI user's guide. Mooresville, IN: Scientific Software.

Kaplan, D. (1989). Model modification in covariance structure analysis: Application of the expected parameter change statistic. Multivariate Behavioral Research, 24, 285-305.

Kegeles, S.M., Adler, N.E., \& Irwin, C.E. (1988). Sexually active adolescents and condoms: Change over one year in knowledge, attitudes and use. American Journal of Public Health, $\underline{78}, 460-461$.

Kelly, J.A., \& Murphy, D.A. (1992). Psychological interventions with AIDS and HIV: Prevention and treatment. Journal of Consulting and Clinical Psychology, 60, 576-585.

Kelly, J.A., St. Lawrence, J.S., Hood, H.V., \& Brasfield, T.L. (1989). Behavioral intervention to reduce AIDS risk activities. Journal of Consulting and Clinical Psychology, 57, 60-67.

Leigh, B.C. (1990). "Venus gets in my thinking": Drinking and female sexuality in the age of AIDS. Journal of Substance Abuse, 2, 129-145.

Long, J.S. (1983). Confirmatory factor analysis: A preface to LISREL. Newbury Park, CA: Sage.

MacCallum, R.C., (1986). Specification searches in covariance structure modeling. Psychological Bulletin, 100, 107-120. 
Marcus, B.H., Rossi, J.S., Selby, V.C., Niaura, R.S., \& Abrams, D.B. (1992). The stages and processes of exercise behavior change in a worksite sample. Health Psychology, 11, 386-395.

Marcus, B.H., Selby, V.C., Niaura, R.S., \& Rossi, J.S. (1992). Self-efficacy and the stages of exercise behavior change. Research Quarterly for Exercise and Sport, $\underline{63}, 60-66$.

Marsh, H.W., Balla, J.R., \& McDonald, R.P. (1988). Goodness-of-fit indexes in confirmatory factor analysis: The effect of sample size. Psychological Bulletin, 103, 391-410.

Martin, J.L. (1990). Drug use and unprotected anal intercourse among gay men. Health Psychology, 9, 450-465.

Mott, F.L., \& Haurin, R.J. (1988). Linkages between sexual activity and alcohol and drug use among American adolescents. Family Planning Perspectives, $\underline{20}, 128-136$.

Mulaik, S.A., James, L.R., Van Alstine, J., Bennett, N., Lind, S., \& Stilwell, C.D. (1989). Evaluation of goodness-of-fit indices for structural equation models. Psychological Bulletin, 105, 430-445.

Nagy, S., Hunt, B., \& Adcock, A. (1990). A comparison of AIDS and STD knowledge between sexually active alcohol consumers and abstainers. Journal of School Health, 60, 276-279.

Prochaska, J.O., \& DiClemente, C.C. (1983). Stages and processes of self-change in smoking: Towards an integrative model of change. Journal of Consulting and Clinical Psychology, 51, 390-395. 
Prochaska, J.O., \& DiClemente, C.C. (1985). Common processes of self-change in smoking, weight control, and psychological distress. In S. Shiffman \& T. Wills (Eds.), Coping and substance use (pp. 345-363). New York: Academic Press.

Prochaska, J.O., Harlow, L.L., Redding, C.A., Snow, M.G., Rossi, J.S., Velicer, W.F., Rhodes, F., Schnell, D., \& Galavotti, C. (1990). Stages of change. self-efficacy, and decisional balance of condom use in a high HIV-risk sample. Manuscript in preparation.

Prochaska, J.O., Norcross, J.C., Fowler, J.L., Follick, M.J., \& Abrams, D.B. (1992). Attendance and outcome in a work site weight control program: Processes and stages of change as process and predictor variables. Addictive Behaviors, 17, 35-45.

Prochaska, J.O., Redding, C.A., Harlow, L.L., Rossi, J.S., \& Velicer, W.F. (1992). The Transtheoretical model and HIV prevention: A review. Manuscript submitted for publication.

Prochaska, J.O., Velicer, W.F., DiClemente, C.C., \& Fava, J. (1988). Measuring processes of change: Applications to the cessation of smoking. Journal of Consulting and Clinical Psychology, 56, 520-528.

Prochaska, J.O., Velicer, W.F., Guadagnoli, E., \& Rossi, J.S., \& DiClemente, C.C. (1991). Patterns of change: Dynamic typology applied to smoking cessation. Multivariate Behavioral Research, 26, 83-107.

Rakowski, W., Dube, C., Marcus, B.H., Prochaska, J.O., Velicer, W.F., \& Abrams, D.B. (1992). Assessing motivational readiness and decision-making for mammography. Health Psychology, 11, 111-118. 
Rossi, J.S. (1989). Exploring behavioral approaches to UV risk reduction. In A. Moshell \& L.W. Blankenbaker (Eds.), Sunlight, ultraviolet radiation, and the skin (pp. 91-93). Bethesda, MD: National Institutes of Health.

Rossi, J.S. (1990). Statistical power of psychological research: What have we gained in 20 years? Journal of Consulting and Clinical Psychology, $\underline{58}, 646-$ 656.

Rossi, J.S. (1992, August). Processes of change for nine problem behaviors. Paper presented at the 100th annual convention of the American Psychological Association, Washington, D.C.

Rugg, D.L. (1990). AIDS prevention: A public health psychology perspective. In Leviton, L.C., Hegedus, A.M., \& Kubrin, A. (eds.) Evaluating AIDS prevention: Contributions of multiple disciplines. San Francisco, CA: JoseyBass Inc., 7-22.

Schnell, D.J., Galavotti, C., \& O'Reilly, K.R. (in press). An evaluation of sexual behavior change using statistical and cognitive models. Statistics in Medicine.

Silvia, E.S.M., \& MacCallum, R.C. (1988). Some factors affecting the success of specification searches in covariance structure modeling. Multivariate Behavioral Research, 23, 297-326.

Sonstroem, R.J. (1988). Psychological models. In R. Dishman (Ed.), Exercise adherence (pp. 125-154). Champaign, IL: Human Kinetics Books. 
St. Lawrence, J.S. (1993). African-American adolescents' knowledge, health-related attitudes, sexual behavior, and contraceptive decisions: Implications for the prevention of adolescent HIV infection. Journal of Consulting and Clinical Psychology, 61, 104-112.

Stall, R., McKusick, L., Wiley, J., Coates, T.J., \& Ostrow, D.G. (1986). Alcohol and drug use during sexual activity and compliance with safe sex guidelines for AIDS: The AIDS Behavioral Research Project. Health Education Quarterly, $\underline{13}, 359-371$.

Tucker, L.R., \& Lewis, C. (1973). A reliability coefficient for maximum likelihood factor analysis. Psychometrika, $\underline{38}, 1-10$.

U. S. Department of Health and Human Services (1991). Healthy people 2000: National health promotion and disease prevention objectives. DHHS Pub. No. (PHS) 91-50212. Washington, DC: U.S. Government Printing Office. Velicer, W.F. (1976). Determining the number of components from the matrix of partial correlations. Psychometrika, 41, 321-327.

Velicer, W.F., \& Fava, J.L. (1987). An evaluation of the effects of variable sampling on component, image, and factor analysis. Multivariate Behavioral Research, 22, 193-209.

Velicer, W.F., DiClemente, C.C., Rossi, J.S., \& Prochaska, J.O. (1990). Relapse situations and self-efficacy. Addictive Behaviors, 15, 271-283.

Velicer, W.F., Prochaska, J.O., Bellis, J.M., DiClemente, C.C., Rossi, J.S., Fava, J.L., \& Steiger, J.H. (in press). An expert system intervention for smoking cessation. Addictive Behaviors. 
Footnote

${ }^{1}$ Cohen (1977) has defined small, medium, and large effects as proportions of variance accounted for of $.01, .06$, and .14 , respectively. Subsequent research has generally substantiated these definitions (see Rossi, 1990). 
Table 3-1

Maximum Likelihood Factor Loadings for the 15 CSS Items

Item

Sample $1 \quad$ Sample 2

$(\underline{N}=144)$

$(\underline{N}=139)$

When I am really sexually aroused.

When I really want sex.

When I am really sexually excited.

.96

.96

When I am affected by alcohol or drugs.

.96

When I am a little drunk or high.

.88

When I am under the influence of alcohol or drugs.

When my partner is insulted that I want safer sex.

When my partner pressures me to take a chance this time.

When my partner gets annoyed about having safer sex.

When I am feeling angry.

When I am upset.

When I feel depressed.

When I think the risk is small.

.80

When there's not much risk.

When the risk seems low. 
Table 3-2

Maximum Likelihood Factor Loadings for the 15 TUS Items

$\underline{\text { Item }}$

When I am really sexually aroused.

When I really want sex.

When I am really sexually excited.

When I am affected by alcohol or drugs.

When I am a little drunk or high.

When I am under the influence of alcohol or drugs.

When my partner is insulted that I want safer sex.

When my partner pressures me to take a chance this time.

When my partner gets annoyed about having safer sex.

When I am feeling angry.

When I am upset.

When I feel depressed.

When I think the risk is small.

When there's not much risk.

When the risk seems low.
Sample 1 $\quad$ Sample 2

$$
(\underline{N}=144) \quad(\underline{N}=139)
$$

.92

.94

.93

.92

.97

.96

.92

.92

.92

.93

.97

.97

.86

.80

.88

.81

.90

.78

.93

.90

.94

.95

.72

.82

.92

.91

.92

.95

.97

.95 
Table 3-3

CSS and TUS Subscale Means and Internal Consistency

\section{Testing}

CONFIDENCE

$\underline{\text { Subscale }}$

Sexual Arousal

Substance Use

Partner Pressure

Negative Affect

Perceived Low Risk

\section{Sample $1(\mathrm{~N}=144)$}

Mean SD

3.28

1.22

.94

3.08

1.25

.96

1.13

.89

3.72

3.62

1.06

.87

3.57

.91
Cross-validation

Sample $2(N=139)$

Mean SD $\alpha$

$\begin{array}{lll}3.44 & 1.16 \quad .90\end{array}$

$\begin{array}{lll}3.05 & 1.18 & .92\end{array}$

$\begin{array}{lll}3.58 & 1.10 \quad .80\end{array}$

$3.34 \quad 1.16 \quad .91$

\section{TEMPTATION}

Subscale

Sexual Arousal

$\begin{array}{llllll}3.27 & 1.29 & .96 & 3.46 & 1.27 & .96\end{array}$

Substance Use

$\begin{array}{llllll}3.19 & 1.25 & .95 & 3.37 & 1.27 & .96\end{array}$

Partner Pressure

2.29

1.11

.91

2.27

1.02

.86

Negative Affect

2.06

1.02

.88

2.12

1.03

.92

Perceived Low Risk

2.84

1.21

.95

$2.96^{\circ}$

$1.29 \quad .95$ 
Table 3-4

Comparative Fit Indices for Alternative Models

$\begin{array}{lllllll}\text { Model } & \chi^{2} \text { df } & \text { GFI } & \text { RMR } & \text { CFI } & \text { TLI } & \text { IFI2 }\left(\chi^{2}\right)\end{array}$

Confidence (CSS)

Null

$\begin{array}{lllll}1812.5 & 105 & .219 & .473\end{array}$

One Factor

$\begin{array}{lllllll}734.8 & 90 & .532 & .135 & .622 & .559 & .626\end{array}$

$\begin{array}{lllllll}5 \text { Uncorrelated Factors } 503.9 & 90 & .661 & .395 & .757 & .717 & .759\end{array}$

$\begin{array}{llllllll}5 \text { Correlated Factors } & 159.2 & 80 & .877 & .050 & .954 & .939 & .954\end{array}$

One Hierarchical

Factor

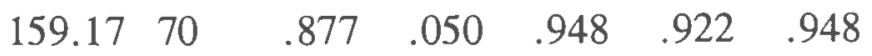

\section{Temptation (TUS)}

Null

$2484.1 \quad 105 \quad .159 \quad .575$

One Factor

$$
887.690
$$

$.524 \quad .107$

$\begin{array}{lll}.665 & .609 & .667\end{array}$

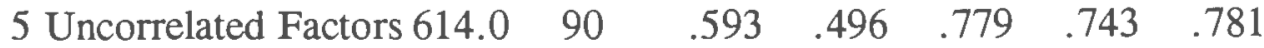

$\begin{array}{llllllll}5 \text { Correlated Factors } & 172.5 & 80 & .860 & .041 & .961 & .949 & .961\end{array}$

One Hierarchical

Factor

$$
\begin{array}{lllllll}
172.46 & 70 & .860 & .041 & .957 & .935 & .957
\end{array}
$$

Note: $\underline{\mathrm{N}}=139 ; \mathrm{df}=$ degrees of freedom; $\mathrm{GFI}=$ Goodness of fit index (Jöreskog \& Sörbom, 1984); RMR = root mean square residual (Jöreskog \& Sörbom, 1984); CFI = Comparative Fit Index (Bentler, 1990); TLI = Tucker-Lewis index (Tucker \& Lewis, 1973); IFI2( $\left.\chi^{2}\right)=$ incremental chi-square fit index, type 2 (Mulaik et al., 1989). 
Table 3-5

CSS T-score Means, S.D.'s and MANOVA Results for the Stages of Change Stage of Change

$\begin{array}{lcccccc}\text { Scale } & \text { PC } & \text { C } & \text { A } & \text { M } & \underline{F}(3,278) & \eta^{2} \\ \text { Sexual } & 40.62 & 44.72 & 51.76 & 52.13 & 17.29 & .16 \\ \quad \text { Arousal. } & (9.0) & (10.6) & (8.7) & (9.1) & & \\ \text { Substance } & 42.86 & 45.71 & 51.40 & 51.69 & 9.78 & .10 \\ \quad \text { Use } & (9.8) & (9.6) & (10.0) & (9.5) & & \\ \text { Partner } & 45.75 & 46.05 & 52.54 & 50.97 & 6.25 & .06 \\ \quad \text { Pressure } & (11.2) & (9.5) & (8.1) & (10.1) & & \\ \text { Negative } & 44.11 & 46.26 & 51.33 & 51.41 & 8.67 & .09 \\ \quad \text { Affect } & (10.4) & (10.0) & (9.3) & (9.7) & & \\ \text { Perceived } & 37.86 & 43.34 & 49.87 & 49.89 & 12.91 & .12 \\ \quad \text { Low Risk } & (10.8) & (10.8) & (9.0) & (10.1) & & \end{array}$

Note: Standard deviations are given in parentheses. $\mathrm{PC}=$ Precontemplation $(\underline{\mathrm{N}}=$ 18); $\mathrm{C}=$ Contemplation $(\underline{\mathrm{N}}=52) ; \mathrm{A}=$ Action $(\underline{\mathrm{N}}=46) ; \mathrm{M}=$ Maintenance $(\underline{\mathrm{N}}=$ 170); $\eta^{2}=$ effect size (proportion of variance accounted for). All $\underline{F}$ tests are significant $(\underline{\mathrm{p}}<.01)$. 
Table 3-6

CSS T-Score Means, S.D. 's and MANOVA Results for Sex

$\begin{array}{lcccc}\underline{\text { Scale }} & \begin{array}{c}\text { Females } \\ (\underline{\mathrm{N}}=160)\end{array} & \begin{array}{c}\text { Males } \\ (\underline{\mathrm{N}}=133)\end{array} & \underline{\mathrm{F}}(1,278) & \eta^{2} \\ & 51.19 & 48.73 & 8.49^{*} & .03 \\ \text { Sexual } & (9.5) & (10.3) & & \\ \quad \text { Arousal } & 50.78 & 48.95 & 2.25 & - \\ \text { Substance } & (10.2) & (9.6) & & .06 \\ \text { Use } & 52.20 & 47.17 & 17.56^{*} & .05 \\ \text { Partner } & (10.1) & (9.1) & & \\ \text { Pressure } & 51.67 & 47.86 & 13.68^{*} & .01 \\ \text { Negative } & (9.7) & (10.0) & & \\ \text { Affect } & 48.92 & 46.69 & 4.05^{*} & .01 \\ \text { Perceived } & (10.4) & (10.8) & & \\ \text { Low Risk } & & & \end{array}$

Note: Standard deviations are given in parentheses; $\eta^{2}=$ effect size (proportion of variance accounted for); * indicates that the $\underline{\mathrm{F}}$ test is significant $(\mathrm{p}<.05)$. 
Table 3-7

TUS T-score Means, S.D.'s and MANOVA Results for the Stages of Change Stage of Change

$\begin{array}{lcccccc}\text { Scale } & \text { PC } & \text { C } & \text { A } & \text { M } & \underline{F}(3,276) & \eta^{2} \\ \text { Sexual } & 53.83 & 53.63 & 49.21 & 48.67 & 5.86 & .06 \\ \quad \text { Arousal } & (10.3) & (9.0) & (9.8) & (10.0) & & \\ \text { Substance } & 49.37 & 53.43 & 49.96 & 49.00 & 2.99 & .03 \\ \quad \text { Use } & (11.0) & (8.9) & (9.8) & (10.1) & & \\ \text { Partner } & 53.24 & 51.48 & 51.03 & 48.89 & 3.63 & .04 \\ \quad \text { Pressure } & (10.7) & (8.9) & (10.6) & (9.9) & & \\ \text { Negative } & 52.02 & 52.94 & 48.89 & 49.18 & 4.58 & .05 \\ \quad \text { Affect } & (7.8) & (10.7) & (10.1) & (9.8) & & \\ \text { Perceived } & 52.18 & 53.31 & 49.79 & 48.79 & 4.48 & .05 \\ \quad \text { Low Risk } & (11.5) & (9.4) & (9.8) & (9.9) & & \end{array}$

Note: Standard deviations are given in parentheses. $\mathrm{PC}=$ Precontemplation $(\underline{\mathrm{N}}=$ 18); $\mathrm{C}=$ Contemplation ( $\underline{\mathrm{N}}=52) ; \mathrm{A}=$ Action $(\underline{\mathrm{N}}=48) ; \mathrm{M}=$ Maintenance $(\underline{\mathrm{N}}=$ 166); $\eta^{2}=$ effect size (proportion of variance accounted for); all $\underline{\mathrm{F}}$ tests are significant $(\underline{p}<.05)$. 
Table 3-8

TUS Subscale T-Score Means, S.D. 's and MANOVA Results for Sex

$\underline{\text { Scale }}$

$\begin{array}{lcccc} & (\underline{\mathrm{N}}=158) & (\underline{\mathrm{N}}=134) & & \\ \text { Sexual } & 48.58 & 51.89 & 14.15 & .05 \\ \text { Arousal } & (9.9) & (9.8) & & \\ \text { Substance } & 48.68 & 51.65 & 8.47 & .03 \\ \text { Use } & (10.3) & (9.3) & & \\ \text { Partner } & 46.86 & 53.90 & 26.93 & .09 \\ \text { Pressure } & (9.4) & (9.5) & & .06 \\ \text { Negative } & 48.10 & 52.24 & 16.51 & \\ \text { Affect } & (9.8) & (9.8) & & .06 \\ \text { Perceived } & 47.85 & 52.58 & 18.04 & \\ \text { Low Risk } & (9.8) & (9.5) & & \end{array}$

Note: Standard deviations are given in parentheses; $\eta^{2}=$ effect size (proportion of variance accounted for $)$; all $\underline{\mathrm{F}}$ tests are significant $(\mathrm{p}<.05)$. 


\section{Figure Captions}

Figure 3-1. Standardized maximum likelihood parameter estimates for the 5 factor hierarchical model of CSS

Figure 3-2. Standardized maximum likelihood parameter estimates for the 5 factor hierarchical model of TUS Figure 3-3. Stage by subscale graphs for the 5 standardized confidence subscales.

Figure 3-4. Stage by subscale graphs for the 5 standardized temptation subscales. 


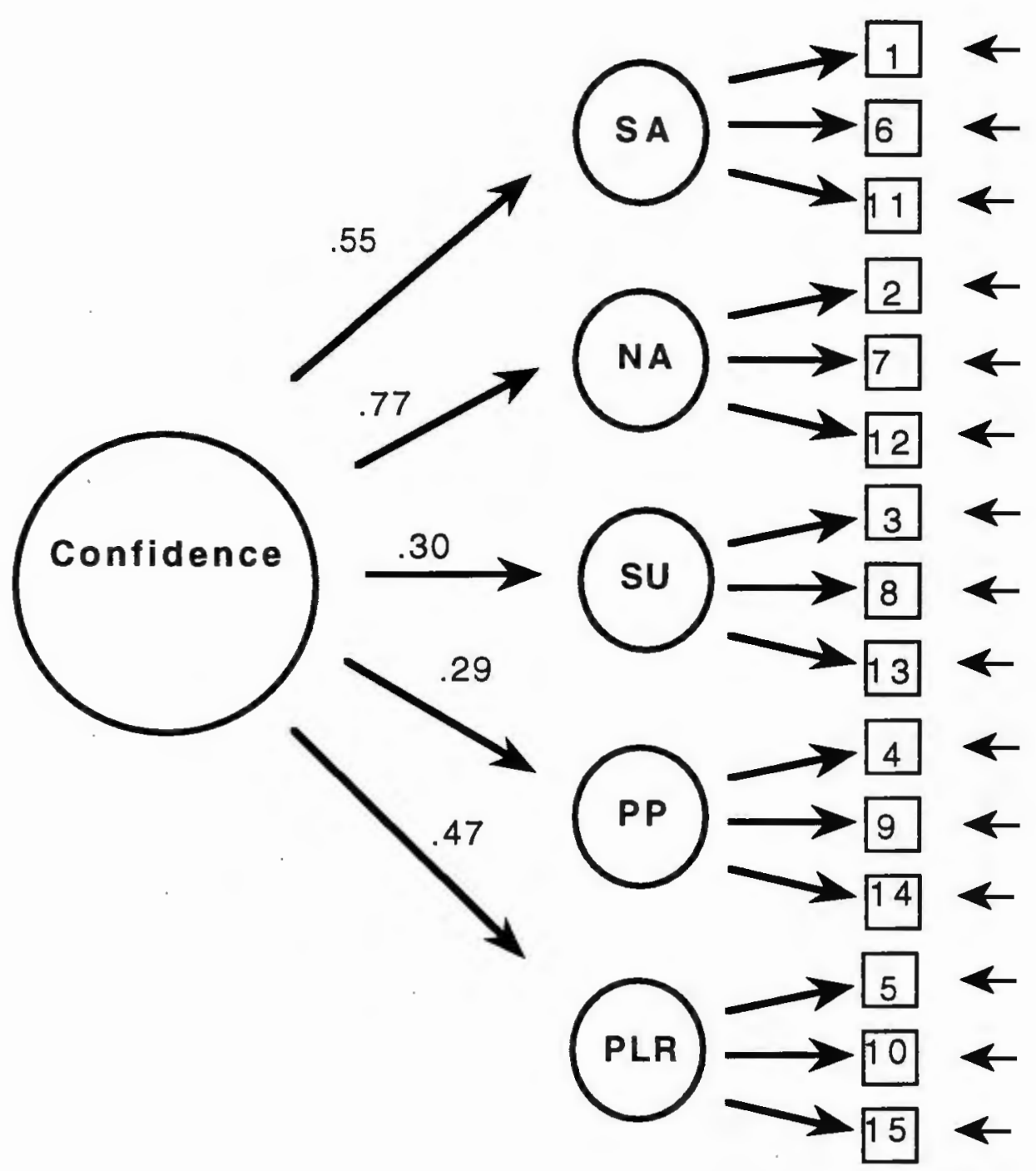




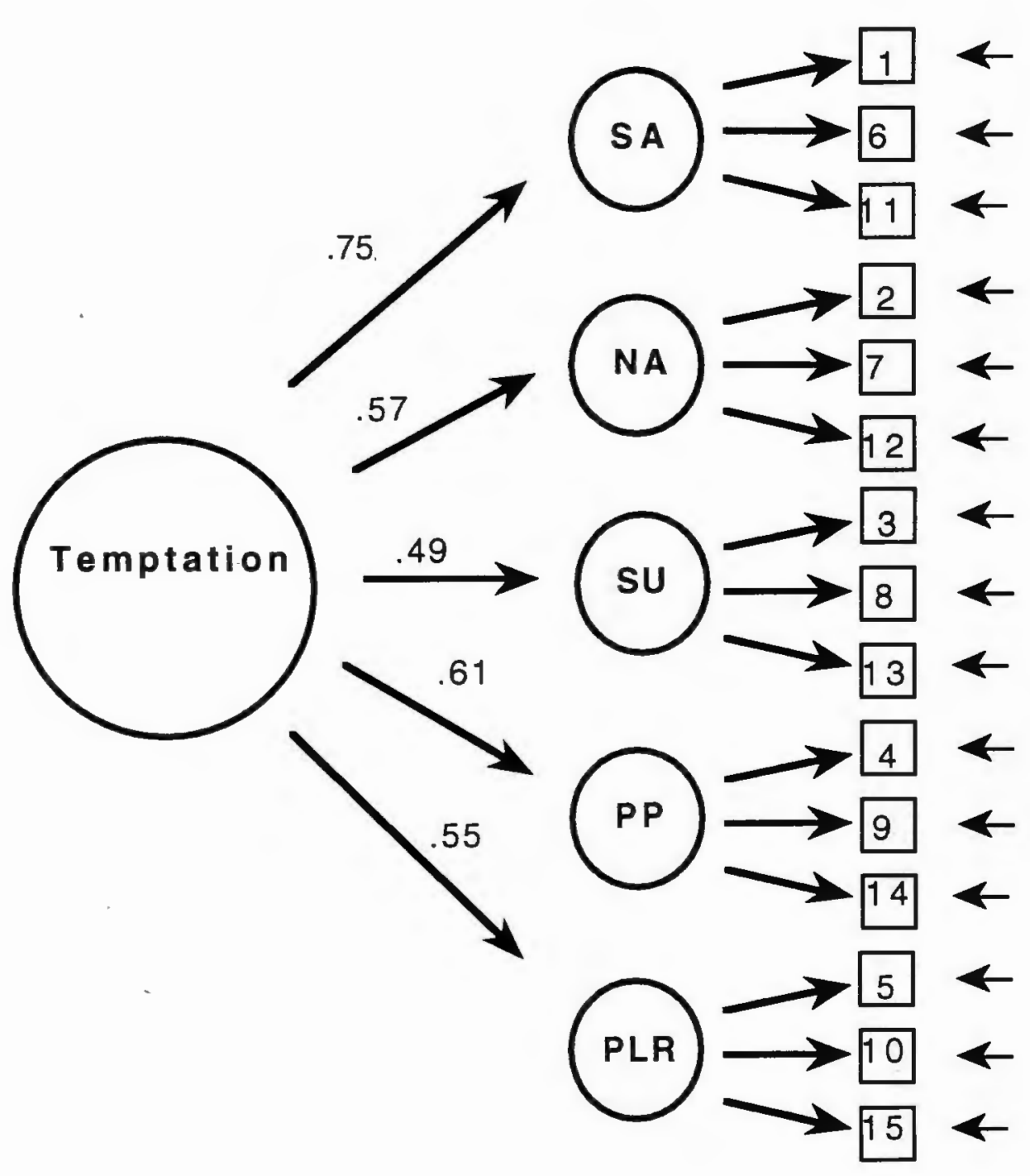


Confidence Subscales by Stage

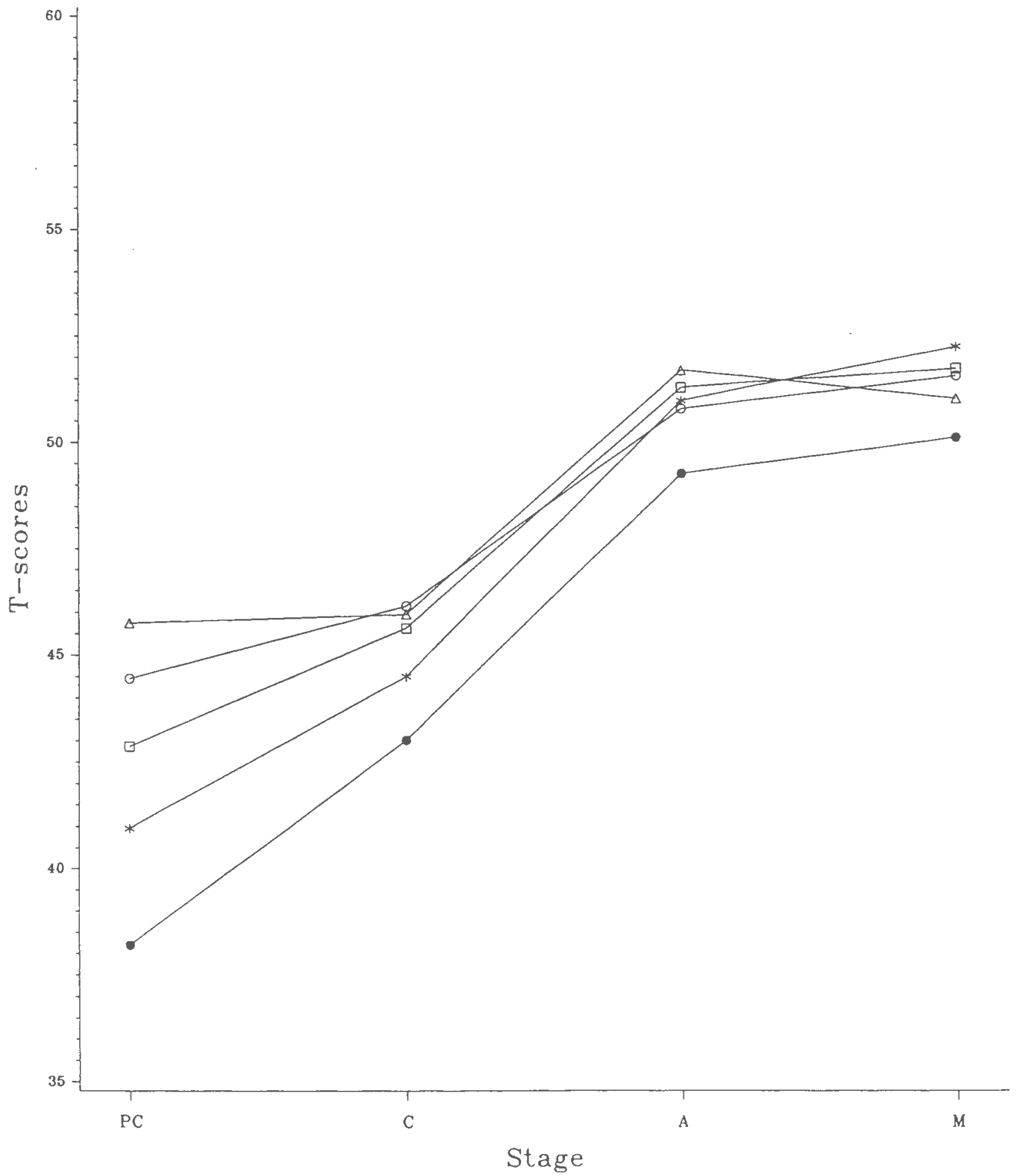

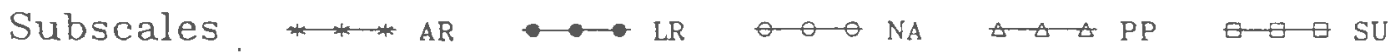


Temptation Subscales by Stage

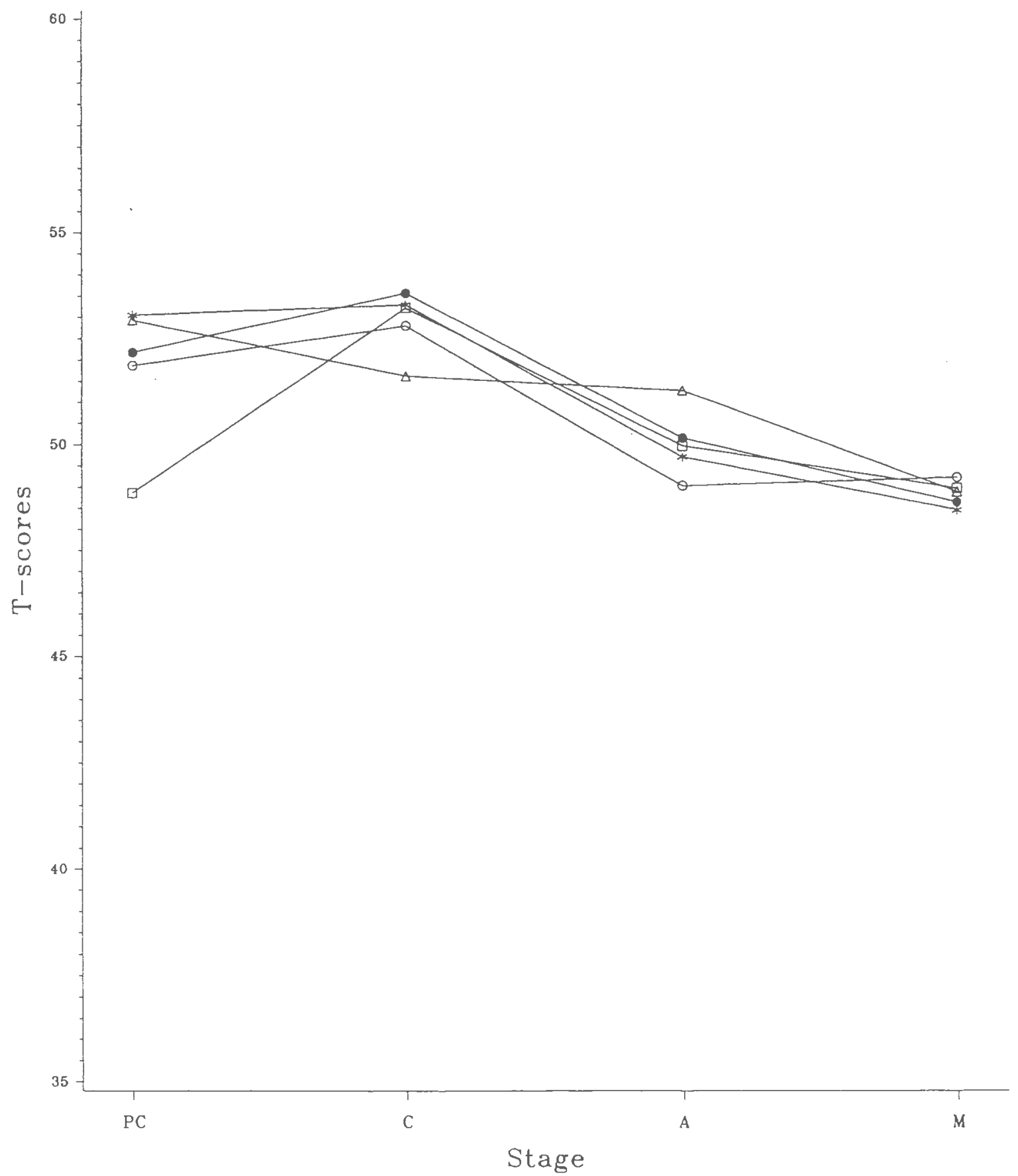

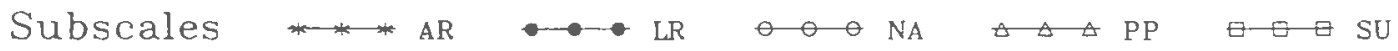


PART IV

\section{PROCESSES OF SAFER SEX ADOPTION}

Practicing safer sex would prevent a wide variety of sexually transmitted diseases, including AIDS, and other health problems (e.g., unwanted pregnancy). Since the benefits of safer sex are clear, researchers and clinicians are faced with two main challenges: how to get people to initiate safer sexual activity, and how to get people to maintain safer sexual activity.

The transtheoretical model (DiClemente, Prochaska, Fairhurst, Velicer, Velasquez, \& Rossi, 1991; Prochaska \& DiClemente, 1983, 1985; Prochaska, DiClemente, \& Norcross, 1992) has investigated and predicted how people change behaviors. Model-based research has found that individuals engaging in a new behavior (acquisition) or stopping an old behavior (cessation) move through a series of stages of change: Precontemplation, Contemplation, Preparation, Action and Maintenance. Movement through these stages is usually cyclical, rather than linear, since many individuals must make several attempts at behavior change before their goals are realized. The processes of change are strategies and techniques people use as they progress through the different stages of change over time. Research has documented that common processes are used for adopting a positive health behavior such as regular exercise (Marcus, Rossi, Selby, Niaura, \& Abrams, 1992), and stopping unhealthy behaviors such as smoking (Kristeller, Rossi, Ockene, Goldberg, \& Prochaska, 1992; Prochaska \& DiClemente, 1983, 1985; Prochaska, Velicer, DiClemente, \& Fava, 1988), overeating (Prochaska, Norcross, Fowler, Follick, \& Abrams, 1992; Rossi, Rossi, Rossi-DelPrete, Prochaska, Banspach, \& Carleton, in press), alcohol abuse (Snow, 1991; Snow, Prochaska, \& Rossi, in press), or cocaine use (Martin, Rossi, Rosenbloom, Monti, \& Rohsenow, 1992; Rosenbloom, 1991; 
Rossi, 1992). Use of the processes of change is strongly dependent on the individual's stage of change (DiClemente et al., 1991; Marcus et al., 1992; Prochaska \& DiClemente, 1983, 1985; Prochaska, Velicer, Guadagnoli, Rossi, \& DiClemente, 1991). For example, use of the experiential processes tends to peak in the Preparation stage, while use of the behavioral processes tends to peak in the Action stage. Precontemplators use the processes of change least of all. These results suggest that the tailoring of intervention programs to processes may accelerate progress through the stages and thus increase adoption of safer sex, as .well as improve maintenance. Stage-targeted interventions have been successful in the area of smoking cessation (Prochaska, DiClemente, Velicer, \& Rossi, in press) and exercise adoption (Marcus, Banspach, Lefebvre, Rossi, Carleton, \& Abrams, 1992).

The transtheoretical model has been applied to a wide range of health behaviors, especially the addictions (Prochaska \& DiClemente, 1983, 1985; Prochaska, DiClemente, \& Norcross, 1992; Prochaska, Harlow, Redding, Snow, Rossi, \& Velicer, 1990; Prochaska, Norcross et al., 1992; Prochaska, Redding, Harlow, Rossi, \& Velicer, 1992; Rakowski, Dube, Marcus, Prochaska, Velicer, \& Abrams, 1992; Rosenbloom, 1991; Rossi, 1989, 1992; Snow, 1991; Tejero, Trujols, \& Hernández, 1991). AIDS prevention researchers (CDC, 1992; Fisher \& Fisher, 1992; Kelly \& Murphy, 1992; Valdisseri, 1989) have independently cited this model as an example of a health behavior change model which has important implications for AIDS prevention. Other researchers have called for a shift from a reliance on epidemiological models to the use of process models which can improve our understanding of mediating mechanisms of behavior change (Becker \& Joseph, 
1988; Coates, 1990; Catania, Kegeles, \& Coates, 1990). This study was designed to examine the application of the transtheoretical model to safer sex behavior. Specific aims were to develop scales to measure both the stages and the processes of safer sex behavior change and to determine which processes people use when they are in different stages of change. How this model is adapted to safer sex behavior change will have important ramifications for both intervention development and future research.

\section{Method}

\section{Subjects}

Subjects were 305 male and female, sexually active students attending a midsize, northeastern state university. Approximately $54 \%$ of the subjects were female, $91 \%$ were Caucasian, $99 \%$ were single, and $98 \%$ identified themselves as heterosexual. Modal age was 19 years (34\%), and modal year in college was freshman $(47 \%)$.

\section{Procedure}

Subjects were recruited from within their classrooms. Participation was anonymous and voluntary. Some subjects received class credit for participating in research. Study participants provided informed consent and completed questionnaires within approximately 30 minutes.

Questionnaire Development

The development of the Processes of Safer Sex (PSS) questionnaire followed the sequential method of scale development (Comrey, 1988; Jackson, 1970). An initial pool of 75 items was generated based on definitions from the stages and processes of change model. Many of the items were adapted and revised for safer 
sex from those used by Prochaska et al. (1988) for smoking cessation and Marcus et al. (1992) for exercise adoption. Content validity was established by having three doctoral level judges classify the items according to conceptual definitions of 11 different change processes: Consciousness Raising, Counterconditioning, Dramatic Relief, Environmental Reevaluation, Helping relationships, Reinforcement Management, Self Liberation, Self Reevaluation, Social Liberation, Stimulus Control, and Interpersonal Systems Control. This last process was tested initially as part of the smoking cessation, weight control, psychological distress, and cocaine cessation processes of change studies, however, for cocaine cessation, it merged with Stimulus Control (Rossi, 1992), while for other areas it emerged as distinct (Prochaska \& Norcross, 1983; Prochaska \& DiClemente, 1985; Rossi, 1992). Since then, however, for unclear reasons interpersonal systems control was excluded when the processes of change for smoking cessation were reported (Prochaska et al., 1988; Rossi, 1992). This process may emerge as distinct for safer sex as well, since sexuality is usually expressed interpersonally. A general definition of the 11 processes is provided in Table 4-1. Seventy-five items were retained for the final questionnaire. Subjects were instructed to think back over the past month and to rate the frequency of occurrence of each item on a Likert scale from 1 (never) to 5 (repeatedly).

Insert Table 4-1 About Here

Five questions designed to assess current stage of safer sex behavior were also administered to all subjects. Four stages were hypothesized based on previous work 
in the area of smoking cessation (DiClemente et al., 1991; Prochaska \& DiClemente, 1983) and HIV prevention (Prochaska et al., 1990): 1)

Precontemplation included subjects who did not practice safer sex and did not intend to start in the next six months; 2) Contemplation included subjects who did not practice safer sex, but did intend to start in the next six months; 4) Action included subjects who practiced safer sex regularly, but for less than six months; and 5) Maintenance included subjects who had been practicing safer sex regularly for six months or more. The validity of this classification scheme for sexual behaviors and intentions has been established in previous studies (Grimley et al., 1992, 1993; Prochaska et al., 1990; Redding, Rossi, Velicer, \& Prochaska, 1989).

Results

Questionnaire Development and Testing

Initial item analysis was based on an examination of the distributions for the 75 PSS items, resulting in the elimination of five items with skewed distributions. The goals of these analyses were to study the measurement structure and psychometric properties of the PSS, and to produce a brief, reliable questionnaire for measuring the processes of change. A common approach to the initial investigation of the structure of an instrument is through the use of exploratory factor or component analysis (ECA). ECA was attempted here utilizing the BMDP component analysis program (P4M). Two good indices (Zwick \& Velicer, 1986) for the number of components to retain suggested a range from 9 (Parallel Analysis; Horn, 1965) to 12 (MAP; Velicer, 1976). Each of these component solutions was examined. The nine component solution merged consciousness raising and dramatic relief items, as well as counterconditioning and self reevaluation items, while 
allowing other usual processes and interpersonal systems control to emerge distinctly. The ten component solution was identical to the nine component solution, except it split social liberation into 2 components (one reflecting safer sex in general and one reflecting condom use only). The eleven component solution allowed self reevaluation items to separate from counterconditioning items. The twelve component solution separated another process into 2 components, and still retained the merged consciousness raising and dramatic relief items as one component.

Exploratory factor analysis is known to possess certain limitations, especially for analyzing complex, hierarchical measures (Long, 1983) such as this one. Recently, more powerful analytical approaches have become available. Methods of confirmatory factor analysis using structural equation modeling may be employed in an exploratory manner, although this is appropriate only when the measurement scales have been based on a strong underlying theoretical model (Bollen, 1989; Dwyer, 1983; Long, 1983). Using a wide range of diagnostic indicators available in programs such as LISREL VI (Jöreskog \& Sörbom, 1984), and through the use of specification searches (MacCallum, 1986; Silvia \& MacCallum, 1988), a more revealing investigation of the measurement structure of an instrument is possible. This approach was adopted in the present study because the processes of change instrument is based on a strong theoretical model, the transtheoretical model, and has consistently produced a robust measurement structure across a variety of problem areas (Bellis, Rossi, \& Prochaska, 1990; Marcus, Rossi et al., 1992; Prochaska \& DiClemente, 1985; Prochaska et al., 1988; Rossi, 1992; Rossi et al., in press). 
Difficulties in using specification searches for the exploratory modification of a model arise when the data used to suggest plausible model modifications are also used to test the adequacy (goodness-of-fit) of the revised model. Such a procedure capitalizes on error variance in improving the fit of a model to the data. Further, uncritical reliance on diagnostic indicators (e.g., modification indices, normalized residuals, and first-order derivatives) to modify a model can have serious consequences, and may lead to the acceptance of an incorrect model (Kaplan, 1989; MacCallum, 1986; Silvia \& MacCallum, 1988). These difficulties can be overcome through the use of cross-validation procedures, in which the final model determined through exploratory procedures is tested on an independent sample of subjects. In addition, the problem of specification search errors can be reduced by allowing only theoretically meaningful changes to be made during the exploratory model modification process (MacCallum, 1986; Silvia \& MacCallum, 1988).

Measurement analyses of the 70 remaining PSS items were conducted using the LISREL VI structural modeling computer program (Jöreskog \& Sörbom, 1984). Diagnostic indicators provided by the analysis were used to detect poorly functioning items. Several items with low loadings (less than .40) on their designated (target) factors were deleted. In order to reduce the chance of confirmatory bias, items were not permitted to load on any other factor than the specific factor each had been written to represent. Further item deletions were accomplished through a restricted specification search (MacCallum, 1986; Silvia \& MacCallum, 1988) using modification indices, normalized residuals, and first-order derivatives. Complex items were detected in this fashion and eliminated. The goal of item deletion was to reduce the number of items per factor to four, a scale length which has worked well 
(Prochaska et al., 1988). After poorly functioning items were deleted, additional (and otherwise well functioning) items were eliminated by emphasizing breadth of construct. These procedures ultimately reduced the number of items from 70 to 44 , four items for each of 11 processes of safer sex adoption. Final measurement analyses were conducted on the 44 remaining items, based on complete item data. Maximum likelihood factor loadings for each item are displayed in Table 4-2. Scale means, standard deviations, internal consistency (alpha) coefficients, and correlations with the Jackson social desirability scale (Jackson, 1967) for the 11 PSS scales are given in Table 4-3.

Insert Tables 4-2 \& 4-3 About Here

\section{Model Testing}

Complete data on the 44 PSS items were available for 290 subjects. To avoid confirmation bias, and as a further test of the adequacy of the model, several alternative models representing different conceptualizations of the structure of the PSS were allowed to compete to best describe the data.

Null Model. The Null Model suggests that there are no latent process of change factors, and that the 44 PSS items are completely independent. This model is not meant as a serious representation of the data, but rather is useful as a baseline against which other models may be compared.

One Factor Model. This model posits the existence of a single general process of change factor for safer sex adoption. Support for this model would 
suggest that subjects do not or cannot differentiate among the processes of change in their attempts at safer sex behavior change.

Two Factor Model. Prochaska et al. (1988) reported that the processes of change for smoking cessation may be conceptualized not only as 10 primary factors, but also as two higher-order general factors, representing experiential and behavioral processes of change. The Two Factor Model tested the possibility that, for safer sex, subjects differentiated among the processes of change only at the level of the higher-order constructs.

11 Uncorrelated Factors Model. This model suggests that subjects are able to discriminate among the 11 processes of change and further that the processes are best represented as independent dimensions of change.

11 Correlated Factors Model. This model is similar to the previous model except that the 11 processes of change are allowed to be correlated. Based on the results from previous studies for other types of problem behaviors (Prochaska \& DiClemente, 1985; Prochaska et al., 1988; Rossi, 1992), this model was considered the most plausible.

The adequacy of the competing models was assessed by maximum likelihood confirmatory factor analysis using the LISREL VI program (Jöreskog \& Sörbom, 1984). Because a general consensus has not yet emerged on which of the many different measures of model adequacy provides the best evaluation of model fit, several different measures were computed for each model. These measures represent a wide variety of conceptual approaches to the problem of assessing model adequacy, thus providing some protection against the possibility of model misspecification and sampling error (Marsh, Balla, \& McDonald, 1988). The 
asymptotic maximum likelihood chi-square statistic, while problematic in itself, is useful as a basis for the computation of other fit indices. The Comparative Fit index (CFI; Bentler, 1990), the Tucker-Lewis index (TLI; Tucker \& Lewis, 1973), and the incremental chi-square fit index, type 2 (IFI2 $\left(\chi^{2}\right)$; Mulaik et al., 1989) are all indices of relative model fit, as compared to the null model. For these indices, higher values indicate better fit, with 1.00 representing a perfect fit to the data and 0 representing a complete lack of fit. While no firm guidelines for interpretations have been established, values of about .90 are generally considered to indicate excellent model fit. The goodness-of-fit index (GFI) and root mean square residual (RMR) are provided by the LISREL VI program (Jöreskog \& Sörbom, 1984) and are indices of absolute model fit (i.e., without reference to a null model). Both indices range from 0 to 1.00 . Better fitting models are indicated by higher GFI values and by lower RMR values.

The competing models are evaluated and compared in Table 4-4. Across all measures of model adequacy, the 11 Correlated Factors Model provided the best fit to the data.

Insert Table 4-4 About Here

Hierarchical Model Testing

Prochaska et al. (1988) found that the processes of change for smoking were organized into two higher-order (hierarchical) factors, each consisting of five primary factors. The experiential factor consisted of Consciousness Raising, Dramatic Relief, Environmental Reevaluation, Self Reevaluation, and Social 
Liberation. The behavioral factor consisted of Counterconditioning, Helping relationships, Reinforcement Management, Self Liberation, and Stimulus Control. Model testing results suggest that the processes of change may be hierarchically organized for safer sex as well. Two structural, hierarchical models were compared.

One Hierarchical Factor Model. In this model the correlations among the 11 processes of change are expressed as a single hierarchical factor, representing a generalized tendency to use the processes of change. This model differs from the previously described One Factor Model in that the distinction among the 11 processes of change is preserved.

Two Hierarchical Factors Model. In this model the correlations among the 11 processes of change are expressed as two hierarchical factors, representing the experiential and behavioral processes. As with the previous model, the distinction among the 11 processes of change is preserved. Based on results obtained in previous studies for smoking cessation and for several other problem behaviors (Marcus et al., 1992; Prochaska et al., 1988; Rossi, 1992), the two hierarchical factors model was considered the most plausible.

Comparative analysis of the two models was conducted using the LISREL VI computer program (Jöreskog \& Sörbom, 1984). The Two Hierarchical Factors model fit the data significantly better than the One Hierarchical Factor model, $\chi$ $2(1)=62.41, \underline{p}<.001$. Standardized maximum likelihood parameter estimates for the structural relations among the 11 processes of change factors and the two hierarchical factors are shown in Figure 4-1. These results are similar to results reported by Prochaska et al. (1988) for smoking cessation and Rossi (1992) for nine 
problem areas. The correlation between the two hierarchical factors for safer sex adoption was .799, which is nearly equivalent to results from other areas (Rossi, 1992). The conceptual organization of the processes of change into two higher order constructs has proven very useful in the area of smoking cessation. Different from previous results, two processes usually considered behavioral (helping relationships and self liberation) loaded on the experiential higher-order factor. Self liberation has loaded on the experiential higher order factor previously in the area of weight control (Rossi, 1992; Rossi et al., in press). Helping relationships, on the other hand, has not previously loaded on the experiential higher order factor in other areas of model-based application. This could be specific to this sample, it could be specific to the area of safer sex adoption, or it could represent a more general difference between acquisition and cessation behavior changes (although it was not found for exercise adoption). Further research and cross-validation should help answer some of these questions raised by the results.

Insert Figure 4-1 About Here

Stage By Process Analyses

Further model testing was conducted by investigating the relationship between the processes of change and the stages of change. According to the stages of change model, the processes of change are used differentially by subjects in the various stages of change. Such results have been obtained consistently in the area of smoking cessation (DiClemente et al., 1991; Prochaska \& DiClemente, 1983; Prochaska et al., 1991) and exercise adoption (Marcus et al., 1992). To determine 
if similar results would also be obtained for safer sex adoption, a multivariate analysis of variance (MANOVA) was conducted using 4 stages of change as the independent variable and the 11 processes of change as dependent variables. Process scale scores were determined by calculating the mean of the summed ratings for the items representing each process, and standardizing them into $\mathrm{T}$-scores (mean $=50$ and $S D=10$ ). Subjects were placed in one of four stages of safer sex behavior change using a short series of questions, as described in the Method section. Only sexually active subjects with complete data on all 44 PSS items and on staging items were retained for the analysis $(\underline{\mathrm{N}}=286)$. The resulting distribution among the stages of change was: Precontemplation $(\underline{\mathrm{N}}=18,6.3 \%)$; Contemplation $(\underline{\mathrm{N}}=50$, $18.1 \%)$; Action ( $\underline{\mathrm{N}}=48,17.6 \%)$; and Maintenance $(\underline{\mathrm{N}}=170,59.6 \%)$.

The stage by sex MANOVA revealed a nonsignificant stage by sex interaction, Wilks $\Lambda=.885$, approximate $\mathrm{F}(33,763.7)=0.983$, $\mathrm{p}>.05$, and significant main effects for both stage of change, Wilks $\Lambda=.749$, approximate $\underline{F}(33$, $763.7)=2.391, \underline{p}<.001$, multivariate $\eta^{2}=.092$, and sex, Wilks $\Lambda=.669$, exact $\underline{\mathrm{F}}(11,259)=11.666, \underline{\mathrm{p}}<.001$, multivariate $\eta^{2}=.331$. Results for stages of change are reported in Table 4-5. Follow-up univariate analyses of variance were conducted for each of the 11 processes of change and five (CC, SL, SR, SC, ISC) were statistically significant $(p<.05)$. The effects of stage of change were generally small to medium in magnitude, with proportions of variance accounted for $\left(\eta^{2} \mathrm{~s}\right)$ ranging from .03 to .11 (mean $\left.=.06\right)$. Follow-up comparisons for each significant PSS subscale as a function of stage of change were conducted using Tukey post-hoc tests. These revealed that precontemplators used all 5 processes of change substantially less often than subjects in other stages of change. 
Insert Table 4-5 About Here

Results for sex differences on the processes are reported in Table 4-6. Follow-up univariate analyses of variance were conducted for each of the 11 processes of change and eight (HR, DR, ER, SR, SC, SL, SO, CR) were statistically significant $(\underline{p}<.05)$. The effect of sex was generally medium-sized in magnitude, with proportions of variance accounted for $\left(\eta^{2} s\right)$ ranging from .02 to .11 $($ mean $=.08)$. Females exceeded males for 7 out of 8 significant differences in process use, except for stimulus control, which males used more often than females.

Insert Table 4-6 and 4-7 About Here

A follow-up discriminant function analysis predicting 4 stages of change using the 11 processes of safer sex adoption as independent variables entered 6 processes of change to form 2 significant discriminant functions. Processes entered into the discriminant equations were: self liberation, consciousness raising, stimulus control, interpersonal systems control, reinforcement management, and social liberation. The first discriminant function separated each stage group from the next, while the second discriminant function separated precontemplators from contemplators and action from maintenance. Group centroids and structure coefficients for are presented in Table 4-7. 


\section{Discussion}

These results confirmed the predictions of the trantheoretical model applied to safer sex adoption. These data demonstrated that, in their efforts to adopt safer sexual behavior, study participants utilized all 11 hypothesized processes of safer sex adoption. These processes were organized in an hierarchical fashion, consisting of two higher-order constructs which may be globally characterized as experiential and behavioral processes of change. Taken together, these data suggest that the use of processes of safer sex adoption are strongly related to both subjects' stage of change and gender. Precontemplators used 8 of the 11 processes of change less than other stages of change, although these differences were statistically significant for only 5 out of 11. Unfortunately, the stage distribution of the current sample limited our ability to compare stage differences with more power. Finally, a brief, internally consistent instrument for assessing the processes of change for safer sex adoption and maintenance has been developed.

The results of this study are similar in many ways to the results previously reported for other areas, such as smoking cessation (DiClemente et al., 1991; Prochaska \& DiClemente, 1983; Prochaska et al., 1991; Rossi, 1992), cocaine cessation (Martin et al., 1992), and exercise adoption (Marcus et al., 1992). For all these areas, precontemplators use the processes of change significantly less than individuals in other stages of change. Prochaska et al. (1988) found that the processes of change for smoking were organized into two higher-order (hierarchical) factors, each consisting of five or six primary factors. The experiential factor consisted of consciousness raising, dramatic relief, environmental reevaluation, self reevaluation, and social liberation. The behavioral factor consisted of 
counterconditioning, helping relationships, reinforcement management, self liberation, and stimulus control. Interpersonal systems control was excluded from these smoking cessation analyses for unclear reasons, however, for safer sex was expected to and did load on the experiential higher-order process. The correlation between the two hierarchical factors for safer sex adoption was .799 , which is nearly equivalent to results from other areas (Rossi, 1992).

Figures 4-2 and 4-3 graph the experiential and behavioral processes of safer sex by stages of change. These results generally confirmed model-based predictions, although again small sample sizes in the earliest stages limited the stability of those points. Figure 4-3 revealed that several experiential processes (CR, ER, HR, SO) looked remarkably flat across the stages of change, which is quite different from results for other areas. It remains unclear whether this represented a difference in the importance of these processes to stage progression in the area of safer sex or whether this merely reflected the skewed stage distribution. Figure 4-2 revealed that, consistent with other findings, use of the behavioral processes peaked in the action stage for safer sex adoption. The decline of ISC from PC to C is likely related to the small number of subjects in the PC stage, more than a true decline, although future research will test this.

Different from previous results, two processes usually considered behavioral (helping relationships and self liberation) loaded on the experiential higher-order factor. Self liberation has merged previously with self reevaluation, an experiential process, in several areas of application (Prochaska \& DiClemente, 1985). Also, self liberation has loaded on the experiential higher-order factor previously in the area of weight control (Rossi, 1992; Rossi et al., in press). Helping relationships, 
on the other hand, has not previously loaded on the experiential higher order factor in other health behavior areas of model-based application. These results could be specific to this sample or they could represent a different conceptual organization of the processes in the area of safer sex adoption. They do not likely represent a more general difference between acquisition and cessation behavior changes, since they were not found for exercise adoption. Further research and cross-validation should help answer some of the questions raised by these results. We do not now regard the differences in hierarchical model organization for the processes of safer sex adoption as a serious departure from the trantheoretical model.

Several limitations of this study should be noted. In particular, this research was based on a cross-sectional sample. Cross-validation of these findings in independent samples could increase their generalizability. The limitations were partly necessitated by sample size requirements for such large structural models and the desire to begin model development in the area of safer sex, along lines similar to those that have proven useful in other areas (DiClemente et al., 1991; Prochaska \& DiClemente, 1983; Prochaska et al., 1991; Prochaska, DiClemente, \& Norcross, 1992; Rossi, 1992). Since the HIV prevention literature has typically evolved from applied questions, theory-based research has been lacking in this area. As a result, both safer sexual adoption and maintenance remain poorly understood topics. To help address these problems, researchers (CDC, 1992; Fisher \& Fisher, 1992; Valdisseri, 1989) suggest the application of comprehensive behavior change models, such as the transtheoretical model.

The results of this study have clinical implications for sexual behavior

change. People use at least 10-11 change processes during the acquisition and 
maintenance of smoking cessation, weight control, psychological distress, exercise adoption, cocaine cessation, and safer sex, and these processes are used significantly less by people who are in precontemplation. These kind of data have been very useful in the development of innovative smoking cessation interventions (Velicer et al., in press). It remains to be seen if other transtheoretical model-based predictions about which processes facilitate stage movement and which processes may be counterproductive at each stage will apply to safer sex adoption. Assuming they do, clinicians can, by measuring and understanding individuals' use of specific processes of safer sex, design and test specific process-based, stage-targeted interventions to accelerate individuals' movement from stage to stage. Development of more successful interventions will decrease the incidence and prevalence of STD's, unwanted pregnancy, HIV infection, and AIDS by decreasing the level of risky sexual activity, all of which will help us achieve the national health objectives that have been established for the year 2000 (USDHHS, 1991). 
References

Becker, M.H., \& Joseph, J.G. (1988). AIDS and behavioral change to reduce risk:

A review. American Journal of Public Health, $\underline{78}, 394-410$.

Bellis, J.M., Rossi, J.S., \& Prochaska, J.O. (1990, August) Structural invariance of the processes of change. Paper presented at the 98th annual conference of the American Psychological Association, Boston, MA.

Bentler, P.M. (1990). Comparative fit indexes in structural models. Psychological Bulletin, 107, 238-246.

Bollen, K.A. (1989). Structural equations with latent variables. New York: Wiley. Catania, J.A., Kegeles, S.M., \& Coates, T.J. (1990). Towards an understanding of risk behavior: An AIDS Risk Reduction Model (ARRM). Health Education Quarterly, 17, 53-72.

CDC (1992). A conceptual framework for evaluating behavior change. HIV/AIDS Prevention Newsletter, $\underline{3}(4), 2-3$.

Coates, T.J. (1990). Strategies for modifying sexual behavior for primary and secondary prevention of HIV disease. Journal of Consulting and Clinical Psychology, 58, 57-69.

Cohen, J. (1977). Statistical power analysis for the behavioral sciences (rev. ed.). New York: Academic Press.

Comrey, A.L. (1988). Factor-analytic methods of scale development in personality and clinical psychology. Journal of Consulting and Clinical Psychology, 56, 754-761. 
DiClemente, C.C., Prochaska, J.O., Fairhurst, S.K., Velicer, W.F., Velasquez, M.M., \& Rossi, J.S. (1991). The process of smoking cessation: An analysis of precontemplation, contemplation and preparation stages of change. Journal of Consulting and Clinical Psychology, 59, 295-304.

Dishman, R.K. (1982). Compliance/adherence in health-related exercise. Health Psychology, 1, 237-267.

Dwyer, J.H. (1983). Statistical models for the social and behavioral sciences. New York: Oxford University Press.

Fisher, J.D., \& Fisher, W.A. (1992). Changing AIDS-risk behavior. Psychological Bulletin, 111, 455-474.

Grimley, D., Riley, G.E., Prochaska, J.O., Redding, C.A., Ruggiero, L., Velicer, W.F., \& Rossi, J.S. (1992). Application of the transtheoretical model to contraceptive and condom use in high-risk women. Technical Report submitted to the Centers for Disease Control and Prevention (CDC) contract grant \#CSA-92-109.

Hatcher, R.A., Stewart, F., Trussel, J., Kowal, D., Guest, F., Stewart, G.K., \& Cates. W. (1990). Contraceptive Technology: 1990-1992, 15th Revised Edition. New York, NY:Irvington Publishers, Inc.

Horn, J.L. (1965). A rationale and test for the number of factors in factor analysis. Psychometrika, $\underline{30}, 179-185$.

Hunt, W.A., Barnett, L.W. \& Branch, L.G. (1971). Relapse rates in addictions programs. Journal of Clinical Psychology, 27, 455-456. 
Jackson, D.N. (1970). A sequential system for personality scale development. In C.D. Spielberger (Ed.), Current topics in clinical and community psychology (Vol. 2, pp. 61-96). New York: Academic Press.

Jöreskog, K.G., \& Sörbom, D. (1984). LISREL VI user's guide. Mooresville, IN: Scientific Software.

Kaplan, D. (1989). Model modification in covariance structure analysis: Application of the expected parameter change statistic. Multivariate Behavioral Research, 24, 285-305.

Kelly, J.A., \& Murphy, D.A. (1992). Psychological interventions with AIDS and HIV: Prevention and treatment. Journal of Consulting and Clinical Psychology, $\underline{60}, 576-585$.

Kristeller, J.L., Rossi, J.S., Ockene, J.K., Goldberg, R., \& Prochaska, J.O. (1992). Processes of change in smoking cessation: A cross-validation study in cardiac patients. Journal of Substance Abuse, 4, 263-276.

Long, J.S. (1983). Confirmatory factor analysis: A preface to LISREL. Newbury Park, CA: Sage.

MacCallum, R.C. (1986). Specification searches in covariance structure modeling. Psychological Bulletin, 100, 107-120.

Marcus, B.H., Banspach, S.W., Lefebvre, R.C., Rossi, J.S., Carleton, R.A., \& Abrams, D.B. (1992). Using the stages of change model to increase the adoption of physical activity among community participants. American Journal of Health Promotion, $\underline{6}, 424-429$. 
Marcus, B.H., Rossi, J.S., Selby, V.C., Niaura, R.S., \& Abrams, D.B. (1992). The stages and processes of exercise behavior change in a worksite sample. Health Psychology, 11, 386-395.

Marcus, B.H., Selby, V.C., Niaura, R.S., \& Rossi, J.S. (1992). Self-efficacy and the stages of exercise behavior change. Research Quarterly for Exercise and Sport, $\underline{63}, 60-66$.

Marlatt, G.A., \& Gordon, J.R. (Eds.) (1985). Relapse Prevention: Maintenance strategies in the treatment of addictive behaviors. New York: The Guilford Press.

Marsh, H.W., Balla, J.R., \& McDonald, R.P. (1988). Goodness of fit indexes in confirmatory factor analysis: The effect of sample size. Psychological Bulletin, 103, 391-410.

Martin, R.A., Rossi, J.S., Rosenbloom, D., Monti, P.M., \& Rohsenow, D.J. (1992, November) Stages and processes of change for quitting cocaine. Paper presented at the 26th annual meeting of the Association for the Advancement of Behavior Therapy, Boston, MA.

Mulaik, S.A., James, L.R., Van Alstine, J., Bennett, N., Lind, S., \& Stilwell, C.D. (1989). Evaluation of goodness-of-fit indices for structural equation models. Psychological Bulletin, 105, 430-445.

Norcross, J.C., \& Prochaska, J.O. (1986a). Psychotherapist heal thyself - I. The psychological distress and self-change of psychologists, counselors, and laypersons. Psychotherapy, 23, 102-114. 
Norcross, J.C., \& Prochaska, J.O. (1986b). Psychotherapist heal thyself - II. The self-initiated and therapy facilitated change of psychological distress. Psychotherapy, 23, 345-356.

Norcross, J.C., Prochaska, J.O., \& DiClemente, C.C. (1986). Self-change of psychological distress: Layperson's vs. psychologist's coping strategies. Journal of Clinical Psychology, 42, 834-840.

O'Reilly, K.R. \& Higgins, D.L. (1991). AIDS community demonstration projects for HIV prevention among hard-to-reach groups. Public Health Reports, 106, 714-720.

Prochaska, J.O., \& DiClemente, C.C. (1983). Stages and processes of self-change in smoking: Towards an integrative model of change. Journal of Consulting and Clinical Psychology, 51, 390-395.

Prochaska, J.O., \& DiClemente, C.C. (1985). Common processes of self-change in smoking, weight control, and psychological distress. In S. Shiffman \& T. Wills (Eds.), Coping and substance use (pp. 345-363). New York: Academic Press.

Prochaska J.O., DiClemente, C.C., \& Norcross, J.C. (1992). In search of how people charge: Applications to the addictive behaviors. American Psychologist, 47, 1102-1114.

Prochaska, J.O., DiClemente, C.C., Velicer, W.F., \& Rossi, J.S. (in press). Standardized, individualized, interactive and personalized self-help programs for smoking cessation. Health Psychology. 
Prochaska, J.O., Harlow, L.L., Redding, C.A., Snow, M.G., Rossi, J.S., \& Velicer, W.F. (1990). Stages of change, self-efficacy, and decisional balance of condom use in a high HIV-risk sample. Technical report to the Centers for Disease Control and Prevention, contract grant \# .

Prochaska, J.O. \& Norcross, J.C. (1983). Psychotherapists' perspectives on treating themselves and their clients for psychic distress. Professional Psychology: Research and Practice, 14, 642-655.

Prochaska, J.O., Norcross, J.C., Fowler, J.L., Follick, M.J., \& Abrams, D.B. (1992). Attendance and outcome in a work site weight control program: Processes and stages of change as process and predictor variables. Addictive Behaviors, $17,35-45$.

Prochaska, J.O., Redding, C.A., Harlow, L.L., Rossi, J.S., \& Velicer, W.F. (1992). The transtheoretical model applied to HIV prevention: A review. Manuscript submitted for publication.

Prochaska, J.O., Velicer, W.F., DiClemente, C.C., \& Fava, J. (1988). Measuring processes of change: Applications to the cessation of smoking. Journal of Consulting and Clinical Psychology, 56, 520-528.

Prochaska, J.O., Velicer, W.F., Guadagnoli, E., \& Rossi, J.S., \& DiClemente, C.C. (1991). Patterns of change: Dynamic typology applied to smoking cessation. Multivariate Behavioral Research, 26, 83-107.

Rakowski, W., Dube, C., Marcus, B.H., Prochaska, J.O., Velicer, W.F., \& Abrams, D.B. (1992). Assessing motivational readiness and decision-making for mammography. Health Psychology, 11, 111-118. 
Rosenbloom, D. (1991). A transtheoretical analysis of change among cocaine users. Unpublished doctoral dissertation, University of Rhode Island, Kingston, RI. Rossi, J.S. (1989). Exploring behavioral approaches to UV risk reduction. In A. Moshell \& L.W. Blankenbaker (Eds.), Sunlight, ultraviolet radiation, and the skin (pp. 91-93). Bethesda, MD: National Institutes of Health.

Rossi, J.S. (1990). Statistical power of psychological research: What have we gained in 20 years? Journal of Consulting and Clinical Psychology, $\underline{58}, 646-$ 656.

Rossi, J.S. (1992, August). Common processes of change across nine problem behaviors. Paper presented at the 100th annual conference of the American Psychological Association, Washington, DC.

Rossi, S.R., Rossi, J.S., Rossi-DelPrete, L.M., Prochaska, J.O., Banspach, S.W., \& Carleton, R.A. (in press). A processes of change model for weight control for participants in a community-based weight loss program. International Journal of the Addictions.

Silvia, E.S.M., \& MacCallum, R.C. (1988). Some factors affecting the success of specification searches in covariance structure modeling. Multivariate Behavioral Research, 23, 297-326.

Snow, M.G. (1991). A transtheoretical analysis of strategies in the recovery process from alcohol problems. Unpublished doctoral dissertation, University of Rhode Island, Kingston, RI.

Snow, M.G., Prochaska, J.O., \& Rossi, J.S. (in press). Processes of change in AA: Maintenance factors in long-term sobriety. Journal of Studies on Alcohol. 
Sonstroem, R.J. (1987, August). Stage model of exercise adoption. Paper presented at the 95th Annual Convention of the American Psychological Association. New York, NY.

Sonstroem, R.J. (1988). Psychological models. In R. Dishman (Ed.), Exercise adherence (pp. 125-154). Champaign, IL: Human Kinetics Books.

Tejero, A., Trujols, J., \& Hernández, E. (1991). Processes of change in heroin addicts: A preliminary report. Manuscript submitted for publication.

Tucker, L.R., \& Lewis, C. (1973). A reliability coefficient for maximum likelihood factor analysis. Psychometrika, $\underline{38}, 1-10$.

U.S. Department of Health and Human Services (1991). Healthy people 2000: National health promotion and disease prevention objectives. DHHS Pub. No. (PHS) 91-50212. Washington, DC: U.S. Government Printing Office.

Valdiserri, R.O. (1989). Preventing AIDS: The design of effective programs.

Rutgers Press: New Brunswick, NJ.

Velicer, W.F. (1976). Determining the number of components from the matrix of partial correlations. Psychometrika, 41, 321-327.

Velicer, W.F., DiClemente, C.C., Rossi, J.S., \& Prochaska, J.O. (1990). Relapse situations and self-efficacy. Addictive Behaviors, 15, 271-283.

Velicer, W.F., Prochaska, J.O., Bellis, J.M., DiClemente, C.C., Rossi, J.S., Fava, J.L., \& Steiger, J.H. (in press). An expert system intervention for smoking cessation. Addictive Behaviors.

Zwick, W.R., \& Velicer, W.F. (1986). Factors influencing five rules for determining the number of components to retain. Psychological Bulletin, $\underline{99}$, 432-442. 


\section{Footnote}

${ }^{1}$ Cohen (1977) has defined small, medium, and large effects as proportions of variance accounted for of $.01, .06$, and .14 , respectively. Subsequent research has generally substantiated these definitions (see Rossi, 1990). 
Table 4-1

$\underline{\text { Process }}$

Consciousness Raising

Counterconditioning

Dramatic Relief

Environmental

Reevaluation

Helping Relationships

Reinforcement

Management

Self-Liberation

Self-Reevaluation

Social Liberation

(Table 4-1 continues)
General Definition

efforts by the individual to seek new information and to gain understanding about the problem behavior

substitution of alternative behaviors for the problem behavior

affective aspects of change, often involving intense emotions related to the problem behavior consideration \& assessment of how the problem behavior affects the physical \& social environment trusting, accepting, \& utilizing the support of caring others during efforts to change the problem behavior

changing the contingencies that control or maintain the problem behavior choosing and making commitments to change the problem behavior, even in the face of pressure emotional and cognitive reappraisal of values by the individual with respect to the problem behavior awareness, availability $\&$ acceptance by the individual of alternative, problem-free life-styles in society 
Table 4-1 (continued)

Stimulus Control

Interpersonal Systems

Control control of environmental or situational cues which could trigger the problem behavior monitoring of people and situations which could trigger the problem behavior 
Table 4-2

Maximum Likelihood Factor Loadings for the 44 PSS Items

Items

Factor Loadings

\section{Consciousness Raising}

12. I look for information related to sexual risk reduction.

23. I think about information on safer sex.

34. I look for television shows about reducing the risk of exposure to AIDS.

56. I think about information on how to limit my exposure to AIDS.

Counterconditioning

17. Instead of risky sex, I engage in other safer sexual activities.

39. When I am tempted to have unprotected sex

I think about doing something else instead.

50. I find that other safer sexual activities

are good substitutes for risky sex.

61. When I am tempted to have risky sex,

I think about the unhealthy consequences.

Dramatic Relief

26. Television stories about people with AIDS upset me. $\quad .580$

37. I react emotionally to warnings about the risks of unprotected sex. $\quad .780$

48. I react emotionally when people

ignore health warnings to avoid unsafe sex.

59. Articles about the risks of unprotected sex upset me. 
Table 4-2 (continued)

Environmental Reevaluation

22. I think the world would be a better place

if more people practiced safer sex.

33. I think the world would be a better place if people developed healthier sexual habits.

44. I think about the view that society would be more responsible if more people practiced safer sex.

65 . I consider that the world would be healthier if people practiced safer sex.

Helping Relationships

31. I have someone I can count on to discuss safer sex with. .928

53. I have someone I can trust when I need to talk about safer sex. $\quad .972$

63. I have someone to talk to when I want

to talk about how to practice safer sex.

73. I have someone I can count on to support

my decision to practice safer sex.

$\underline{\text { Reinforcement Management }}$

16. I reward myself with something when I practice safer sex.

27. I am rewarded by others when I practice safer sex.

49. When I practice safer sex, I can

expect to be praised by others.

(Table 4-2 continues) 
Table 4-2 continued

60. People in my life try to make me feel

good when I practice safer sex.

Self-Liberation

46. I make a commitment to practice safer sex.

57. I make a commitment to avoid risky sexual situations.

66. I tell myself that if I try hard enough, I can insist on safer sex.

68. I would not continue to date anyone who

might push me to have unsafe sex.

\section{$\underline{\text { Self-Reevaluation }}$}

14. I feel good about myself when I practice safer sex.

36. I would feel disappointed in myself if I had risky sex.

47. I feel that being a responsible person includes

my practicing safer sex.

58. I feel it's important for me to practice safer sex, because I am a responsible, health-conscious person.

\section{Social Liberation}

10. I find society changing in ways that make it easier to practice safer sex.

21. I notice that safer sex is really accepted by most people.

32. I notice that safer sex is discussed openly now.

74. I notice condom use being discussed openly.

(Table 4-2 continues) 
Table 4-2 (continued)

$\underline{\text { Stimulus Control }}$

7. I keep things with me to remind me to practice safer sex. $\quad .582$

18. I keep condoms available to remind me to use them. .931

29. I keep condoms with me to remind me to practice safer sex. .981

51. I keep condoms with me so that I'll use them when I have sex. $\quad .916$

Interpersonal Systems Control

41. I seek out people who would encourage safer sex.

52. I look for social situations which would encourage safer sex.

62. I avoid social situations which might tempt me to have unsafe sex.

72. I seek out sexual partners who would encourage safer sex.

Note: $\underline{N}=275$. 
Table 4-3

PSS scale Means, S.D. 's., alphas, \& correlations with social desirability

\begin{tabular}{lcccc} 
Process & Mean & SD & $\alpha$ & JSD $\underline{r}$ \\
Consciousness Raising & 3.13 & 0.92 & .80 & .13 \\
Counterconditioning & 3.18 & 0.95 & .78 & .19 \\
Dramatic Relief & 3.18 & 0.92 & .81 & .09 \\
Environmental Reevaluation & 4.27 & 0.76 & .87 & .14 \\
Helping Relationships & 3.87 & 1.20 & .95 & .23 \\
Reinforcement Management & 2.26 & 0.98 & .82 & .01 \\
Self Liberation & 3.75 & 0.87 & .76 & .29 \\
Self Reevaluation & 3.99 & 0.84 & .82 & .22 \\
Social Liberation & 4.18 & 0.65 & .72 & .33 \\
Stimulus Control & 2.60 & 1.36 & .91 & -.05 \\
Interpersonal Systems Control & 2.91 & 1.03 & .85 & .16 \\
& & &. & \\
\hline
\end{tabular}

Note: $\mathrm{N}=290 ; \mathrm{JSD} \underline{\mathbf{r}}$ column reflects Jackson social desirability correlations for each subscale; correlations larger than 0.16 are significant at $\mathrm{p}<.01$, median $=$ 0.16 . 
Table 4-4

Comparative Fit Indices for Alternative PSS Models

\begin{tabular}{lccccccc} 
Model & $\chi^{2}$ & df & GFI & RMR & CFI & TLI & IFI2 $\left(\chi^{2}\right)$ \\
Null & 14161 & 741 & .133 & .403 & - & - & - \\
One Factor & 4126 & 702 & .656 & .067 & .745 & .731 & .746 \\
Two Factors & 3599 & 701 & .707 & .066 & .784 & .722 & .785 \\
11 Uncorrelated & & & & & & & \\
Factors & 6144 & 702 & .496 & .376 & .594 & .572 & .596 \\
11 Correlated & & & & & &. & \\
Factors & 1913 & 657 & .843 & .048 & .906 & .894 & .907 \\
& & & & & & & \\
\hline
\end{tabular}

Note: $\underline{\mathrm{N}}=290 ; \mathrm{df}=$ degrees of freedom;

GFI $=$ Goodness of fit index (Jöreskog \& Sörbom, 1984);

RMR = root mean square residual (Jöreskog \& Sörbom, 1984);

CFI = Comparative Fit Index (Bentler, 1990);

TLI = Tucker-Lewis index (Tucker \& Lewis, 1973);

$\operatorname{IFI} 2\left(\chi^{2}\right)=$ incremental chi-square fit index, type 2 (Mulaik et al., 1989). 
Table 4-5

PSS T-Score Means, S.D. 's and MANOVA Results for Stages of Change

Stage of Change

$\underline{\text { Process }}$

Consciousness

Raising

Counter-

conditioning

Dramatic

Relief

Environmental

Reevaluation

Helping

Relationships

Reinforcement

Management

Self

Liberation

Self

Reevaluation

Social

Liberation

$$
\text { PC }
$$

C

A

$M \quad \underline{F}(3,269) \quad \eta^{2}$

$\begin{array}{lllll}50.61 & 50.40 & 50.36 & 49.95 & 0.045\end{array}$

$\begin{array}{llll}(10.94) & (9.55) \quad(9.26) & (10.28)\end{array}$

43.94

47.12

51.62

51.14

$4.975 *$

.053

(11.77)

(8.47)

(10.88)

(9.38)

$48.79 \quad 50.95$

49.79

50.23

0.229

(13.96)

(8.29)

(10.18)

(10.12)

49.40

49.53

50.16

50.35

0.556

(13.83) (9.58)

(8.80)

(10.07)

48.75

49.62

50.59

50.19

0.855

(11.39) (9.70)

(9.54)

(10.18)

47.48

49.61

53.06

49.63

1.730

(11.35) (9.43)

(9.80)

(10.05)

43.45

45.37

50.82

51.79

$11.515^{*} \quad .114$

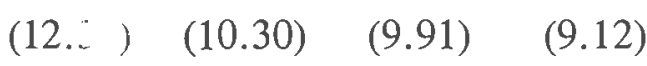

43.33

47.34

50.92

51.48

$7.154 * \quad .074$

$\begin{array}{llll}(14.71) & (9.97) & (9.22) & (9.10)\end{array}$

52.27

48.78

50.29

50.47

1.242

(10.02)

$(10.60)$

(9.18)

(9.78)

(Table 4-5 continues) 
Table 4-5 (continued)

Stimulus

Control

Interpersonal

Systems Control
44.22

(9.89)

49.63

(11.81)

48.49

51.41

50.83

$3.592 *$

.039

$(9.30)$

(10.05)

(10.02)

46.32

50.17

51.30

$2.833 *$

.031

(8.36)

(9.76)

(10.28)

Note: Standard deviations are given in parentheses. $\mathrm{PC}=$ Precontemplation

$(\underline{\mathrm{N}}=17) ; \mathrm{C}=$ Contemplation $(\underline{\mathrm{N}}=51) ; \mathrm{A}=$ Action $(\underline{\mathrm{N}}=46) ; \mathrm{M}=$ Maintenance

$(\underline{N}=163) ; \eta^{2}=$ effect size (proportion of variance accounted for); * indicates $\underline{\mathrm{F}}$ tests are significant $(\mathrm{p}<.05)$. 
Table 4-6

Processes of Safer Sex T-Score Means, S.D. 's and MANOVA Results for Sex

\begin{tabular}{|c|c|c|c|c|}
\hline$\underline{\text { Process }}$ & $\begin{array}{l}\text { Females } \\
(\underline{N}=154)\end{array}$ & $\begin{array}{c}\text { Males } \\
(\underline{N}=131)\end{array}$ & $\underline{F}(1,269)$ & $\eta^{2}$ \\
\hline Consciousness & 52.11 & 47.74 & $6.24 *$ & .02 \\
\hline Raising & $(9.9)$ & $(9.6)$ & & \\
\hline Counter- & 50.81 & 49.11 & 1.81 & - \\
\hline conditioning & $(10.0)$ & $(9.5)$ & & \\
\hline Dramatic & 52.64 & 46.96 & $12.59 *$ & .05 \\
\hline Relief & $(9.3)$ & $(10.1)$ & & \\
\hline Environmental & 52.93 & 46.51 & $23.23 *$ & .08 \\
\hline Reevaluation & $(8.4)$ & $(10.6)$ & & \\
\hline Helping & 53.43 & 46.06 & $27.21^{*}$ & .09 \\
\hline Relationships & $(8.8)$ & $(9.9)$ & & \\
\hline Reinforcement & 49.93 & 50.23 & 0.81 & - \\
\hline Management & $(10.5)$ & $(9.7)$ & & \\
\hline Self & 53.04 & 46.13 & $29.75^{*}$ & .10 \\
\hline Liberation & $(9.5)$ & $(9.5)$ & & \\
\hline Self & 52.73 & 46.73 & $24.25^{*}$ & .08 \\
\hline Reevaluation & $(8.9)$ & $(10.4)$ & & \\
\hline Social & 52.79 & 47.23 & $19.26^{*}$ & .07 \\
\hline Liberation & (8.9) & (10.3) & & \\
\hline
\end{tabular}

(Table 4-6 continues) 
Table 4-6 (continued)

$\begin{array}{lcccc}\text { Stimulus } & 45.89 & 55.19 & 32.41^{*} & .11 \\ \quad \text { Control } & (8.7) & (9.1) & & \\ \text { Interpersonal } & 51.07 & 48.95 & 3.16 & - \\ \quad \text { Systems Control } & (10.9) & (8.8) & \end{array}$

Note: Standard deviations are given in parentheses; $\eta^{2}=$ effect size (proportion of variance accounted for $) ;{ }^{*}$ indicates $\underline{\mathrm{F}}$ tests are significant $(\mathrm{p}<.05)$. 
Table 4-7

Group Centroids and Discriminant Structure Matrix for Discriminant Analysis predicting Stage of Change using the Processes of Safer Sex Adoption.

Discriminant Function

1

2

Stage of Change

Precontemplation

$-1.13$

Contemplation

$-0.57$

0.26

Action

0.12

0.31

Maintenance

0.26

$-0.11$

Variable

Discriminant structure

matrix

Self Liberation

0.70

$-0.14$

Self Reevaluation

0.50

$-0.09$

Counterconditioning

0.47

$-0.06$

Stimulus Control

$\mathbf{0 . 4 0}$

0.26

Interpersonal Systems Control

0.34

$-0.44$

Reinforcement Management

0.12

0.44

Social Liberation

0.03

$-0.28$

Helping Relationships

0.17

$-0.16$

Environmental Reevaluation

0.21

$-0.23$

Dramatic Relief

0.02

$-0.04$

Consciousness Raising

$-0.04$

0.03

Note: Structure matrix values which exceed .30 are in bold type. 


\section{Figure Captions}

Figure 4-1. Standardized maximum likelihood parameter

estimates for the 11 factor hierarchical model of PSS

Figure 4-2. Behavioral processes of safer sex T-scores by Stage of change

Figure 4-3. Experiential processes of safer sex T-scores by Stage of change 


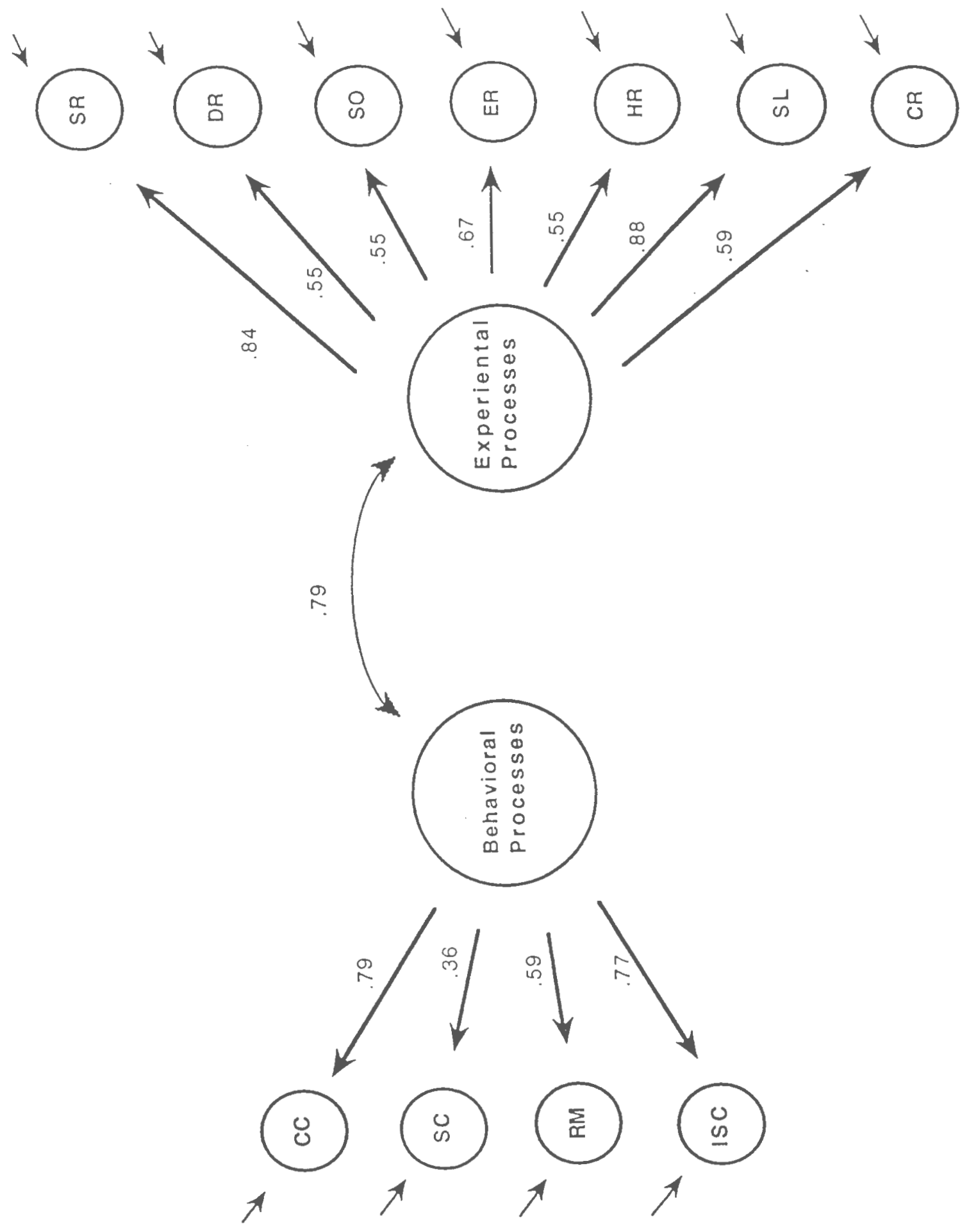


Behavioral Processes by Stage

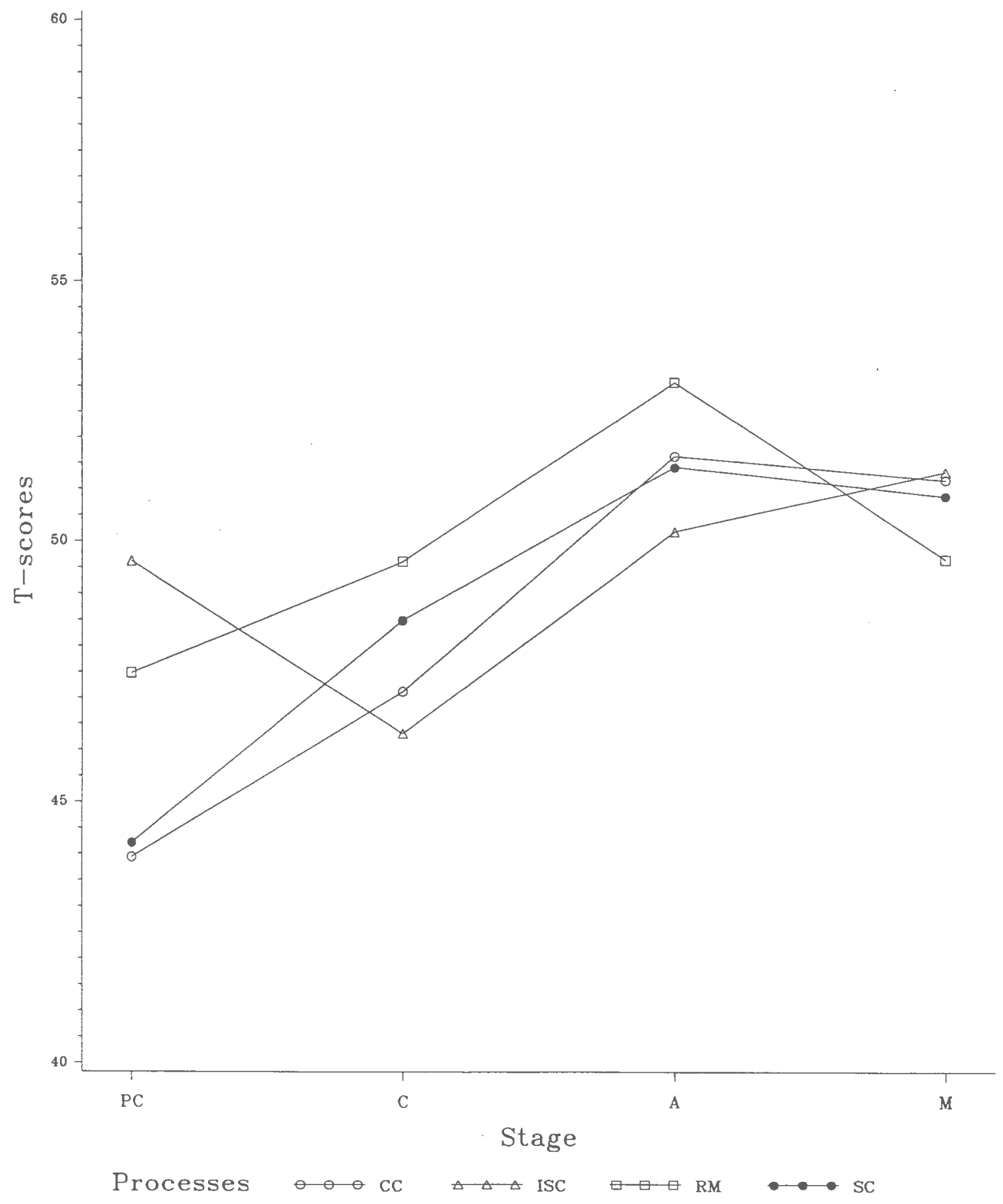


Experiential Processes by Stage

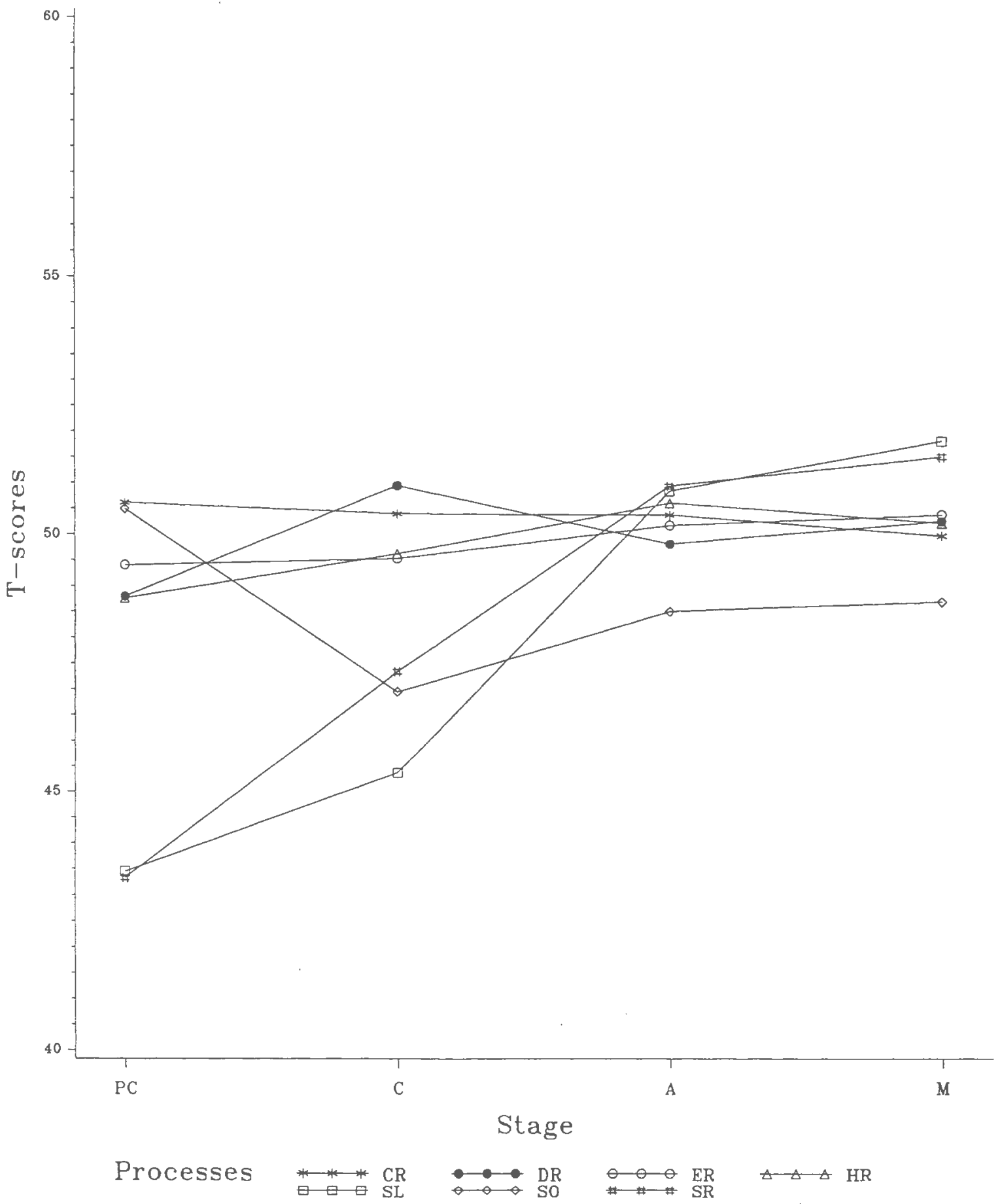




\section{PART V \\ STAGES OF CHANGE FOR SAFER SEX}

Research based on the transtheoretical model has found that cessation of problem behaviors or adoption of more healthful ones does not occur automatically through one trial learning (Prochaska, 1991; Prochaska \& DiClemente, in press). Change requires movement through discrete motivational stages of change, the active use of different processes of change at different stages, and modification of cognitions, affect, and behaviors. This paper will apply the stages of change to safer sex adoption in college students.

Research on how people change behavior in the natural environment (self change) as well as through intervention programs reveals that people progress through a series of stages of change. The stages represent a continuum of motivational readiness for behavior change, and, have been operationalized in both continuous and categorical ways. The stages of change described here are similar to stage concepts proposed elsewhere (Brownell, Marlatt, Lichtenstein, \& Wilson, 1986; Catania, Kegeles, \& Coates, 1990; Horn, 1976; Rosen \& Shipley, 1983). In the trantheoretical model, people move from precontemplation, not even thinking about change, to contemplation, thinking about change within six months, to preparation, actively planning change, to action, overtly making changes, and into maintenance, taking steps to sustain change and resist temptation to relapse (DiClemente, Prochaska, Fairhurst, Velicer, Velasquez, \& Rossi, 1991; Prochaska \& DiClemente, 1983, 1984b, 1986a; Velicer, Prochaska, Rossi, \& Snow, 1992). However, progression through the stages is cyclical, rather than linear, since most people relapse and recycle back to earlier stages of change before eventually succeeding in maintaining change. Relapse is considered a natural part of the 
change cycle. Current applications of the Transtheoretical Model to AIDS risk reduction efforts have not yet used the preparation stage due, in part, to the difficulty of choosing an adequate behavioral criterion (Grimley et al., 1992; Redding et al., 1989; Prochaska et al., 1990).

The stages of change have important implications for intervention programs, since the amount of progress people make as a result of intervention tends to be a function of the stage they are in at the start of treatment. One prospective study of smoking cessation has found that helping people progress just one stage can double the chances that subjects will take action on their own in the next six months (DiClemente et al., 1991; Prochaska \& DiClemente, in press). In addition, subjects apply different processes of change as they progress through the different stages of change (Prochaska et al., 1988; Prochaska et al., 1991). If we are to accelerate safer sex adoption in the population, interventions will have to be developed that target not only people who are prepared to change, but also those who are only considering changing their behavior (contemplators) and even those who are not yet intending to change (precontemplators). Tailoring interventions to participants' stage of change could improve effectiveness in HIV risk reduction efforts, as it has in studies of smoking cessation and exercise adoption (Marcus, Banspach, Lefebvre, Rossi, Carleton, \& Abrams, 1992; Prochaska, DiClemente, Velicer, \& Rossi, in press).

The stages of change have a straightforward algorithm for use with smoking cessation, which works well, in part, because smoking is a discrete behavior. How does one apply this model to complex behavior changes, such as safer sex adoption, dietary fat reduction, or sun exposure, which require several change strategies? This question will become even more salient as the transtheoretical model is applied to 
multiple risk factors. One approach to this problem has been the a priori imposition of one behavioral criterion on the sample being studied, but this can obscure important natural variability. An alternative approach, for example, to the area of dietary fat reduction, staged subjects on 7 different strategies for reducing dietary fat and found low to moderate congruence (Birkett, Hotz, \& O'Hollaren, 1992). This approach could become prohibitively long and cumbersome, for subjects and researchers alike. The question remains, how can one develop an action criterion for a staging algorithm for complex behaviors?

Usually, subjects in the action stage are required to reach some behavioral criterion for some minimal amount of time (Velicer et al., 1992). For example, someone trying to quit smoking must quit for at least 24 hours in order for it to count as an action attempt. People can reduce the number of cigarettes they smoke or change to lower tar cigarette brands, and while this may reduce their risk somewhat, it does not meet the criterion for the action stage. What would the equivalent of a 24-hour quit attempt for smokers in the area of AIDS risk reduction be? Is using a condom during one sexual encounter enough to count as a significant step towards action? Probably not, since one must continue to use condoms consistently in order to reduce HIV risk effectively. Of course, the smoking field agrees that smoking cessation is the criterion for successful intervention. For AIDS risk reduction, there is no clear consensus within the field on behavioral criteria. An action criterion for HIV prevention would most likely be complex, including a combination of several behavioral criteria. Some possible criteria for the action stage of HIV prevention could include: using condoms during all of the past 6-10 sexual encounters; or having a sexually exclusive relationship for a year or more 
after obtaining negative $\mathrm{HIV}$ antibody tests; or abstaining from unprotected receptive anal intercourse; or abstaining from vaginal sex, anal sex, and needle sharing with unknown partners. Choice of criteria depends on the risky behaviors of the population being studied.

In this study, which will focus on heterosexual college students, an optionbased definition of safer sex will be provided to subjects who will then be asked a series of staging questions, as well as demographic and behavioral questions. Validating behavioral data will then be used to test the stages of change for expected behavioral differences between stages as has been found for smoking cessation (DiClemente et al., 1991). Specific behavioral items, especially those related to safer sex, should discriminate subjects in different stages of change.

$$
\text { Method }
$$

\section{Subjects}

Subjects were 305 male and female, sexually active students attending a midsize, northeastern state university. Approximately $54 \%$ of the subjects were female, $99 \%$ were single, $92 \%$ were white, $64 \%$ were Catholic, and $98 \%$ identified themselves as heterosexual. Modal age was 19 years (34\%), and modal year in college was freshman (47\%). In general, the modal subject had 2-3 lifetime sexual partners (32\%), one sexual partner in the last six months (62\%), and one sexual partner in the past six months without condoms (55\%).

The most common contraceptives ever used were condoms (82\%), oral contraceptives (57\%), and condoms with spermacide (52\%) respectively. Subjects indicated their current main method(s) of contraception were birth control pills (37\%), condoms (29\%), and condoms with spermacide (15\%). Surprisingly, 58\% 
of subjects indicated they had relied upon withdrawal as a contraceptive method at some point, and $7 \%$ indicated that this was their main contraceptive method!

\section{Measures}

Eight items were developed to represent the stages of safer sex adoption. Safer sex was defined for subjects as one or more of the following choices:

A) Abstinence from vaginal and anal intercourse.

B) Condom Use with all vaginal and anal sexual partners.

C) Sexually exclusive relationship with only one partner in the past year who has tested negative for HIV antibodies.

Items were screened by a research group already familiar with the model and other staging algorithms. Items were also included to assess behavioral and demographic variables relevant to assessing risk for HIV exposure.

Procedure

Subjects were recruited from within their undergraduate classes and labs. Participation was anonymous, voluntary, and took about 30 minutes. Informed consent was obtained from all subjects. Some subjects completed questionnaires in a large auditorium, while others took the questionnaires home and returned them in a postage-paid envelope.

\section{Results}

Subjects were encouraged to mark one, or to rank order if more than one, choice(s) to indicate how they were practicing safer sex at that time. Subjects who indicated they were not practicing safer sex were asked whether they had tried to practice safer sex within the past year and if so, how. Table 5-1 enumerates subjects' choices for safer sex and how many subjects chose $0,1,2$, or 3 options, 
for all subjects $(\underline{N}=352)$ as well as for sexually active subjects who indicated they were practicing safer sex $(\underline{\mathrm{N}}=231)$.

Insert Table 5-1 about here

Tied for the most popular option among sexually active subjects who are currently practicing safer sex were condom use $(60 \%)$ and a sexually exclusive relationship (59\%). Although $73 \%$ of subjects chose only one option, about $27 \%$ of subjects indicated more complex combinations of 2 or 3 strategies for safer sex. This behavioral variability would be missed if only one choice was offered. When one considered subjects' first choices only, condom use and a sexually exclusive relationship were chosen by nearly equal percentages of subjects, $40.3 \%$ and $39.8 \%$ respectively. Abstinence, in contrast, was considered a first choice for safer sex for only $16.7 \%$ of subjects. This is important information about college students' safer sex strategies.

\section{Stages of Change}

The original algorithm for staging subjects is presented in Appendix C. Results for stages of change for safer sex using this algorithm are reported in Table $5-2$.

Insert Table 5-2 about here

Sexually active participants $(n=305)$ were asked several questions in order to assess their current motivational readiness to reduce their sexual risk behavior. Safer sex 
was defined for subjects as one or more of the choices outlined in the Method section. In general, $76 \%$ of subjects indicated that they were currently practicing safer sex, which explains the large percentages in action and maintenance stages. This also, however, calls into question the validity of that item. A breakdown of subjects in the maintenance stage $(n=174)$ revealed that most $(59.2 \%)$ "maintenance" stage subjects did not actually meet the behavioral criteria for the maintenance stage. The largest percentage ( $42 \%$ ) of these "pseudo-maintainers" (PM) indicated that they were in a sexually exclusive relationship with someone who had tested HIV negative, yet they also indicated their partner had not had an HIV blood test. A smaller percentage (12.6\%) reported they were in a sexually exclusive relationship, but also indicated that they had sex outside this relationship. Very small percentages indicated that their relationship with their main sexual partner had lasted less than one year (2\%), or that their main relationship was not sexually exclusive $(0.5 \%)$. After excluding all these PM's, only $41 \%$ of the original maintenance stage group was left, the true maintainers (M). Indeed, PM group means were compared to true maintainer group means on all behavioral and process measures: pros and cons, confidence, temptation, and processes of safer sex. PM's were closer to contemplation or action subjects' scores than they were to true maintainers' scores. This supported the validity of our distinction between PM's and true maintainers.

To attempt to correct some of the problems with the original staging algorithm, a behavioral criterion was imposed on the maintenance stage, the number of partners in the last six months without condoms. A behavioral criterion was also imposed on the preparation stage, i.e., having tried to practice safer sex 
within the past year. Results using the original and the proposed algorithm are presented in Table 5-3. No major changes occurred as a result. Ánalysis of distribution of proposed stage by gender $\left(\chi^{2}(4)=4.34, \mathrm{p}>.05\right)$ was nonsignificant.

\section{Validating Behavioral Data}

Preliminary discriminant function analyses failed to discriminate contemplation and preparation subjects, partly due to sample size problems. Therefore these stages were combined. In addition, the PM group was excluded from analyses, to see if the more pure stage groups would show expected behavioral differences. A twoway MANOVA on 9 sexual behaviors by both stage and gender found a a nonsignificant stage $\mathrm{X}$ gender interaction, Wilks $\Lambda=.838$, approximate $\mathrm{F}(27$, $520.5)=1.21, \mathrm{p}>.05$, a significant main effect for stage, Wilks $\Lambda=.479$, approximate $\underline{\mathrm{F}}(27,520.5)=5.52, \mathrm{p}<.001$, multivariate $\eta^{2}=.22$, a nonsignificant main effect for gender, Wilks $\Lambda=.938$, exact $\underline{F}(9,178)=1.30$, $p$ $>.05$. Follow-up univariate analyses of variance for stage of change revealed significant differences for the variables: number of sexual partners in the past six months, number of sexual partners in the past six months without condoms, frequency of mixing sex with alcohol, frequency of intercourse with condoms, frequency of intercourse without condoms, and frequency of the use of spermacide with condoms.

Insert Tables 5-3 and 5-4 About Here

Follow-up discriminant function analyses found 2 significant discriminant functions, one defined by risky sex variables (number of sexual partners in the past 
six months, number of sexual partners in the past six months without condoms, intercourse without condoms, and combining sex with alcohol) and the other defined by safer sex variables(intercourse with condoms and use of spermacide with condoms). Just using the four true stage groups resulted in a $58 \%$ correct classification rate, significantly higher than the $25 \%$ which would have been achieved by chance alone.

Using the same discriminant functions developed using only the pure stages of change to classify the PM group placed the PM's into the following stage groups : $34 \%$ - precontemplators, $17 \%$ - contemplators, $48 \%$ - action, and $2 \%$ maintenance.

\section{Discussion}

This stages of change algorithm resulted in behavioral differences among the stages consistent with transtheoretical model-based predictions (DiClemente et al., 1991), that is, that subjects in action and maintenance demonstrated more safer sex behavior and less risky sex behavior than their counterparts in precontemplation and contemplation. No sex differences were found in the percentages of males and females at each stage of change, supporting the application of this model to both males and females. About equal proportions of subjects chose condom use or a sexually exclusive relationship, when asked about their safer sex choices, and fewer subjects chose abstinence as a safer sex strategy.

The stages of change are difficult to adapt to complex behavior changes such as safer sex. We attempted to handle some of these difficulties by developing an algorithm which included safer sex choices for subjects, but still had clearly stated, strict behavioral criteria. Subjects demonstrated willingness or desire to describe 
themselves as practicing safer sex, even when that description conflicted with their current specific behaviors. That subjects answered staging algorithm questions as if they were in maintenance, even when they did not meet behavioral criteria is consistent with other findings for both sun exposure (Blais \& Rossi, 1990) and dietary fat reduction (Curry, Kristal, \& Bowen, 1992), so this problem is not unique to the area of safer sex adoption. Several explanations for these findings present themselves: denial/minimization of risk, optimistic bias (Weinstein, 1984), or that this specific algorithm was somehow confusing.

Ironically, when subjects were asked later in the questionnaire about their current specific behaviors, they did reveal these behaviors even when they conflicted with their prior responses, so subjects were not merely painting a pretty picture. This underscores the importance of clear, specific behavioral questions on sex surveys. That so many subjects misrepresented their current risk status has important implications for college student health. Students may feel so threatened by the riskiness of their current behavior that they need to minimize this as much as possible. This leads to the disturbing conclusion that any description of safer sex practices which is even slightly unclear, will be misinterpreted by subjects, so as to support whatever they are currently doing anyhow. When asked generally whether students believed they were currently practicing safer sex, the majority of students said yes, in spite of behavioral evidence of substantial risk. How researchers deal with these challenges remains to be seen. 


\section{References}

Becker, M.H., \& Joseph, J.G. (1988). AIDS and behavioral change to reduce risk: A review. American Journal of Public Health, 78, 394-410.

Bellis, J.M., Rossi, J.S., \& Prochaska, J.O. (1990, August) Structural invariance of the processes of change. Paper presented at the 98th annual conference of the American Psychological Association, Boston, MA.

Blais, L.M., \& Rossi, J.S. (1990, August) Precautionary sun exposure behaviors: A comparison of early adopters and non-adopters. Paper presented at the 98th annual conference of the American Psychological Association, Boston, MA.

Catania, J.A., Kegeles, S.M., \& Coates, T.J. (1990). Towards an understanding of risk behavior: An AIDS Risk Reduction Model (ARRM). Health Education Quarterly, 17, 53-72.

CDC (1992). A conceptual framework for evaluating behavior change. HIV/AIDS Prevention Newsletter, $\underline{3}(4), 2-3$.

Coates, T.J. (1990). Strategies for modifying sexual behavior for primary and secondary prevention of HIV disease. Journal of Consulting and Clinical Psychology, 58, 57-69.

Cohen, J. (1977). Statistical power analysis for the behavioral sciences (rev. ed.). New York: Academic Press.

Comrey, A.L. (1988). Factor-analytic methods of scale development in personality and clinical psychology. Journal of Consulting and Clinical Psychology, $\underline{56}$, 754-761. 
Curry, S.J., Kristal, A.R., \& Bowen, D.J. (1992). An application of the Stage Model of Behavior Change to Dietary Fat Reduction. Health Education Research: Theory \& Practice, 7, 95-105.

DiClemente, C.C., Prochaska, J.O., Fairhurst, S.K., Velicer, W.F., Velasquez, M.M., \& Rossi, J.S. (1991). The process of smoking cessation: An analysis of precontemplation, contemplation and preparation stages of change. Journal of Consulting and Clinical Psychology, 59, 295-304.

Fisher, J.D., \& Fisher, W.A. (1992). Changing AIDS-risk behavior. Psychological Bulletin, 111, 455-474.

Hatcher, R.A., Stewart, F., Trussel, J., Kowal, D., Guest, F., Stewart, G.K., \& Cates. W. (1990). Contraceptive Technology: 1990-1992, 15th Revised Edition. New York, NY:Irvington Publishers, Inc.

Kelly, J.A., \& Murphy, D.A. (1992). Psychological interventions with AIDS and HIV: Prevention and treatment. Journal of Consulting and Clinical Psychology, 60, 576-585.

Marcus, B.H., Banspach, S.W., Lefebvre, R.C., Rossi, J.S., Carleton, R.A., \& Abrams, D.B. (1992). Using the stages of change model to increase the adoption of physical activity among community participants. American Journal of Health Promotion, $\underline{6}, 424-429$.

Marcus, B.H., Rossi, J.S., Selby, V.C., Niaura, R.S., \& Abrams, D.B. (1992). The stages and processes of exercise behavior change in a worksite sample. Health Psychology, 11, 386-395. 
O'Reilly, K.R. \& Higgins, D.L. (1991). AIDS community demonstration projects for HIV prevention among hard-to-reach groups. Public Health Reports, $\underline{106}$, 714-720.

Prochaska, J.O., \& DiClemente, C.C. (1983). Stages and processes of self-change in smoking: Towards an integrative model of change. Journal of Consulting and Clinical Psychology, 51, 390-395.

Prochaska, J.O., \& DiClemente, C.C. (1985). Common processes of self-change in smoking, weight control, and psychological distress. In S. Shiffman \& T. Wills (Eds.), Coping and substance use (pp. 345-363). New York: Academic Press.

Prochaska J.O., DiClemente, C.C., \& Norcross, J.C. (1992). In search of how people change: Applications to the addictive behaviors. American Psychologist, 47, 1102-1114.

Prochaska, J.O., DiClemente, C.C., Velicer, W.F., \& Rossi, J.S. (in press). Standardized, individualized, interactive and personalized self-help programs for smoking cessation. Health Psychology.

Prochaska, J.O., Harlow, L.L., Redding, C.A., Snow; M.G., Róssi, J.S., \& Velicer, W.F. (1990). Stages of change, self-efficacy, and decisional balance of condom use in a high HIV-risk sample. Technical report to the Centers for Disease Control and Prevention, contract grant \# .

Prochaska, J.O., Norcross, J.C., Fowler, J.L., Follick, M.J., \& Abrams, D.B. (1992). Attendance and outcome in a work site weight control program: Processes and stages of change as process and predictor variables. Addictive Behaviors, 17, 35-45. 
Prochaska, J.O., Redding, C.A., Harlow, L.L., Rossi, J.S., \& Velicer, W.F. (1992). The transtheoretical model applied to HIV prevention: A review. Manuscript submitted for publication.

Prochaska, J.O., Velicer, W.F., DiClemente, C.C., \& Fava, J. (1988). Measuring processes of change: Applications to the cessation of smoking. Journal of Consulting and Clinical Psychology, 56, 520-528.

Prochaska, J.O., Velicer, W.F., Guadagnoli, E., \& Rossi, J.S., \& DiClemente, C.C. (1991). Patterns of change: Dynamic typology applied to smoking cessation. Multivariate Behavioral Research, 26, 83-107.

Rossi, J.S. (1989). Exploring behavioral approaches to UV risk reduction. In A. Moshell \& L.W. Blankenbaker (Eds.), Sunlight, ultraviolet radiation, and the skin (pp. 91-93). Bethesda, MD: National Institutes of Health.

Rossi, J.S. (1990). Statistical power of psychological research: What have we gained in 20 years? Journal of Consulting and Clinical Psychology, $\underline{58}, 646-$ 656.

Rossi, J.S. (1992, August). Common processes of change across nine problem behaviors. Paper presented at the 100th annual conference of the American Psychological Association, Washington, DC.

U.S. Department of Health and Human Services (1991). Healthy people 2000: National health promotion and disease prevention objectives. DHHS Pub. No. (PHS) 91-50212. Washington, DC: U.S. Government Printing Office. Valdiserri, R.O. (1989). Preventing AIDS: The design of effective programs. Rutgers Press: New Brunswick, NJ. 
Velicer, W.F., DiClemente, C.C., Rossi, J.S., \& Prochaska, J.O. (1990). Relapse situations and self-efficacy. Addictive Behaviors, $\underline{15}, 271-283$. 
Table 5-1

Safer sex strategies chosen by two subject groupings
All Subjects
Sexually Active Subjects
Practicing Safer Sex
$(\underline{N}=352)$
$(\underline{N}=231)$

Method Choices

N $\quad$ Percent

N $\quad \underline{\text { Percent }}$

Abstinence

62

17.6

27

11.7

Condom use

$175 \quad 49.7$

$139 \quad 60.2$

Sexually exclusive

$154 \quad 43.8$

$136 \quad 58.9$

relationship

None

$41 \quad 11.6$

Note: Subjects could choose more than one, so total percent $>100$.

Numbers of Safer Sex Strategies chosen

All Subjects

$(\underline{\mathrm{N}}=352)$

Number of methods chosen

0

1

2

3 $\underline{\text { N }} \quad \underline{\text { Percent }}$

41

11.6

239

67.9

$169 \quad 72.8$

$64 \quad 18.2$

$8 \cdot 2.3$
24.1

$\begin{array}{ll}7 & 3.0\end{array}$


Table 5-2

Stages of Change using original algorithm among sexually active subjects $(N=305)$

$\begin{array}{lcc}\text { Stage of Change } & \underline{\mathrm{N}} & \underline{\text { Percent }} \\ \text { Precontemplation } & 19 & 6.2 \\ \text { Contemplation } & 11 & 3.6 \\ \text { Preparation } & 43 & 14.1 \\ \text { Action } & 50 & 16.4 \\ \text { Maintenance } & 174 & 57.1 \\ \text { unstageable responses } & 8 & 2.6\end{array}$

Stages of Change using proposed algorithm among sexually active subjects $(\mathrm{N}=305)$

$\begin{array}{lcc}\text { Stage of Change } & \underline{N} & \underline{\text { Percent }} \\ \text { Precontemplation } & 19 & 6.2 \\ \text { Contemplation } & 15 & 4.9 \\ \text { Preparation } & 43 & 14.1 \\ \text { Action } & 50 & 16.4 \\ \text { Maintenance } & 74 & 24.3 \\ \text { Pseudo-Maintenance } & 100 & 32.8 \\ \text { unstageable responses } & 4 & 1.3\end{array}$


Táble 5-3

Sexual Behavior Means, S.D. 's and MANOVA Results by Stage of Change Stage of Change

Variable PC C

A

$M \quad \underline{F}(3,186) \quad \eta^{2}$

\# of sexual partners

in the past 6 months

1.38

1.06

0.29

$28.95^{*} \quad .32$

WOC

$(0.65)$

$(0.78)$

$(0.80)$

(0.46)

Number of sexual

partners in the

$\begin{array}{llllll}1.22 & 1.84 & 1.43 & 0.96 & 17.50 * & .22\end{array}$

past 6 months

$\begin{array}{llll}(0.43) & (0.81) & (0.71) & (0.57)\end{array}$

Frequency of

intercourse

3.13

2.35

$1.8324 .25^{*}$

.28

WOC

$(0.83)$

(1.04)

(1.13)

(1.19)

Frequency of

\begin{tabular}{lcccccc} 
intercourse & 1.39 & 2.36 & 2.82 & 2.60 & $7.96 *$ & .11 \\
\multicolumn{1}{c}{ With condoms } & $(0.70)$ & $(1.01)$ & $(1.13)$ & $(1.23)$ & & \\
Frequency of anal sex & 1.00 & 1.11 & 1.08 & 1.10 & 0.65 & - \\
$\quad$ With condoms & $(0.00)$ & $(0.46)$ & $(0.34)$ & $(0.38)$ & & \\
Frequency of anal sex & 1.22 & 1.31 & 1.08 & 1.08 & $2.79 *$ & .04 \\
$\quad$ WOC & $(0.43)$ & $(0.74)$ & $(0.28)$ & $(0.37)$ & &
\end{tabular}

(Table 5-3 continues on next page) 
Table 5-3 (continued)

$\begin{array}{lllllll}\text { Use of spermacide with } & 1.11 & 1.62 & 2.10 & 2.03 & 5.10 * & .08\end{array}$ $\begin{array}{lllll}\text { condoms } & (0.32) & (0.93) & (1.31) & (1.24)\end{array}$

$\begin{array}{llllll}\text { Frequency of sex with } & 1.00 & 1.02 & 1.02 & 1.03 & 0.14\end{array}$ prostitutes $\quad(0.00)(0.13) \quad(0.14) \quad(0.24)$

$\begin{array}{lllllll}\text { Frequency of having sex } & 2.67 & 2.71 & 2.45 & 2.01 & 5.70 * & .09\end{array}$ after drinking alcohol (1.08) (0.99) (0.91) (1.05)

Note: WOC $=$ without condoms; Standard deviations are given in parentheses; $\mathrm{PC}=$ Precontemplation $(\underline{\mathrm{N}}=18) ; \mathrm{C}=$ Contemplation $(\underline{\mathrm{N}}=55)$; $A=$ Action $(\underline{N}=49) ; M=$ Maintenance $(\underline{N}=72) ; \eta^{2}=$ effect size (proportion of variance accounted for); * $\underline{\mathrm{F}}$ tests are significant $(\mathrm{p}<.05)$. 
Table 5-4

Group Centroids and Discriminant Structure Matrix for Discriminant Function Analysis predicting Stage of Change using Sexual Behavior variables.

Discriminant Function

$$
1
$$

Stage of Change

Precontemplation

0.11

Contemplation

0.42

0.54

Action

$-0.36$

Maintenance $-0.45$

Variable

Discriminant structure

matrix

Number of partners in past 6 mos. WOC

0.87

0.26

Frequency of Intercourse WOC

0.73

$-0.47$

Number of partners in the past 6 mos.

0.60

0.47

Frequency of mixing sex with alcohol

0.38

0.05

Frequency of Intercourse with condoms

$-0.22$

0.65

Frequency of spermacide use with condoms

$-0.25$

0.39

Frequency of Anal sex WOC

0.22

$-0.05$

Frequency of Anal sex with condoms

$-0.02$

0.12

Frequency of sex with prostitutes

$-0.04$

0.05

Note: Structure matrix values which exceed 0.30 are in bold type. 
PART VI

PREDICTORS OF AIDS RISK, RISKY SEXUAL BEHAVIORS, AND SAFER SEX BEHAVIORS

In their efforts at AIDS prevention, public health officials and researchers have called for more rigorous assessment of how knowledge and attitudes are related to risk reduction, along with a theoretical model which would explain why some people do not modify their sexual behavior despite adequate information (Becker \& Joseph, 1988; Catania, Kegeles, \& Coates, 1990; Coates, 1990; Fisher \& Fisher, 1992; Kelly \& Murphy, 1992). There are several theoretical models which provide partial answers to this question. This paper will examine and compare important variables from two of these models and their ability to predict behavioral outcome criteria.

The Transtheoretical Model (TTT) is one such model. This model describes the relationships among several core concepts: the stages of change, the processes of change, confidence, temptation, and decisional balance. Model testing and measurement development has applied these concepts to safer sex behavior (see papers \# 2,3,4, and 5). The stages of change are a developmental sequence of motivational readiness or intention to modify problem behaviors, including: precontemplation, contemplation, preparation, action, and maintenance. The catalysts for movement through the stages are the processes of change (see paper \# 4). Other intervening variables within this model include situational confidence in safer sex behavior and temptation in unsafe sex (see paper \# 3 ), and decisional balance (see paper \# 2). The transtheoretical model has received empirical support in its application to the area of safer sex adoption (Grimley et al., 1992; in press; Prochaska et al., 1990; Redding et al, 1989; 1993). 
The Health Beliefs Model (HBM) (Abraham, Sheeran, Spears, \& Abrams, 1992; Becker, 1974; Cummings, Jette, \& Rosenstock, 1978; Maiman, Becker, Kirscht, Haefner, \& Drachman, 1977; Sonstroem, 1988) posits several beliefs as vital to preventive intention and action: assessment of perceived severity, personal susceptibility (risk), perceived effectiveness of risk reduction strategies, barriers to and facilitators of preventive behavior changes. This model has received empirical support in the area of AIDS risk reduction (Abraham et al., 1992; Hingson et al., 1990). In this application, we allowed the pros and cons of safer sex to represent the barriers and facilitators, in part based on their theoretical similarity, in part based on empirical data from other areas (Rakowski et al., 1992), and in part because no existing scales measuring barriers and facilitators to safer sex adoption were available. It is important to note that the perceived efficacy of risk reduction strategies was not assessed in the present application.

Within the TTT model, perceived risk has not been assessed previously as a potential predictor variable. Since so many AIDS risk reduction researchers value risk assessment in predicting AIDS preventive behaviors (Coates, 1990; Fisher \& Fisher, 1992; Kelly \& Murphy, 1992), how might perceived risk be related to TTT variables?

Variables from these two models will be included in this study to compare their ability to predict independent outcome criteria.

\section{Method}

The present study developed an independent grouping criterion called AIDS risk. All TTT variables, and two HBM variables, as well as demographic variables were allowed to compete to improve prediction of AIDS risk group among college 
student subjects using discriminant function analyses. Finally, all variables were combined in a structural equations model to see how well each variable could predict both safer sexual behavior and risky sexual behavior.

\section{Subjects}

Subjects were 305 male and female, sexually active students attending a midsize, northeastern state university. Approximately $54 \%$ of the subjects were female, $91 \%$ were Caucasian, $99 \%$ were single, and $98 \%$ identified themselves as heterosexual. Modal age was 19 years (34\%), and modal year in college was freshman $(47 \%)$.

\section{Procedure}

Subjects were recruited from within their classrooms. Their participation was anonymous and voluntary. Some subjects received partial class credit for participating in research. Study participants provided informed consent and completed questionnaires within approximately 30 minutes.

\section{Measures}

Several different independent and dependent measures were used in this study.

AIDS Risk Group. There are precedents for assessing the numbers of risk factors among heterosexuals (Catania et al., 1992). Previous risk assessments have included multiple partners, risky partners, and blood transfusions as indicators of some non-zero risk. In this study, a rationally defined grouping variable assigned subjects points for various risk factors or behaviors they endorsed as follows: the number of sexual partners in the past 6 months without condoms earned subjects the same number of points as their actual variable value (ranged from 0 to 4 ); one point was added for each of the following potential risk factors: having received a blood 
transfusion; having had sex with a prostitute; having had sex with an intravenous drug user; having mixed sex with alcohol; or having mixed sex with illegal drug use. These risk factors followed the reasoning of Catania et al. (1992), except for the two variables reflecting mixing substance use with sexual behavior.

Risky Sexual Behavior. This variable was defined by two behavioral items: the number of sexual partners in the past six months without condoms and the frequency of intercourse without condoms. Standardized internal consistency (alpha) coefficient for these items was .67.

Safer Sexual Behavior. This variable was defined by two behavioral items: the frequency of intercourse with condoms, and the frequency of using spermacide with condoms. Standardized alpha for these items was .80 .

Demographic variables. Several categorical variables were included in these questionnaires: sex; race; religion; and annual family income. In addition, age was included as a continuous variable.

Decisional Balance: The Pros and Cons of safer sex. A 12-item decisional balance of safer sex measure was developed and cross-validated, with 4-factors: Pros-self and Pros-relationship and Cons-self and Cons-relationship. The factors were organized hierarchically, so that the Pros and Cons were primary factors, each with 2 lower-order factors for self and other. These scales have demonstrated good psychometric properties and internal consistencies (see paper \# 2):

Self-Efficacy: Confidence and Temptation. Two 15-item scales were developed representing confidence in safer sex and temptation to have unsafe sex. These variables each had 5 subscales reflecting sexual arousal (AR), substance use (SU), partner pressure (PP), negative affect (NA), and perceived low risk (PLR). 
Again, the higher order constructs of either confidence or temptation, respectively, were used as factors, each with 5 lower order factors. These scales have demonstrated good psychometric properties and internal consistencies (see paper \# $3)$.

Experiential and Behavioral Processes of Safer Sex Adoption. A 44-item scale was developed representing 11 processes of safer sex adoption. These 11 processes were organized hierarchically into two factors: experiential processes and behavioral processes. The two higher-order factors were independent variables used to represent the processes of change in this study. These scales have demonstrated good psychometric properties and internal consistencies (see paper \# 4).

Perceived Risk. Two items were developed to assess subjects' perceived risk or susceptibility for HIV exposure. Standardized alpha for these items was .78. A third item assessed subjects' normative perceived risk so that possible optimistic bias (Weinstein, 1983, 1984) could also be assessed.

Perceived severity. Two items were developed to assess subjects' perceptions of the severity of HIV exposure. Standardized alpha for both these items was .68.

\section{Results}

Classifying subjects into AIDS risk group produced four different risk factor groups as follows: No risk factors $(\mathrm{N}=29,10.8 \%)$; one risk factor $(\mathrm{N}=51$, $19.0 \%)$; two AIDS risk factors $(\mathrm{N}=93,34.7 \%)$; and three or more risk factors ( $\mathrm{N}$ $=95,35.4 \%$ ). This grouping variable was used in the following discriminant analyses. 


\section{Discriminant Function Analyses}

A series of discriminant function analyses (DFA) using Wilks method were conducted predicting AIDS risk group using 4 different combinations of variables: demographic variables only, HBM variables only, TTT variables only, and all variables combined. Follow-up MANOVAs were conducted for each significant DFA.

Demographic variables only. The first analysis included only demographic variables: sex, race, family income, religion, and age. This was not expected to predict AIDS risk group well, although it was run as a baseline against which to measure other more theoretically based models. It was not without interest, however, since some public health scientists who have been epidemiologically trained rely on demographic variables to predict health-related outcome criteria. The DFA found one significant discriminant function defined by family income and race and accounting for $3.6 \%$ of the variance in AIDS risk group, however, the follow-up MANOVA did not attain significance. Higher family income and white (vs. nonwhite) status were both associated with higher risk group status.

HBM variables only. The second DFA included variables: perceived risk, perceived severity, and the pros and cons of safer sex. One normative risk assessment item was also included with these variables. The DFA found one significant discriminant function accounting for $11.8 \%$ of the variance in AIDS risk group. Results are presented in Table 6-1. A follow-up MANOVA was significant, Wilks $\Lambda=.843$, approximate $\underline{\mathrm{F}}(21,813.2)=2.37, \mathrm{p}<.001$, multivariate $\eta^{2}=$ .06. Follow-up univariate analyses found three variables significantly different across AIDS risk groups, revealing that most of the variance was accounted for by 
Cons-self $\left(\eta^{2}=.08\right)$, Cons-relationship $\left(\eta^{2}=.04\right)$, and Perceived risk $\left(\eta^{2}=\right.$ $.05)$.

\section{Insert Table 6-1 About Here}

TTT variables only. The third DFA included variables: the pros and cons of safer sex 4 subscales, confidence in safer sex 5 subscales, temptation in unsafe sex 5 subscales, and all 11 processes of safer sex. The DFA found two significant discriminant functions accounting for $22.1 \%$ and $12.5 \%$ of the variance in AIDS risk group, respectively. Results are presented in Table 6-2. A follow-up MANOVA was significant, Wilks $\Lambda=.599$, approximate $\underline{F}(75,688.4)=1.72, \underline{p}$ $<.001$, multivariate $\eta^{2}=.16$. Follow-up univariate analyses found 15 TTT variables significantly different across AIDS risk group, revealing that most of the variance was accounted for by 4 processes (ISC, SR, SL, CC), 4 confidence subscales (AR, PLR, NA, SU), all 5 temptation subscales (AR, PLR, NA, SU, PP), and 2 decisional balance subscales, Cons-self and Cons-relationship.

Insert Table 6-2 About Here

All variables included. The final DFA included all TTT, HBM, and demographic variables. One additional categorical variable, whether or not the subject had obtained an HIV blood test, was also used. It was thought that this variable may improve discrimination of subjects at different levels of AIDS risk. The DFA found two significant discriminant functions accounting for $31.1 \%$ and 
$18.6 \%$ of the variance in AIDS risk group, respectively. Results are presented in Table 6-3. A follow-up MANOVA was significant, Wilks $\Lambda=.467$, approximate $\underline{\mathrm{F}}(102,644.7)=1.83, \underline{\mathrm{p}}<.001$, multivariate $\eta^{2}=.22$. Follow-up univariate analyses found 17 variables significantly different across AIDS risk group as follows: 4 processes (ISC, SR, SL, CC), 4 confidence subscales (AR, PLR, NA, SU), all 5 temptation subscales (AR, PLR, NA, SU, PP), 1 decisional balance subscale, Cons-Self, 1 HBM variable, Perceived Risk, and 2 demographic variables, family income and race.

Insert Table 6-3 About Here

\section{Structural Models Predicting Risky and Safer Sex Behavior}

Linear structural equation modeling using both the maximum likelihood and elliptical estimators from the EQS statistical software package (BMDP, 1988) were used to fit this large model. In this model, all constructs were independent variables, and they were allowed to predict the 2 dependent constructs: risky and safer sex behaviors. The elliptical estimator was also used because it is far less sensitive to variable non-normality than maximum likelihood is (Bentler, 1989). First, a fully correlated measurement model was run including all-variables of interest. Maximum likelihood fit indices included: .74 (Bentler-Bonett Normed Fit Index; Bentler \& Bonett, 1980), .80 (Tucker-Lewis Fit Index; Tucker \& Lewis, 1973), and .83 (Comparative Fit Index; Bentler, 1990), indicating adequate model fit. The pattern of correlations among all these constructs is presented in Table 6-4. 
Insert Table 6-4 About Here

Secondly, a structural model was run, placing directional paths between the dependent and independent variables. Independent latent variables included: Perceived Severity, Perceived Risk, Pros of Safer Sex, Cons of Safer Sex, Confidence, Temptation, Experiential Processes, and Behavioral Processes. Jackson Social Desirability demonstrated minute relationships with the constructs of interest and was, therefore, dropped from these analyses. Dependent latent variables included: Risky Sexual Behavior and Safer Sexual Behavior. Maximum likelihood fit indices were: .79 (Bentler-Bonett Normed Fit Index; Bentler \& Bonett, 1980), .80 (Tucker-Lewis Fit Index; Tucker \& Lewis, 1973), and .83 (Comparative Fit Index; Bentler, 1990), indicating adequate model fit. Elliptical fit indices were: .88 (Bentler-Bonett Normed Fit Index; Bentler \& Bonett, 1980), .92 (Tucker-Lewis Fit Index; Tucker \& Lewis, 1973), and .93 (Comparative Fit Index; Bentler, 1990), indicating good model fit. These constructs together accounted for $34 \%$ of the variance in Risky Sexual Behavior and 12\% of the variance in Safer Sex Behavior. There were several small, non-significant paths. A final, third model was run, which excluded 5 independent constructs without significant path relationships to Risky or Safer Sexual Behavior. The remaining independent constructs, Experiential Processes of Change, Behavioral Processes of Change, and Confidence in Safer Sex produced in the model presented in Figure 6-1. 


\section{Insert Figure 6-1 About Here}

Maximum likelihood fit indices for this model included: .77 (Bentler-Bonett Normed Fit Index; Bentler \& Bonett, 1980), .78 (Tucker-Lewis Fit Index; Tucker \& Lewis, 1973), and .82 (Comparative Fit Index; Bentler, 1990), indicating adequate model fit. Elliptical fit indices included: .87 (Bentler-Bonett Normed Fit Index; Bentler \& Bonett, 1980), .89 (Tucker-Lewis Fit Index; Tucker \& Lewis, 1973), and .91 (Comparative Fit Index; Bentler, 1990), indicating good model fit. Taken together, Experiential Processes of Change, Behavioral Processes of Change, and Confidence in Safer Sex accounted for $30.6 \%$ of the variance in Risky sexual behavior and $10.5 \%$ of the variance in Safer Sexual Behavior.

\section{Discussion}

Almost $90 \%$ of the college students in this sample had at least one risk factor for AIDS. This has important ramifications for college student health, suggesting that college students should be adopting safer sexual practices at higher rates, and should be receiving more attention as a target group for intervention. It is some reassurance that the rates of HIV infection in this population are still relatively low compared to other more disadvantaged groups (e.g., IVDU, minorities). The rapid spread of other STD's through college student populations is disquieting, however, and prevention is the only means to stop this from occurring with AIDS as well.

Variables from both the Trantheoretical and Health Beliefs models were included in this study of college student subjects to compare their ability to predict two independently derived outcome criteria, AIDS risk group, and Risky and Safer 
Sexual Behaviors. The best group of predictors combined variables from both models, which collectively accounted for nearly $50 \%$ of the variance in AIDS risk group. All model-based variables, regardless of their theoretical origins, strongly outpredicted demographic variables in their ability to predict these two outcome criteria, supporting the importance of psychological studies of mediating variables. This provides some empirical support for the need for a "public health psychology" (Rugg, 1990) which combines aspects of public health/Epidemiology and psychology in response to the AIDS epidemic. In the final cross-sectional structural equations model, which used directional paths to predict Risky and Safer Sexual behavior, slightly more modest outcomes were obtained. Taken together, Experiential Processes of Change, Behavioral Processes of Change, and Confidence in Safer Sex accounted for $30.6 \%$ of the variance in Risky sexual behavior and $10.5 \%$ of the variance in Safer Sexual Behavior. Risky and safer sexual behavior were only somewhat negatively correlated $(\underline{r}=-.323)$ in this model, supporting their distinction from one another. Longitudinal verification of these suggestive cross-sectional findings is strongly recommended.

The best predictor from the Health Beliefs model was Perceived Risk. The variable, Barriers to safer sex, also received support, except that these barriers were operationalized as the Cons of safer sex, a Transtheoretical variable. Evidence was found here to question the utility of Perceived Severity in improving the prediction outcome variables, contrary to HBM predictions. Perceived Severity has received equivocal support within the Health Beliefs model literature as well (Sonstroem, 1988). It remains unclear how much better this model would have fared if the variable, perceived efficacy of risk reduction strategies had been included. A fairer 
test of the HBM would be to use measures developed by the proponents of that model. However, these were not available when this study was being developed. Most Transtheoretical variables did very well, most notably, 4 Processes of safer sex (ISC, CC, SR, SL), 4 Confidence subscales, 5 Temptation subscales, and the Cons of Safer Sex. In fact, in the structural equations model analyses, the final model included Experiential Processes of Change, Behavioral Processes of Change, and Confidence in Safer Sex, which together emerged as the best predictor variables from among all other variables and which accounted for $30.6 \%$ of the variance in Risky sexual behavior and $10.5 \%$ of the variance in Safer Sexual Behavior. This is strong support for the predictive power of the Transtheoretical model-based variables and the model itself. Hopefully, efforts such as this have laid the groundwork for theoretical eclecticism, as we determine the best variables, regardless of their theoretical origins, to improve the prediction of, and ultimately, more effective interventions with AIDS risk behaviors. 


\section{References}

Abraham, C., Sheeran, P., Spears, R., Abrams, D. (1992). Health beliefs and promotion of HIV-preventive intentions among teenagers: A Scottish perspective. Health Psychology, 11, 363-370.

Becker, M.H. (Ed.) (1974). The health belief model and personal health behavior. Health Education Monograph, 2, 324-508.

Becker, M.H., \& Joseph, J.G. (1988). AIDS and behavioral change to reduce risk: A review. American Journal of Public Health, 78, 394-410.

Bentler, P.M. (1989). EOS: Structural Equations Program Manual, Los Angeles, CA: BMDP Statistical Software, Inc.

Bentler, P.M. (1990). Comparative fit indexes in structural models. Psychological Bulletin, 107, 238-246.

Bentler, P.M., \& Bonett, D.G. (1980). Significance tests and goodness of fit in the analysis of covariance structures. Psychological Bulletin, $\underline{88}, 588-606$.

Betz, N.E. (1987). Use of discriminant analysis in counseling psychology research. Journal of Counseling Psychology, 34, 393-403.

Catania, J.A., Coates, T.J., Stall, R., Turner, H., Peterson, J., Hearst, N., Dolcini, M., Hudes, E., Gagnon, J., Wiley, J., \& Groves, R. (1992). Prevalence of AIDS-related risk factors and condom use in the United States. Science, 258, 1101-1106.

Cummings, K.M., Jette, A.M., \& Rosenstock, I.M. (1978). Construct validation of the Health Belief Model. Health Education Monographs, $\underline{6}$, 394-405. 
Gladis, M.M., Michela, J.L., Walter, H.J., \& Vaughan, R.D. (1992). High school students' perceptions of AIDS risk: Realistic appraisal or motivated denial? Health Psychology, 11, 307-316.

Hatcher, R.A., Stewart, F., Trussel, J., Kowal, D., Guest, F., Stewart, G.K., \& Cates. W. (1990). Contraceptive Technology: 1990-1992, 15th Revised Edition. New York, NY:Irvington Publishers, Inc.

Hingson, R.W., Strunin, L.,\& Berlin, B.M. (1989). Changes in knowledge and behaviors among adolescents: Massachusetts Statewide Surveys, 1986-88. Pediatrics, 8 5. 24-29.

Hingson, R.W., Strunin, L., Berlin, B.M., \& Heeren, T. (1990). Beliefs about AIDS; use of alcohol and drugs, and unprotected sex among Massachusetts adolescents. American Journal of Public Health, 0, 295-299.

Horn, D. (1976). A model for the study of personal choice health behavior. International Journal of Health Education, 19, 89-98.

Janz, N.K., \& Becker, M.H. (1984). The Health Belief Model: A decade later. Health Education Quarterly, 11, 1-47.

Kelly, J.A., \& Murphy, D.A. (1992). Psychological interventions with AIDS and HIV: Prevention and treatment. Journal of Consulting and Clinical Psychology, $\underline{60}, 576-585$.

Kelly, J.A., St. Lawrence, J.S., Hood, H.V., \& Brasfield, T.L. (1989). Behavioral intervention to reduce AIDS risk activities. Journal of Consulting and Clinical Psychology, 57, 60-67. 
Kelly, J.A., St. Lawrence, J.S., Brasfield, T.L., Lemke, A., Amidei, T., Roffman, R.E., Hood, H.V., Smith, J.E., Kilgore, H., \& McNeill, C. (1990). Psychological factors that predict AIDS high-risk versus AIDS precautionary behavior. Journal of Consulting and Clinical Psychology, 58, 117-120. Maiman, L.A., Becker, M.H., Kirscht, J.P., Haefner, D.P., \& Drachman, R.H. (1977). Scales for measuring Health Belief Model dimensions: A test of predictive value, internal consistency, and relationships among beliefs. Health Education Monographs, $\underline{5}$, 215-230.

Rugg, D.L. (1990). AIDS prevention: A public health psychology perspective. In Leviton, L.C., Hegedus, A.M., \& Kubrin, A. (eds.) Evaluating AIDS prevention: Contributions of multiple disciplines. San Francisco, CA: JoseyBass Inc., 7-22.

Sonstroem, R.J. (1988). Psychological models. In R. Dishman (Ed.), Exercise adherence (pp. 125-154). Champaign, IL: Human Kinetics Books.

Weinstein, N.D. (1983). Reducing unrealistic optimism about illness susceptibility. Health Psychology, 2, 11-20.

Weinstein, N.D. (1984). Why it won't happen to me: Perceptions of risk factors and susceptibility. Health Psychology, $\underline{3}$, 431-457.

Wyatt, G. (1990). Risk-taking and risk-avoiding behavior: The impact of some dispositional and situational variables. The Journal of Psychology, 124, $437-$ 447. 
Table 6-1

Group Centroids and Discriminant Structure Matrix for Discriminant Function Analysis predicting AIDS Risk Group using HBM variables.

Risk Group

No Risk Factors

One Risk Factor

Two Risk Factors

Three or more Risk Factors

Variable

Cons - Self

Perceived Risk

Cons - Relationship

Normative Perceived Risk

Perceived Severity

Pros - Relationship

Pros - Self

\section{Discriminant Function}

$-0.43$

$-0.41$

$-0.11$

0.46

Discriminant structure matrix

0.80

0.64

0.42

0.27

0.20

$-0.15$

$-0.12$

Note: Structure matrix values which exceed 0.30 are in bold type. 
Table 6-2

Group Centroids and Discriminant Structure Matrix for Discriminant Function Analysis predicting AIDS Risk Group using all TTT variables.

\section{Discriminant Function}

1

2

Risk Group

No Risk Factors

$-0.94$

0.57

One Risk Factor

$-0.52$

0.06

Two Risk Factors

$-0.04$

$-0.48$

Three or more Risk Factors

0.61

0.26

Variable

Discriminant structure matrix

Pros - Self

$-0.18$

0.11

Pros - Relationship

$-0.25$

0.16

Cons - Self

0.59

0.03

Cons - Relationship

0.33

0.05

Confidence - Sexual Arousal

$-0.51$

0.15

Confidence - Substance Use

$-0.58$

0.08

Confidence - Perceived Low Risk

$-0.39$

0.23

Confidence - Negative Affect

$-0.36$

$-0.06$

Confidence - Partner Pressure

$-0.30$

$-0.03$

Temptation - Sexual Arousal

0.45

$-0.03$

Temptation - Substance Use

0.59

0.27

Temptation - Perceived Low Risk

0.39

$-0.18$

(Table 6-2 continues on next page) 
Table 6-2 continued

$\begin{array}{lcc}\text { Temptation - Negative Affect } & \mathbf{0 . 3 3} & 0.28 \\ \text { Temptation - Partner Pressure } & \mathbf{0 . 3 1} & 0.11 \\ \text { Self Liberation } & \mathbf{- 0 . 4 7} & 0.15 \\ \text { Self Reevaluation } & \mathbf{- 0 . 4 5} & 0.28 \\ \text { Social Liberation } & -0.11 & 0.02 \\ \text { Dramatic Relief } & 0.05 & -0.08 \\ \text { Consciousness Raising } & 0.09 & 0.24 \\ \text { Environmental Reevaluation } & -0.22 & 0.04 \\ \text { Helping Relationships } & -0.07 & -0.14 \\ \text { Interpersonal Systems Control } & \mathbf{- 0 . 4 6} & 0.01 \\ \text { Counterconditioning } & \mathbf{- 0 . 4 4} & \mathbf{0 . 4 2} \\ \text { Stimulus Control } & -0.10 & \mathbf{0 . 3 0} \\ \text { Reinforcement Management } & -0.11 & 0.12\end{array}$

Note: Structure matrix values which exceed 0.30 are in bold type. 
Table 6-3

Group Centroids and Discriminant Structure Matrix for Discriminant Function Analysis predicting AIDS Risk Group using all variables.

\section{Discriminant Function}

1

2

Risk Group

No Risk Factors

$-1.00$

$-0.79$

One Risk Factor

$-0.74$

$-0.09$

Two Risk Factors

$-0.10$

0.61

Three or more Risk Factors

0.79

$-0.28$

Variable

Discriminant structure matrix

Temptation - Substance Use

$\mathbf{0 . 5 2}$

$-0.18$

Cons - Self

0.48

0.03

Confidence - Sexual Arousal

$-0.42$

$-0.21$

Confidence - Substance Use

$-0.40$

$-0.02$

Confidence - Perceived Low Risk

$-0.37$

$-0.25$

Interpersonal Systems Control

$\begin{array}{ll}-\mathbf{0 . 3 7} & -0.08\end{array}$

Temptation - Sexual Arousal

0.36

0.09

Perceived Risk

0.34

$-0.08$

Self Liberation

$-0.34$

$-0.15$

Self Reevaluation

$-0.33$

$-0.29$

Temptation - Perceived Low Risk

0.32

0.21

(Table 6-3 continues on next page) 
Table 6-3 continued

\begin{tabular}{|c|c|}
\hline Confidence - Negative Affect & -0.30 \\
\hline Pros - Relationship & -0.25 \\
\hline Confidence - Partner Pressure & -0.24 \\
\hline Race & -0.24 \\
\hline Cons - Relationship & 0.23 \\
\hline Environmental Reevaluation & -0.18 \\
\hline Normative Perceived Risk & 0.17 \\
\hline Sex & -0.15 \\
\hline Counterconditioning & -0.33 \\
\hline Family Income Level & 0.17 \\
\hline Stimulus Control & -0.18 \\
\hline Age & 0.04 \\
\hline Reinforcement Management & -0.10 \\
\hline Had an HIV Test & 0.03 \\
\hline Consciousness Raising & 0.07 \\
\hline Temptation - Negative Affect & 0.28 \\
\hline Helping Relationships & -0.08 \\
\hline Temptation - Partner Pressure & 0.19 \\
\hline Pros - Self & -0.09 \\
\hline
\end{tabular}

(Table 6-3 continues on next page) 
Table 6-3 continued

Religion

Social Liberation

Dramatic Relief

Perceived Severity
0.01 $-0.07$

$-0.01$

$-0.02$

0.03

0.08

$-0.01$

0.04

Note: Structure matrix values which exceed 0.30 are in bold type. 
苞

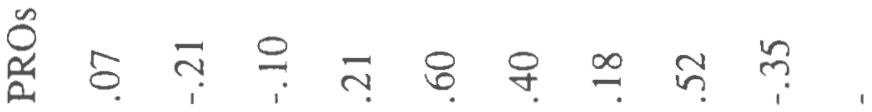

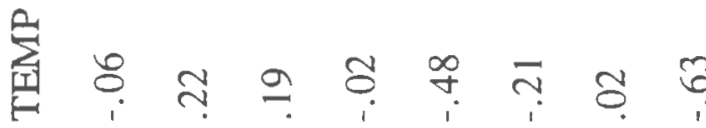

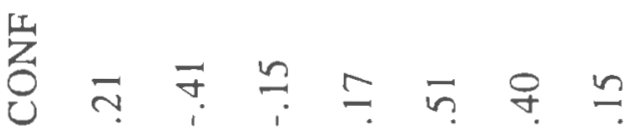

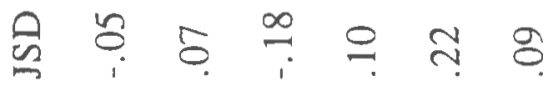

椆 ๆ ๆ

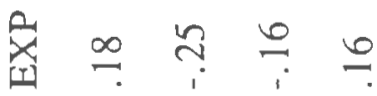

ऐ

$\stackrel{5}{\cong} 5$

$\frac{m}{2}$ ?

$\stackrel{m}{\sim}$

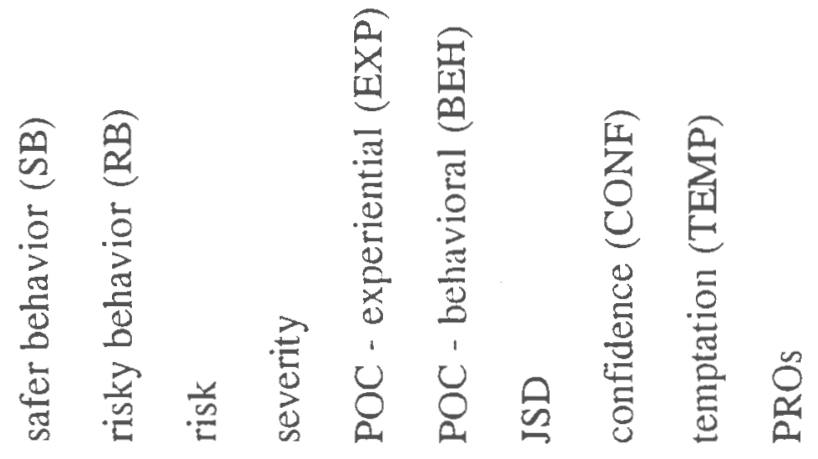




\section{Figure Captions}

Figure 6-1. Standardized elliptical parameter estimates for the final structural model including only constructs with significant paths predicting risky and safer sex behavior 


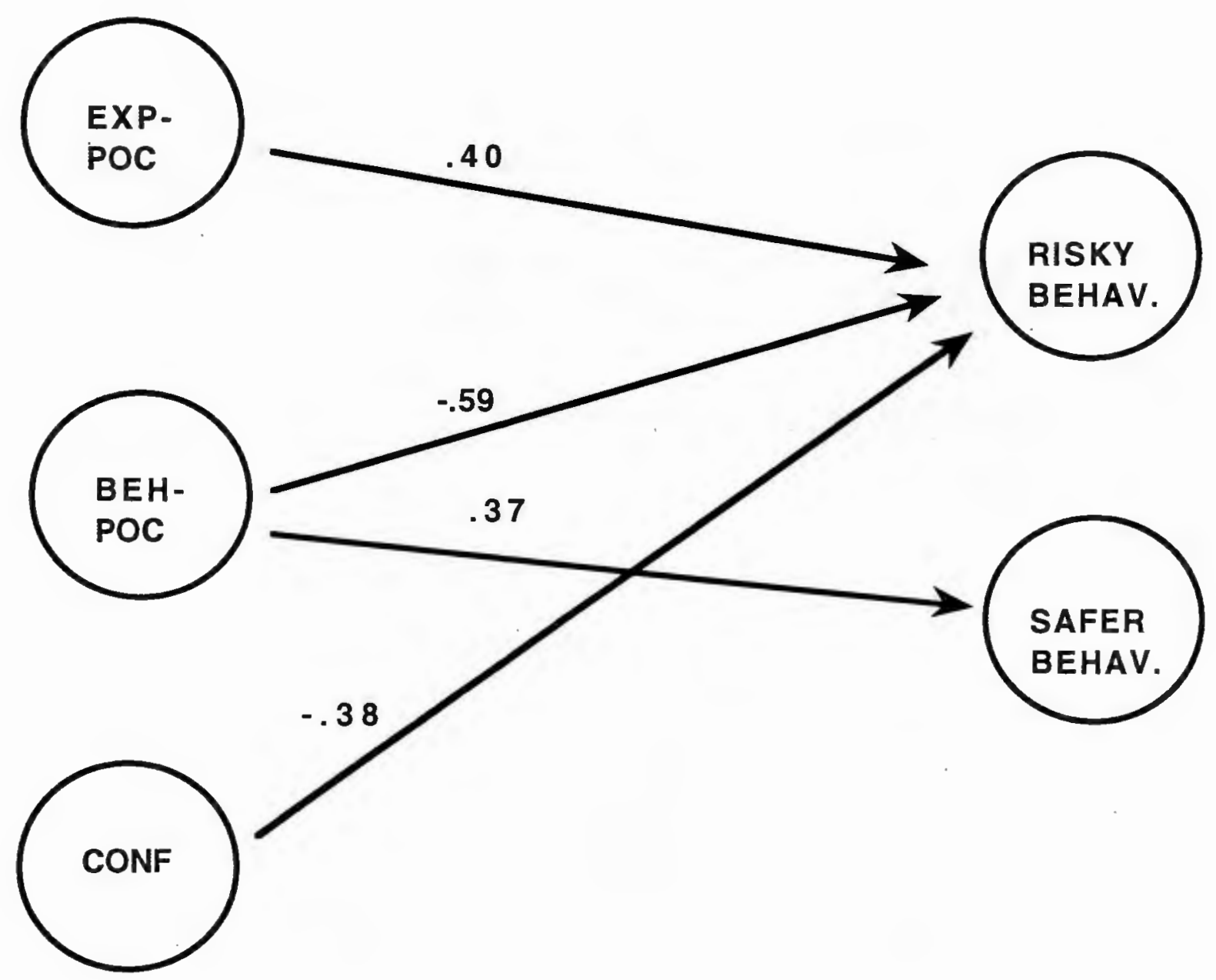




\section{PART VII \\ FINAL DISCUSSION}

There are many final comments to make and a few more results to present following these six papers. Table 7-1 describes the entire sample more fully in terms of demographic variables. These comments will be organized into the following sections: College Students and AIDS Risk; The Transtheoretical Model; Gender Differences; and Recommendations for Future Research.

\section{College Students and AIDS Risk}

College students in this study, consistent with other research (Baldwin \& Baldwin, 1988), are engaging in a significant amount of risky sexual behavior. In the national RDD heterosexual AIDS risk sample (Catania et al., 1992), young educated people, especially males, were clearly implicated as at higher risk than other heterosexual groups. Certainly, the findings in this study are consistent with these. Tables 7-2, 7-3, and 7-4 describe the frequencies, Stage-based differences, and sex differences in all sexual behavior variables. Table 7-5 illustrates the numbers of sexual partners subjects indicated across different time periods, including ever, within the past 6 months, and within the past 6 months without condoms. Although $76 \%$ of sexually active subjects, when asked, said they were currently practicing safer sex, a closer inspection of their behavioral responses revealed that this was not the case. Most of these "pseudomaintainers" indicated they were "safe" because they were in a relatively (within a college student timeframe) long-term sexual relationship. This is consistent with previous findings that subjects, even those at higher risk, are more likely to use condoms with casual or non-steady partners than with their main partner (Catania, Coates, \& Kegeles, 1993; Grimley et al., 1992; Prochaska, Harlow et al., 1990). Table 7-6 describes relationship 
characteristics (sexual exclusiveness, duration, projected future duration, number of other sexual partners since start of this relationship, and number of sexual partners in the past 6 months) of subjects $(\underline{\mathrm{N}}=230)$ who said they were in primary sexual relationships. Almost $30 \%$ of subjects had between 2-10 sexual partners in the past six months, regardless of when their current relationship began. This clearly indicates some risk to the current partner. At the same time, nearly $71 \%$ of these college students' believed their current relationship would last more than one year into the future. How accurate are these projections? Is it possible that giving up condom use is one step in the process of relationship formation towards more intimacy? Are students confusing feeling intimate and feeling safe from disease? This certainly suggests that more about the relationship context of safer sex materials be included in safer sex curricula. Many safer sex pamphlets describe well what physical acts carry what degree of risk. What these pamphlets are missing, however, is the relationship context in which these acts performed, and how that context may make safer sex more or less problematic. These are complex issues and more research in this area would be important.

It should be noted that a small proportion of $(\underline{N}=47)$ subjects in this study denied any lifetime experience with sexual intercourse. Table 7-7 describes the mean importance ratings of different reasons for sexual abstinence, demonstrating that AIDS, pregnancy, and STD prevention are important concerns among these students in spite of their lack of sexual experience.

\section{The Transtheoretical Model}

These results provide strong support for the transtheoretical model-based predictions in the area of safer sex adoption among heterosexual university students. 
This is the only data set to date with all the transtheoretical constructs represented. Overall each transtheoretical construct, decisional balance, confidence, temptation, and the processes of change, as well as its functional relationship to stages of change, confirmed model-based predictions and supported construct validity. Some of the scales, however, did not fare so well (see below). In fact, in the final paper allowing constructs from different theoretical models to compete to predict AIDS outcome criteria, most TTT model-based variables did very well, and three of these emerged as the best predictors: experiential and behavioral processes of change, and confidence in safer sex.

Unfortunately, the weakest translation was for the stages of 'change themselves, which resulted in a large group of pseudomaintainers. It is strong praise for the model that even with relatively weak stages of change so many model-based predictions for constructs and their stage relationships were confirmed. Further, these "weak" stages of change accounted for $22 \%$ of the variance in sexual behaviors and risk factors, strong support for the stage-based conceptual schema. It remains to be seen how the dilemma of complex behavioral changes can be handled by a stages of change algorithm, especially in an area where denial / minimization of risk is as relevant as AIDS risk reduction.

Several processes differentiated subjects in different stages of change, as well as different risk groups, and those include: Self Liberation, Self Reevaluation, Interpersonal Systems Control, Counterconditioning, and Stimulus Control. These processes have several implications for improving interventions with college students to accelerate their adoption of safer sex. First, encouraging people who are ready to substitute safer sexual practices for risky sex (Counterconditioning) is vital to 
reducing risk. Parenthetically, eroticizing safer sexual activities will also make Counterconditioning more compelling and easier to maintain for subjects. Second, focusing on making AIDS information relevant to each individual (e.g., what does this mean for you?) to increase their Self Reevaluation is indicated, especially for subjects who may only be thinking about practicing safer sex. Clinicians should support and teach assertiveness skills regarding safer sex (i.e., Self Liberation) and encourage people to seek out friends/lovers who support their practicing safer sex and avoid friends/lovers who do not (Interpersonal Systems Control).

Surprisingly, several experiential processes of change appeared relatively flat across the stages of change (see Figures 4-2 and 4-3), specifically, Consciousness Raising, Helping Relationships, Dramatic Relief, Environmental Reevaluation, and Social Liberation. Environmental Reevaluation is probably not sensitive enough to stage differences because it is endorsed too highly across the board, suggested by its high mean value. It is possible that the skewed stage distribution obscured differences which could have been found were there a better representation of early stage subjects. Another possible explanation is that we may be permeated with safer sex information and admonitions, such that subjects at all stages are engaging in these processes at about equal rates. Future research will sort out these possibilities.

Dramatic Relief and Consciousness Raising tended to merge in the PCA's. Even when separated in the structural modeling, their correlation remained high (프 $=.782$ ). This is troubling for two reasons. First, these two processes have emerged more distinctly in previous research across problem areas. Secondly, it suggests that college students are not differentiating between cognitive processes and affective processes in the area of safer sex adoption. Other psychological theories 
support the importance of the differentiation of affect and cognition (Bowen, 1978). It could be that subjects are saturated with anxiety-provoking information about safer sex. Perhaps some fear-arousing messages have gotten through and, paradoxically, limited subjects ability or willingness to seek out appropriate new information about AIDS risk reduction. Or could it be that the fear inherent in the current AIDS pandemic is so threatening that defense mechanisms, such as denial and minimization, are used which interfere with clear cognitive processing of information regarding safer sex? Certainly, evidence from the Stages of Change section supports the conclusion that pseudomaintainers wanted and/or needed to present themselves as safe, even when that description conflicted with other behaviors which they endorsed. Certainly more research would help sort out all the possibilities.

The final paper supported including perceived risk in future Transtheoretical research in the AIDS risk reduction area. An ANOVA on perceived risk by Stage group was significant, $\underline{F}(3,292)=6.15, \underline{p}<.001$. Tukey post-hoc follow-up tests revealed that contemplators felt significantly more perceived risk than those in the maintenance stage. Figure 7-1 graphs these relationships. So, perceived risk can help differentiate stage groups, and it was included in the DFA's predicting AIDS risk group as well.

\section{Gender Differences}

Several gender differences were found in this study. Table 7-3 illustrates gender differences in sexual behaviors. Males endorsed more lifetime sexual partners, more frequent alcohol consumption, more frequent masturbation, and more frequent use of spermacide with condoms than females. Other studies have found 
similar sex differences in alcohol consumption (Migneault, 1992). The sexual differences are consistent with previous research on sexual behavior (Catania et al., 1990, 1992; Doyle, 1989). Aside from these differences, the genders did not differ on the frequencies of all other specific sexual behaviors, with the exception of those that reflect heterosexual activities (i.e., several oral sex items specified the gender of the partner; see Tables 7-1 to 7-3).

The gender differences on Transtheoretical variables are more interesting. Specifically, females endorsed higher pros of safer sex, more confidence in safer sex, and more experiential process use than males. Males endorsed higher cons of safer sex, more temptation for unsafe sex, as well as higher use of one behavioral process, stimulus control. Stimulus control, as a process, largely reflects condom use items, since other more general safer sex items were difficult to generate. Therefore, the sex difference on Stimulus Control, as well as the previously reported difference on use of spermacide with condoms, likely reflects males higher endorsement of condom use in general, probably because condoms are the only form of contraception/STD prevention made specifically for males. That females endorse higher experiential, but not behavioral, process use suggests, at first glance, that females may be more prepared to adopt safer sex than males, but this was not found. Indeed, processes of change must be used at appropriate stages in order to facilitate progression, so while higher experiential process use would be helpful for an early stage person, it may hinder the progress of a later stage person (Prochaska, DiClemente, \& Norcross, 1992; Fitzgerald \& Prochaska, 1990). It is interesting that no stage by sex interaction was observed. This suggests that the genders may require different levels of pros/cons and confidence/temptation in order to progress 
to the next stage. It further suggests that any normative feedback given to subjects adopting safer sex, e.g., in an expert system (Velicer et al., in press), should include not only stage norm references, but gender norm references. It is important to note, however, that in this mixed gender sample, the Transtheoretical model described behavior well. In other words, in spite of some mean differences on specific variables, the same models of behavior change were used and fit for both sexes.

\section{Recommendations for Future Research}

These data suggest several interesting follow-up studies. Of course, crossvalidating the processes of change would be important. Then, development of better items representing the Pros of safer sex for self subscale would also be important. The loss of the pregnancy related items, combined with the overendorsement of the items used from the Prochaska et al. (1990) study left that scale lacking in terms of good items. Finally, a better staging algorithm should be developed in this area. It is possible that enough safer sex variability can be found using stages of condom use for both main and other partners (Grimley et al., 1992; Prochaska et al., 1990). Finally, longitudinal studies investigating the pros and cons, confidence, temptation, and process use across the stages of change over time would be very interesting and important. Further, studies which investigated the reciprocal influences of sexual partners in potentially different stages of change would be a welcome addition to the literature in this area. 
Table 7-1

Demographic Information on the entire sample $(\underline{\mathrm{N}}=352)$

$\begin{array}{lcc}\text { Sex } & \underline{N} & \underline{\text { Percent }} \\ \text { Female } & 191 & 54.3 \\ \text { Male } & 161 & 45.7 \\ \text { missing } & - & -\end{array}$

Age in years

$\underline{N}$

Percent

18

94

26.7

19

120

34.1

20

79

22.4

21

43

12.2

22

12

3.4

over 23

4

1.1

missing

Sexual Orientation

$\underline{\mathrm{N}}$

$\underline{\text { Percent }}$

Heterosexual

345

98.3

Homosexual/Gay

0

0.0

Bisexual

1

0.3

Don't know

5

1.4

missing

1

Table 7-1 continues next page 
Table 7-1 continued

$\begin{array}{lcc}\text { Marital Status } & \underline{\mathrm{N}} & \text { Percent } \\ \text { Single } & 346 & 98.6 \\ \text { Living Together } & 5 & 1.4 \\ \text { Married } & 0 & 0.0 \\ \text { Other } & 0 & 0.0 \\ \text { missing } & 1 & - \\ & & \\ \text { Ethnicity/Race } & \underline{\mathrm{N}} & \underline{\text { Percent }} \\ \text { Caucasian } & 323 & 91.8 \\ \text { Black } & 6 & 1.7 \\ \text { Hispanic } & 14 & 4.0 \\ \text { Asian } & 7 & 2.0 \\ \text { Indian } & 2 & 0.6 \\ \text { Other } & 0 & 0.0 \\ \text { missing } & - & -\end{array}$

Table 7-1 continues next page 
Table 7-1 continued

$\begin{array}{lcc}\text { Year in College } & \underline{\mathrm{N}} & \underline{\text { Percent }} \\ \text { Freshman } & 167 & 47.4 \\ \text { Sophomore } & 91 & 25.9 \\ \text { Junior } & 65 & 18.5 \\ \text { Senior } & 27 & 7.7 \\ \text { Non-degree seeking } & 2 & 0.6 \\ \text { Other } & 0 & 0.0 \\ \text { missing } & - & - \\ & & \\ \text { Religious Preference } & \underline{\mathbf{N}} & \underline{\text { Percent }} \\ \text { Catholic } & 226 & 64.2 \\ \text { Jewish } & 20 & 5.7 \\ \text { Protestant } & 53 & 15.1 \\ \text { Baptist } & 9 & 2.6 \\ \text { Other } & 44 & 12.5 \\ \text { missing } & - & -\end{array}$

Table 7-1 continues next page 
Table $7-1$ continued

$\begin{array}{lccc}\text { Yearly Income - Self } & \underline{N} & \text { Percent } \\ \text { less than } \$ 4,999 & 271 & 77.0 \\ \$ 5,000-9,999 & 70 & 19.9 \\ \$ 10,000-14,999 & 7 & 2.0 \\ \$ 15,000-29,999 & 4 & 1.2 \\ \$ 30,000 \text { or more } & 0 & 0.0 \\ \text { missing } & - & -\end{array}$

$\begin{array}{lcc}\text { Yearly Income - Family } & \underline{N} & \text { Percent } \\ \text { less than } \$ 4,999 & 3 & 0.9 \\ \$ 5,000-14,999 & 6 & 1.7 \\ \$ 15,000-24,999 & 14 & 4.1 \\ \$ 25,000-34,999 & 47 & 13.7 \\ \$ 35,000-44,999 & 53 & 15.4 \\ \$ 45,000-54,999 & 63 & 18.3 \\ \$ 55,000 \text { or more } & 158 & 45.9 \\ \text { missing } & 8 & -\end{array}$


Table 7-2

Sexual Behavior Frequencies (by percentages) on entire sample $(\underline{\mathrm{N}}=352)$

\begin{tabular}{|c|c|c|c|c|c|c|}
\hline$\underline{\text { Item }}$ & 1 & $\underline{2}$ & $\underline{3}$ & $\underline{4}$ & $\underline{5}$ & $\underline{\text { missing }}$ \\
\hline had beer or wine & 10.6 & 12.6 & 17.4 & 54.6 & 4.8 & - \\
\hline had hard liquor & 17.9 & 19.6 & 32.5 & 29.4 & 0.6 & - \\
\hline used illegal drugs & 55.7 & 19.9 & 12.9 & 9.2 & 2.2 & - \\
\hline shared I.V. needles & 100 & 0 & 0 & 0 & 0 & - \\
\hline received a blood transfusion & 97.8 & 2.0 & 0.3 & 0 & 0 & - \\
\hline wet kissed & 3.4 & 5.3 & 16.8 & 36.1 & 38.4 & - \\
\hline masturbated & 50.6 & 22.2 & 9.6 & 14.9 & 2.8 & - \\
\hline mutual genital touching & 12.1 & 13.0 & 20.3 & 44.9 & 9.6 & - \\
\hline \multicolumn{7}{|l|}{ had sex after } \\
\hline drinking alcohol & 32.9 & 25.8 & 25.3 & 14.9 & 1.1 & - \\
\hline had sex after using drugs & 74.2 & 13.2 & 6.4 & 5.6 & 0.6 & - \\
\hline \multicolumn{7}{|l|}{ received oral sex from my } \\
\hline partner & 23.0 & 21.6 & 25.0 & 28.4 & 2.0 & - \\
\hline \multicolumn{7}{|l|}{ performed oral sex } \\
\hline \multicolumn{7}{|l|}{ on a woman without } \\
\hline a latex barrier & 65.8 & 10.0 & 11.7 & 11.4 & 1.1 & - \\
\hline
\end{tabular}

Table 7-2 continues on next page 
Table 7-2 continued

performed oral sex

on a woman WITH

a latex barrier

$\begin{array}{lllll}94.9 & 1.4 & 2.3 & 1.4 & 0.0\end{array}$

performed oral sex on a man

without condoms

$\begin{array}{lllll}58.7 & 10.9 & 15.8 & 13.8 & 0.9\end{array}$

performed oral sex on a man

WITH condoms

$97.4 \quad 1.1$

1.1

0.3

0.0

had vaginal sex

without condoms

32.

20.2

$16.8 \quad 26.1$

4.5

had vaginal sex

WITH condoms

$\begin{array}{lllll}35.8 & 22.4 & 20.5 & 19.3 & 2.0\end{array}$

had anal sex

without condoms

88.

7.7

1.4

1.4

0.6

had anal sex

WITH condoms

93.3

4.8

1.4

0.6

0.0

used spermacide containing nonoxynol-9 with condoms 59.9 16.8 10.6

10.1

2.5

had sex with prostitute(s)

98.6

0.8

0.3

0.3

0.0

had sex with
I.V. drug user(s)
99.4
0.3
0.3
0.0
0.0

Note: 1 - Never, 2 - Rarely, 3 - Monthly, 4 - Weekly, 5 - Daily (See Appendix B). 
Table 7-3

MANOVA on sexual behavior means by original stages of change $(\underline{N}=284)$

$\begin{array}{lcccccc}\text { Item } & \underline{\mathrm{PC}} & \underline{\mathrm{C}} & \underline{\mathrm{A}} & \underline{\mathrm{M}} & \underline{\mathrm{F}}(3,276) & \eta^{2} \\ \text { \# partners ever } & 2.61 & 3.36 & 2.78 & 2.30 & 9.65^{*} & .095 \\ \text { \# partners past 6 mos. } & 1.22 & 1.83 & 1.43 & 1.17 & 12.32^{*} & .118 \\ \text { \# partners past 6 mos.WOC } & 1.22 & 1.36 & 1.06 & 0.81 & 7.47^{*} & .075 \\ \text { had beer or wine } & 3.06 & 3.62 & 3.55 & 3.30 & 2.82^{*} & .029 \\ \text { had hard liquor } & 2.28 & 2.96 & 2.96 & 2.79 & 2.78^{*} & .029 \\ \text { used illegal drugs } & 1.83 & 2.25 & 2.06 & 1.80 & 1.68 & . \\ \text { wet kissed } & 4.39 & 4.13 & 4.10 & 4.22 & 0.66 & - \\ \text { masturbated } & 2.00 & 2.02 & 2.02 & 1.99 & 0.49 & - \\ \text { mutual genital touching } & 3.83 & 3.48 & 3.39 & 3.47 & 0.77 & -\end{array}$

had sex after

$\begin{array}{lllllll}\text { drinking alcohol } & 2.67 & 2.73 & 2.45 & 2.31 & 2.88^{*} & .030\end{array}$

$\begin{array}{lllllll}\text { had sex after using drugs } & 1.44 & 1.73 & 1.55 & 1.46 & \cdot & 0.67\end{array}$

received oral sex

from my partner

$\begin{array}{llllll}3.56 & 2.81 & 2.86 & 2.80 & 2.64 * & .028\end{array}$

had vaginal sex

without condoms

$\begin{array}{llllll}3.89 & 3.15 & 2.35 & 2.53 & 10.69 * & .104\end{array}$

had vaginal sex

$\begin{array}{lllllll}\text { WITH condoms } & 1.39 & 2.33 & 2.82 & 2.55 & 7.81 * & .078\end{array}$

Table 7-3 continues on next page 
Table 7-3 continued

had anal sex

without condoms

$\begin{array}{llll}1.22 & 1.29 & 1.08 & 1.16\end{array}$

1.18

had anal sex

WITH condoms

$\begin{array}{llll}1.00 & 1.10 & 1.08 & 1.12\end{array}$

0.50

used spermacide containing nonoxynol-9 with condoms

$\begin{array}{llllll}1.11 & 1.58 & 2.10 & 1.97 & 5.27 * & .054 \\ 1.00 & 1.02 & 1.02 & 1.02 & 0.19 & - \\ 1.00 & 1.00 & 1.00 & 1.01 & 0.22 & -\end{array}$

had sex with $\begin{array}{llll}1.00 & 1.00 & 1.00 \quad 1.01\end{array}$

I.V. drug user(s)

Note: $\quad$ WOC - without condoms; PC - precontemplation ( $\underline{\mathrm{N}}=18)$;

$\mathrm{C}$ - contemplation ( $\underline{\mathrm{N}}=52) ; \mathrm{A}$ - action $(\underline{\mathrm{N}}=49)$; and $\mathrm{M}$ - maintenance $(\underline{N}=165)$. 
Table 7-4

MANOVA on sexual behavior with means and S.D.s by gender $(\underline{\mathrm{N}}=284)$

\section{MALES}

$$
(\underline{n}=128)
$$

Mean S.D. Mean $\underline{\text { S.D. }} \underline{\mathrm{F}}(1,276) \quad \eta^{2}$

2.86

1.51

$2.38 \quad 1.21$

$6.18 *$

1.46

0.77

1.24

0.64

3.66

0.96

0.86

1.00

0.64

0.06

without condoms

had beer or wine

3.59

1.00

3.21

1.06

$6.00 *$

.021

had hard liquor

$2.99 \quad 1.08$

2.68

1.04

$8.78^{*}$

.030

used illegal drugs

1.96

1.19

1.90

1.12

0.00

wet kissed

4.27

0.75

4.13

0.86

0.10

masturbated

2.56

1.33

1.54

0.87

$25.12 *$

$3.56 \quad 1.00$

3.42

1.06

0.62

had sex after

drinking alcohol

2.52

1.16

2.37

0.98

2.09

had sex after using drugs

1.55

0.96

1.51

0.91

0.13

received oral sex

from my partner

Table 7-4 continues on next page 
Table 7-4 continued

had vaginal sex

without condoms

$\begin{array}{lllll}2.58 & 1.29 & 2.80 & 1.22 & 0.03\end{array}$

had vaginal sex

WITH condoms

2.69

1.18

2.30

1.14

2.45

had anal sex

without condoms

1.16

0.54

1.19

0.59

0.19

had anal sex

WITH condoms

1.09

0.39

1.10

0.41

0.34

used spermacide containing

nonoxynol-9 with condoms

2.11

1.23

1.67

1.04

$4.03 *$

.014

had sex with prostitute(s)

1.02

0.15

1.01

0.16

0.90

had sex with I.V.drug

1.00

0.00

1.01

0.08

0.09

user(s) 
Table 7-5

Numbers of sexual partners during different time periods among sexually active subjects $(\underline{N}=305)$

Ever

Past 6 mos. $\quad$ Past 6 mos.

Without Condoms

\begin{tabular}{lcccccc} 
Number of Partners & $\underline{N}$ & Percent & $\underline{N}$ & $\underline{\text { Percent }}$ & $\underline{N}$ & $\underline{\text { Percent }}$ \\
none & - & - & 17 & 5.6 & 75 & 24.6 \\
1 & 74 & 24.3 & 188 & 61.6 & 168 & 55.1 \\
$2-3$ & 97 & 31.9 & 81 & 26.6 & 54 & 17.7 \\
$4-5$ & 47 & 15.5 & 15 & 4.9 & 6 & 2.0 \\
$6-10$ & 56 & 18.4 & 4 & 1.3 & 2 & 0.7 \\
$11-20$ & 22 & 7.2 & 0 & 0.0 & 0 & 0.0 \\
more than 21 & 8 & 2.6 & 0 & 0.0 & 0 & 0.0 \\
missing & 1 & - & - & - & - & - \\
& & & & & & \\
\hline
\end{tabular}


Table 7-6

Relationship characteristics among subjects in any relationship $(\underline{\mathrm{N}}=230)$

$\underline{\text { Sexual Exclusivity }}$

Exclusive

Mostly exclusive

Not exclusive

Don't know

missing

Relationship Duration

less than 1 month

1 - 3 months

4 - 6 months

$6-12$ months

more than 1 year

missing

Projected Future Duration

less than 1 month

1 - 3 months

4 - 6 months

6 - 12 months

more than 1 year

missing
N

184

32

7

21

2

$\underline{\mathrm{N}}$

14

19

26

57

128

2

$\underline{\mathrm{N}}$

20

18

13

20

173

2

\section{Percent} 75.4

13.1

2.9

8.6

Percent

5.7

7.8

10.7

23.4

52.5

Percent

8.2

7.4

5.3

8.2

70.9

Table 7-6 continues on next page 
Table 7-6 continued

\begin{tabular}{lcc} 
Number of other sexual & $\underline{N}$ & Percent \\
partners since start of this & & \\
relationship & 152 & 62.0 \\
none & 37 & 15.1 \\
1 - once & 22 & 9.0 \\
1 - more than once & & \\
more than 1 - & 32 & 13.1 \\
more than once & 1 & - \\
missing & & \\
Number of sexual partners & $\underline{N}$ & $\underline{\text { Percent }}$ \\
$\underline{\text { in past six months }}$ & & \\
none & 10 & 4.1 \\
1 & 163 & 66.5 \\
$2-3$ & 61 & 24.9 \\
4 - 5 & 8 & 3.3 \\
6 - 10 & 3 & 1.2 \\
\hline & & \\
\hline
\end{tabular}


Table 7-7

Reasons for primary abstinence as indicated by sexually abstinent subjects $(\underline{\mathrm{N}}=47)$

$\underline{\text { Possible Reasons }}$

I just don't have a partner now

Sex before marriage is against my

beliefs.

I want to avoid the risk of AIDS.

I haven't found the right partner yet.

I want to avoid the risk of pregnancy.

I'm not ready to have sex yet.

I want to avoid the risk of STD's.

My religion doesn't allow sex before marriage.

I'm just in between partners right now.
Mean

S.D.

Importance

2.85

1.63

2.88

1.55

4.15

1.22

4.00

1.48

4.20

1.09

3.29

1.52

4.00

1.34

2.76

1.59

1.63

1.26 


\section{Figure Captions}

Figure 7-1. Perceived risk across the Stages of Change. 
Perceived Risk by Stage of Change

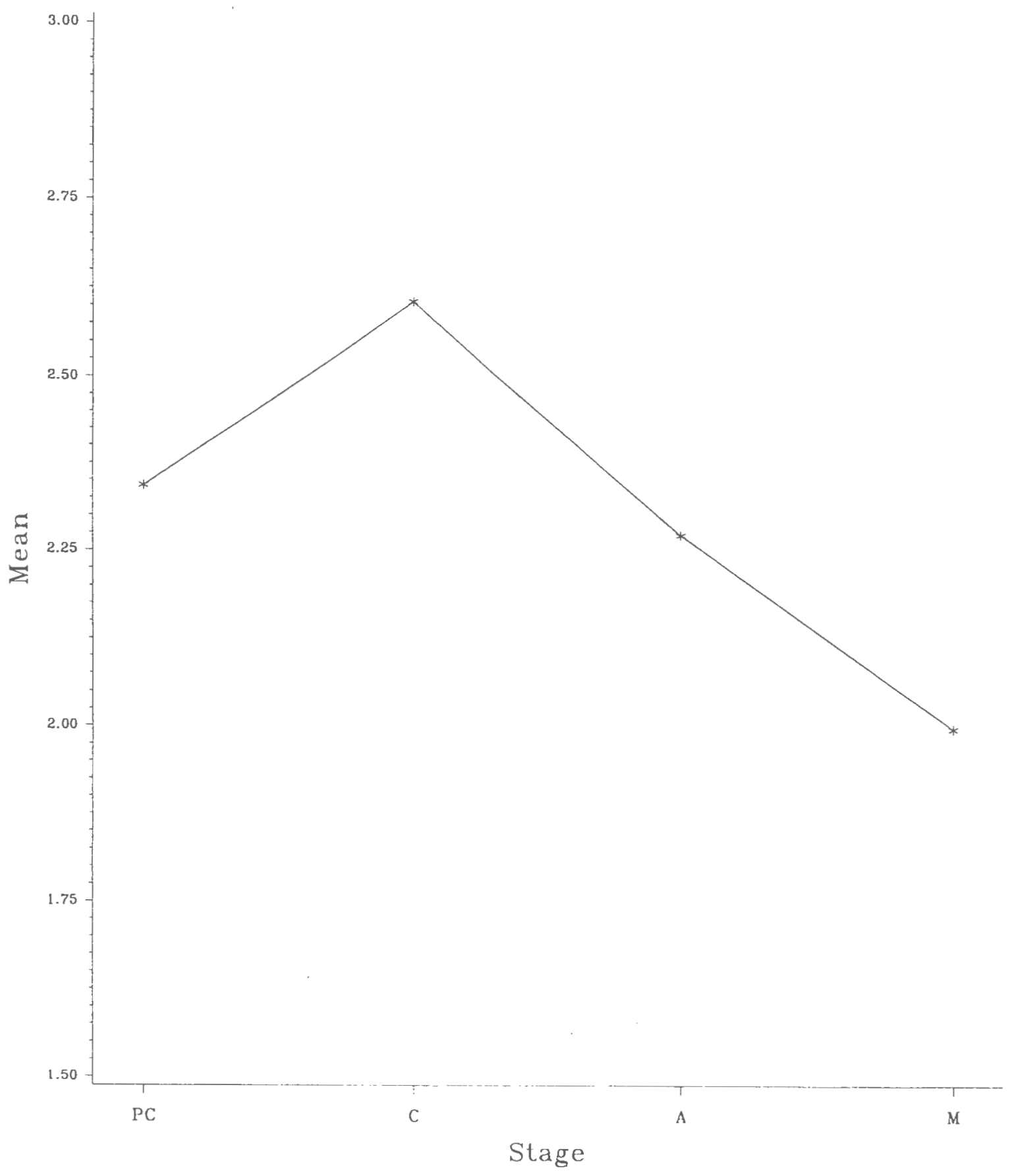


Dear Subject:

We are asking you to participate in a study of sexual decision making and development by filling out these questionnaires. Some of the questions are quite personal and have to do with parts of Iife which people have traditionally been hesitant to talk about or study. However, if social scientists are to help create a healthier environment and to help individuals change their behavior, more information is needed about the specific ways people think about and practice their sexuality, especially in relationship to AIDS. With this in mind, we hope you will decide to participate.

You are under no obligation to participate. Much as we would like your cooperation, you should feel free not to fill out a questionnaire. If at first you decide to participate and later change your mind, feel free to stop answering the questions at any point.

Your responses are anonymous and confidential. In order to ensure your privacy, we will not ask for your name or any other identifying information. All questionnaires will be guarded very carefully, with no one but the researchers having access to them.

If you have any questions, feel free to ask the researcher now or later about it. If you do not wish to participate, please leave the forms blank and return them.

It is also important that you be as honest as possible in completing these forms. Please complete them privately before returning them to the researcher.

Some of these questions may increase your curiousity about AIDS and its possible impact on the community and on you. For this reason, more information about AIDS and AIDS testing is available at the Rhode Island Department of Health toll free number: 1-(800)541-9977. U.R.I. Health Services (792-2246) also has information about AIDS and AIDS testing available here on campus.

Thank you for your time, consideration, and cooperation with this research project. Please feel free to keep this letter. If you have any questions or concerns, please contact me at the self Change Laboratory (792-2830). If you have decided to participate, the questionnaires begin on the next page.

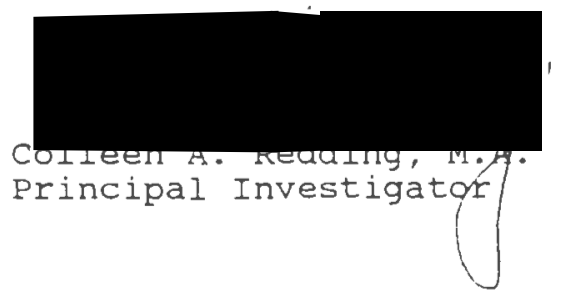




\section{Demographics Form}

Please complete and check the appropriate information below. If more than one category applies to you, check the most current and accurate one. If you are under 18 years old, DO NOT fill out these forms. Thank you.

1) Age:

- - years

2) Today's Date:

$$
\text { Mo. T' Day } / \text { Y } \overline{\text { ear }}
$$

3) Sex (Check one):

_ Female _ Male

4) Race/Ethnicity (Check one):

White _ Black _ Hispanic _ Asian _ Indian _ Other _

5) Year of University (Check one):

$$
\begin{aligned}
& \text { Freshman _ Sophomore _ Junior _ Senior _ Other _ } \\
& \text { Graduate Student _ N Non-degree-seeking student }
\end{aligned}
$$

6) Marital Status (Check one):

$$
\begin{array}{cc}
\text { Single _ } & \text { Married } \\
\text { Separated } & \text { Living Together } \\
\text { - Widowed } & \text { Divorced }
\end{array}
$$

7) Religion (Check one):

Catholic _ Jewish _ Protestant _ Baptist_ Other _

8) Approximate Yearly Personal Income:

$$
\begin{aligned}
& \text { _ Under } \$ 4,999 \quad \text { - } \$ 15,000-\$ 19,999 \\
& \text { - } \$ 5,000-\$ 9,999 \quad-\$ 20,000-\$ 29,999 \\
& \text { - } \$ 10,000-\$ 14,999 \quad \text { - over } \$ 30,000
\end{aligned}
$$

9) Approximate Yearly Family Income:

$$
\begin{array}{ll}
\quad \text { Under } \$ 4,999 & -\$ 25,000-\$ 34,999 \\
-\$ 5,000-\$ 14,999 & -\$ 35,000-\$ 44,999 \\
-\$ 15,000-\$ 24,999 & -\$ 45,000-\$ 54,999 \\
& -\quad \text { over } \$ 55,000
\end{array}
$$


For the purposes of this survey, safer sex is defined as at least one of the following:
A) Abstinence from vaginal and anal intercourse.
B) Condom use with all vaginal and anal sexual partners.
C) Sexually exclusive relationship with only one partner in the past year who has tested negative for HIV antibodies.

1) Do you currently practice safer sex as defined above?

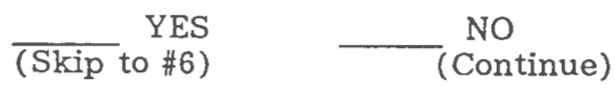

2) Are you thinking about practicing safer sex within the next six months? YES NO

3) Are you planning to practice safer sex within the next thirty days? YES N NO

4) Have you tried to practice safer sex in the last year?

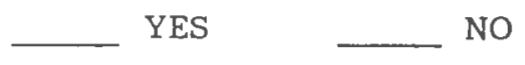

5) Check the way (s) in which you have tried to practice safer sex in the past year: (Note: If more than one of these, please number in order of priority.)
A) Abstinence from vaginal and anal intercourse.
B) Condom use with all vaginal and anal sexual partners.
C) Sexually exclusive relationship with one partner in the past year who has tested negative for HIV antibodies.
D) (write in)

6) Check the way(s) in which you now practice safer sex:

(Note: If more than one of these, please number in order of priority.)
A) Abstinence from vaginal and anal intercourse.
B) Condom use with all vaginal and anal sexual partners.
C) Sexually exclusive relationship with one partner in the past year who has tested negative for HIV antibodies.
D) None of the above - I do not practice safer sex. 
7) Check how long you have been practicing safer sex consistently:

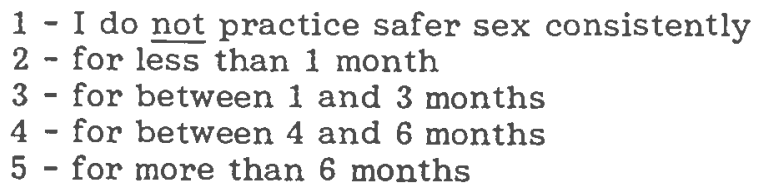

8) Check how long into the future you plan to continue practicing safer sex consistently:

1 - I do not practice safer sex consistently

2 - for less than 1 month

3 - for between 1 and 3 months

4 - for between 4 and 6 months

5 - for more than 6 months

If you abstain from vaginal and anal sex, then please continue.

If you do not abstain from vaginal and anal sex, then please check here and skip ahead to the next page.

I do not abstain from vaginal and anal sex.

(Skip ahead to next page)

To continue, rate how important the following considerations are TO YOU in your decision to abstain from vaginal and anal sex using the following 5-point scale:

$$
1 \text { = NOT AT ALL IMPORTANT } \ldots 5 \text { = VERY IMPORTANT }
$$

a) I just don't have a partner right now.

b) Sex before marriage is against my beliefs.

c) I want to aroid the risk of AIDS.

d) I haven't found the right partner yet.

e) I want to avoid the risk of pregnancy.

f) I'm not ready to have sex yet.

g) I want to avoid the risk of sexually transmitted diseases.

h) My religion doesn't allow sex before marriage.

i) I'm just in between partners right now.

\begin{tabular}{|c|c|c|c|c|}
\hline \multirow{2}{*}{\multicolumn{2}{|c|}{$\begin{array}{l}\text { WOT AT ALL } \\
\text { INPORTANT } \\
\downarrow\end{array}$}} & \multicolumn{3}{|c|}{$\begin{array}{r}\text { VERYY } \\
\text { IMPORTART }\end{array}$} \\
\hline & & & & \\
\hline 1 & 2 & 3 & 4 & 5 \\
\hline 1 & 2 & 3 & 4 & 5 \\
\hline 1 & 2 & 3 & 4 & 5 \\
\hline 1 & 2 & 3 & 4 & 5 \\
\hline 1 & 2 & 3 & 4 & 5 \\
\hline 1 & 2 & 3 & 4 & 5 \\
\hline 1 & 2 & 3 & 4 & 5 \\
\hline 1 & 2 & 3 & 4 & 5 \\
\hline 1 & 2 & 3 & 4 & 5 \\
\hline
\end{tabular}


For the purposes of this survey, safer sex is defined as at least one of the following:

A) Abstinence from vaginal and anal intercourse.

B) Condom use with all vaginal and anal sexual partners.

C) Sexually exclusive relationship with only one partner in the past year who has tested negative for HIV antibodies.

The following statements represent different opinions about safer sex. Please rate how important each item is to YOUR decision-making about practicing safer sex using the following 5-point scale:

$$
1=\text { NOT AT ALL IMPORTANT . . 5 = VERY IMPORTANT }
$$

1. I would feel safer.

\begin{tabular}{|c|c|c|c|}
\hline $\begin{array}{l}\text { rom } \\
\text { IDI } \\
1\end{array}$ & & & \\
\hline 1 & 2 & 3 & 4 \\
\hline 1 & 2 & 3 & 4 \\
\hline 1 & 2 & 3 & 4 \\
\hline 1 & 2 & 3 & 4 \\
\hline 1 & 2 & 3 & 4 \\
\hline 1 & 2 & 3 & 4 \\
\hline 1 & 2 & 3 & 4 \\
\hline 1 & 2 & 3 & 4 \\
\hline
\end{tabular}

8. My partner would be annoyed.

$\begin{array}{lllll}1 & 2 & 3 & 4 & 5\end{array}$

9. Talking about sex first would spoil the spontaneity. $\begin{array}{llllll}1 & 2 & 3 & 4 & 5\end{array}$

10. I would enjoy sex more.

$\begin{array}{lllll}1 & 2 & 3 & 4 & 5\end{array}$

11. I would have less freedom.

$\begin{array}{lllll}1 & 2 & 3 & 4 & 5\end{array}$

12. I would feel more responsible.

$\begin{array}{lllll}1 & 2 & 3 & 4 & 5\end{array}$

13. Sex would be less exciting.

$\begin{array}{lllll}1 & 2 & 3 & 4 & 5\end{array}$

14. It would make me feel closer to my partner.

$\begin{array}{lllll}1 & 2 & 3 & 4 & 5\end{array}$

15. My self-esteem would increase.

$\begin{array}{lllll}1 & 2 & 3 & 4 & 5\end{array}$

16. My partner would enjoy sex less.

$\begin{array}{lllll}1 & 2 & 3 & 4 & 5\end{array}$

17. Others would see me as more responsible.

$\begin{array}{lllll}1 & 2 & 3 & 4 & 5\end{array}$

18. Sex would be less enjoyable.

$\begin{array}{lllll}1 & 2 & 3 & 4 & 5\end{array}$

19. It would be embarrassing.

$\begin{array}{lllll}1 & 2 & 3 & 4 & 5\end{array}$

20. My partner would fear pregnancy less.

$\begin{array}{lllll}1 & 2 & 3 & 4 & 5\end{array}$

21. My partner would feel insulted.

$\begin{array}{lllll}1 & 2 & 3 & 4 & 5\end{array}$




$$
1 \text { = NOT AT ALL IMPORTANT .. 5 = VERY IMPORTANT }
$$

22. I would fear sexually transmitted diseases, like AIDS, less.

\begin{tabular}{|c|c|c|c|c|}
\hline $\begin{array}{l}\text { NO } \\
\text { IM } \\
!\end{array}$ & & & & $\begin{array}{r}\text { VERY } \\
\text { CANT } \\
!\end{array}$ \\
\hline 1 & 2 & 3 & 4 & 5 \\
\hline 1 & 2 & 3 & 4 & 5 \\
\hline 1 & 2 & 3 & 4 & 5 \\
\hline 1 & 2 & 3 & 4 & 5 \\
\hline 1 & 2 & 3 & 4 & 5 \\
\hline 1 & 2 & 3 & 4 & 5 \\
\hline 1 & 2 & 3 & 4 & 5 \\
\hline 1 & 2 & 3 & 4 & 5 \\
\hline 1 & 2 & 3 & 4 & 5 \\
\hline 1 & 2 & 3 & 4 & 5 \\
\hline 1 & 2 & 3 & 4 & 5 \\
\hline 1 & 2 & 3 & 4 & 5 \\
\hline 1 & 2 & 3 & 4 & 5 \\
\hline
\end{tabular}

34. It would promote trust. 
For the purposes of this survey, safer sex is defined as at least one of the following:

A) Abstinence from vaginal and anal intercourse.

B) Condom use with all vaginal and anal sexual partners.

C) Sexually exclusive relationship with only one partner in the past year who has tested negative for HIV antibodies.

Listed below are situations that affect some people's ability to have safer sex.

HOW CONFIDENT are you that you WOULD ENGAGE IN SAFER SEX in these situations, using the following 5 -point scale?:

1 = NOT AT ALL CONFIDENT . . 5 = VERY CONFIDENT

1. When I am affected by alcohol or drugs.

ROT AT RIS

CONFIDEMT

2. When I'm feeling angry.

3. When I feel really turned on.

4. When my partner looks safe to me.

$\downarrow$

5. When I am upset. 1

6. When my partner really wants to have risky sex.

7. When I am really sexually aroused.

8. When I think the risk is small.

9. When I am a little drunk or high.

10. When I am really lonely.

$\begin{array}{lllll}1 & 2 & 3 & 4 & 5\end{array}$

$\begin{array}{lllll}1 & 2 & 3 & 4 & 5\end{array}$

11. When my partner pressures me to take a chance this time.

12. When I really want sex.

$\begin{array}{lllll}1 & 2 & 3 & 4 & 5\end{array}$

13. When I am under the influence of alcohol or drugs.

14. When there's not much risk.

15. When I feel depressed.

$\begin{array}{lllll}1 & 2 & 3 & 4 & 5\end{array}$

16. When my partner is insulted that I want safer sex.

17. When I am really sexually excited.

$\begin{array}{llllll}1 & 2 & 3 & 4 & 5\end{array}$

18. When my partner gets annoyed about having safer sex.

$\begin{array}{lllll}1 & 2 & 3 & 4 & 5\end{array}$

$\begin{array}{lllll}1 & 2 & 3 & 4 & 5\end{array}$

$\begin{array}{lllll}1 & 2 & 3 & 4 . & 5\end{array}$

$\begin{array}{lllll}1 & 2 & 3 & 4 & 5\end{array}$

19. When the risk seems low.

20. When I have been partying.

$\begin{array}{lllll}1 & 2 & 3 & 4 & 5\end{array}$

$\begin{array}{lllll}1 & 2 & 3 & 4 & 5\end{array}$


For the purposes of this survey, safer sex is defined as at least one of the following:

A) Abstinence from vaginal and anal intercourse.

B) Condom use with all vaginal and anal sexual partners.

C) Sexually exclusive relationship with only one partner in the past year who has tested negative for HIV antibodies.

Listed below are situations that can affect safer sex. HOW TEMPTED WOULD YOU BE to have Unprotected Sex in these situations, using the following 5-point scale?:

$$
1 \text { = NOT AT ALL TEMPTED . . . } 5 \text { = VERY TEMPTED }
$$

1. When I am affected by alcohol or drugs.

\begin{tabular}{|c|c|c|c|c|}
\hline & & & & $\begin{array}{l}\text { UERY } \\
\text { PTED }\end{array}$ \\
\hline 1 & & & & 1 \\
\hline 1 & 2 & 3 & 4 & 5 \\
\hline 1 & 2 & 3 & 4 & 5 \\
\hline 1 & 2 & 3 & 4 & 5 \\
\hline 1 & 2 & 3 & 4 & 5 \\
\hline 1 & 2 & 3 & 4 & 5 \\
\hline
\end{tabular}

5. When I am upset. 5

6. When my partner really wants to have risky sex.

7. When I am really sexually aroused.

8. When I think the risk is small.

9. When I am a little drunk or high.

10. When I am really lonely.

11. When my partner pressures me to take a chance this time.

12. When I really want sex.

13. When I am under the influence of alcohol or drugs .

14. When there's not much risk.

15. When I feel depressed.

16. When my partner is insulted that I want safer sex.

17. When I am really sexually excited.

$\begin{array}{lllll}1 & 2 & 3 & 4 & 5\end{array}$

18. When my partner gets annoyed about having safer sex.

19. When the risk seems low.

20. When I have been partying.

$\begin{array}{lllll}1 & 2 & 3 & 4 & 5 \\ 1 & 2 & 3 & 4 & 5\end{array}$


For the purposes of this survey, "safer sex" is defined as at least one of the following:

A) Abstinence from vaginal and anal intercourse.

B) Condom use with all vaginal and anal sex partners.

C) Sexually exclusive relationship with only one partner in the past year who has tested negative for HIV antibodies.

The following experiences can affect some people's practice of safer sex. Think of any similar experiences you may be currently having or have had in the last month. Then rate the FREQUENCY of each event using the following 5-point scale:

$$
\begin{aligned}
& 1=\text { Never } \\
& 2=\text { Seldom } \\
& 3=\text { Occasional1y } \\
& 4=\text { Often } \\
& 5=\text { Repeated } 1 y
\end{aligned}
$$

1) I consider articles and ads about safer sexual practices.

2) I tell myself I can choose to have safer sex or not.

3) I consider that feeling content with myself includes changing my sexual habits to reduce my risk.

1

4) Articles describing risky sexual behaviors bother me.

1

5) When I insist on safer sex, I do something nice for myself.

1

3

6) Instead of unprotected sex, I engage in other physical activities.

2

3

4

$\downarrow$ 


$$
\begin{aligned}
& 1=\text { Never } \\
& 2=\text { Seldom } \\
& 3=\text { Occasionally } \\
& 4=\text { Often } \\
& 5=\text { Repeatedly }
\end{aligned}
$$

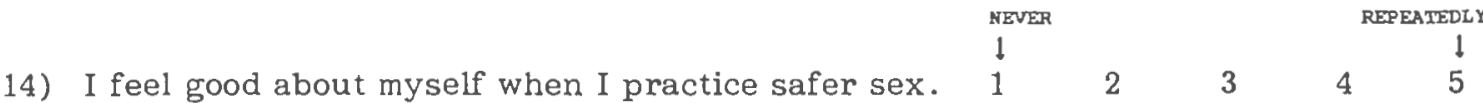

15) Dramatic portrayals of people with AIDS affect me emotionally.

16) I reward myself with something when I practice safer sex.

$\begin{array}{lllll}1 & 2 & 3 & 4 & 5\end{array}$

17) Instead of risky sex, I engage in other safer sexual activities.

18) I keep condoms available to remind me to use them. 1

19) I avoid sexual partners who might encourage me to have unsafe sex.

$\begin{array}{lllll}1 & 2 & 3 & 4 & 5\end{array}$

20) I have someone to count on when I need to talk about my sexual behavior.

$\begin{array}{lllll}1 & 2 & 3 & 4 & 5\end{array}$

21) I notice that safer sex is really accepted by most people.

22) I think the world would be a better place if more people practiced safer sex.

23) I think about information on safer sex.

24) I tell myself I can choose how I will have sex.

25) I feel bad about myself when I have risky sex. $\quad \begin{array}{llllll}1 & 2 & 3 & 4 & 5\end{array}$

26) Television stories about people with AIDS upset me. $\begin{array}{llllll}1 & 2 & 3 & 4 & 5\end{array}$

27) I am rewarded by others when I practice safer sex. $\begin{array}{llllll}1 & 2 & 3 & 4 & 5\end{array}$

28) When I have the urge to have risky sex, I stop and think about the health risks.

$\begin{array}{lllll}1 & 2 & 3 & 4 & 5\end{array}$

29) I keep condoms with me to remind me to practice safer sex.

$\begin{array}{lllll}1 & 2 & 3 & 4 & 5\end{array}$

30) I seek out social situations which promote safer sex. $1 \quad 2 \begin{array}{llll}2 & 3 & 4 & 5\end{array}$

31) I have someone I can count on to discuss safer sex with.

$\begin{array}{lllll}1 & 2 & 3 & 4 & 5\end{array}$

32) I notice that safer sex is discussed openly now. $\quad \begin{array}{lllllll}1 & 2 & 3 & 4 & 5\end{array}$

33) I think the world would be a better place if people developed healthier sexual habits.

$\begin{array}{lllll}1 & 2 & 3 & 4 & 5\end{array}$

34) I look for television shows about reducing the risk of exposure to AIDS.

$3 \quad 4 \quad 5$


$1=$ Never

35) I tell myself I can reduce my

$2=$ Seldom

$3=$ Occasionally

$4=$ Often

$5=$ Repeatedly

sexual risks if I want to.

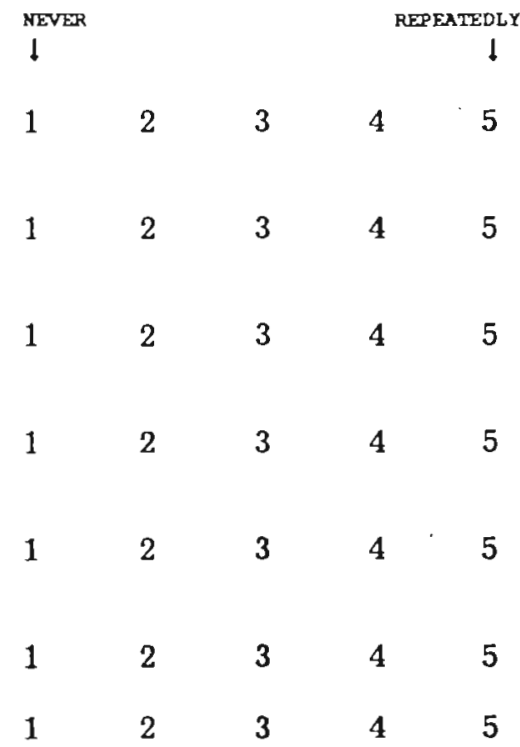

41) I seek out people who would encourage safer sex. $\begin{array}{lllllll}1 & 2 & 3 & 4 & 5\end{array}$

42) Special people in my life support

my practicing safer sex.

$\begin{array}{lllll}1 & 2 & 3 & 4 & 5\end{array}$

43) I notice people getting to know each other better before getting involved sexually.

$\begin{array}{lllll}1 & 2 & 3 & 4 & 5\end{array}$

44) I think about the view that society would be more responsible if more people practiced safer sex. $\begin{array}{llllll}1 & 2 & 3 & 4 & 5\end{array}$

45) I recall information people have given me on the risks of unprotected sex.

46) I make a commitment to practice safer sex.

$\begin{array}{lllll}1 & 2 & 3 & 4 & 5\end{array}$

47) I feel that being a responsible person includes my practicing safer sex.

$\begin{array}{lllll}1 & 2 & 3 & 4 & 5\end{array}$

48) I react emotionally when people ignore health warnings to avoid unsafe sex.

$\begin{array}{lllll}1 & 2 & 3 & 4 & 5\end{array}$

49) When I practice safer sex, I can expect to be praised by others.

$\begin{array}{lllll}1 & 2 & 3 & 4 & 5 \\ 1 & 2 & 3 & 4 & 5 \\ 1 & 2 & 3 & 4 & 5 \\ 1 & 2 & 3 & 4 & 5\end{array}$

53) I have someone I can trust when I need to talk about safer sex.

$\begin{array}{lllll}1 & 2 & 3 & 4 & 5\end{array}$




$$
\begin{aligned}
& 1=\text { Never } \\
& 2=\text { Seldom } \\
& 3=\text { Occasionally } \\
& 4=\text { Often } \\
& 5=\text { Repeatedly }
\end{aligned}
$$

NEVER

1

REPEATEDLY

54) I notice more couples are dating each

other exclusively.

55) I consider the view that my children deserve a safer sexual environment than

the one we currently live in.

56) I think about information on how to limit my exposure to AIDS.

57) I make a commitment to avoid risky sexual situations.

58) I feel it's important for me to practice safer sex, because I am a responsible, health-conscious person.

59) Articles about the risks of unprotected sex upset me.

60) People in my life try to make me feel good when I practice safer sex.$$
1
$$$$
2
$$

$$
3
$$

4$$
1
$$

2

3

4

$$
1
$$

2

3

4

3

5

61) When I am tempted to have risky sex, I think about the unhealthy consequences.

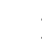

1

2

3

4

5

$\begin{array}{llllll}1 & 2 & 3 & 4 & 5\end{array}$

62) I avoid social situations which might tempt me to have unsafe sex.

63) I have someone to talk to when I want to talk about how to practice safer sex.

$\begin{array}{lllll}1 & 2 & 3 & 4 & 5 \\ 1 & 2 & 3 & 4 & 5 \\ 1 & 2 & 3 & 4 & 5\end{array}$

64) I notice few people having sex with more than one partner.

$\begin{array}{lllll}1 & 2 & 3 & 4 & 5\end{array}$

$\begin{array}{lllll}1 & 2 & 3 & 4 & 5\end{array}$

65) I consider that the world would be healthier if people practiced safer sex.

$\begin{array}{lllll}1 & 2 & 3 & 4 & 5\end{array}$

66) I tell myself that if I try hard enough, I can insist on safer sex.

$\begin{array}{lllll}1 & 2 & 3 & 4 & 5 \\ 1 & 2 & 3 & 4 & 5 \\ 1 & 2 & 3 & 4 & 5 \\ 1 & 2 & 3 & 4 & 5 \\ 1 & 2 & 3 & 4 & 5\end{array}$

67) People in my life would be upset if they knew I had risky sex.

68) I would not continue to date anyone who might push me to have unsafe sex.

69) I have someone I can rely on to support my decision to develop healthier sexual habits.

70) I notice condoms being sold in many places.

5




$$
\begin{aligned}
& 1=\text { Never } \\
& 2=\text { Seldom } \\
& 3=\text { Occasionally } \\
& 4=\text { Often } \\
& 5=\text { Repeatedly }
\end{aligned}
$$

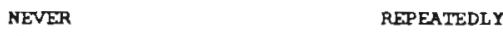$$
2
$$$$
3
$$
about my practicing safer sex.

72) I seek out sexual partners who would encourage safer sex.

73) I have someone I can count on to support my decision to practice safer sex.

74) I notice condom use being discussed openly.

75) I avoid social situations which encourage unsafe sex.

$\begin{array}{lllll}1 & 2 & 3 & 4 & 5\end{array}$

$\begin{array}{lllll}1 & 2 & 3 & 4 & 5\end{array}$

$\begin{array}{lllll}1 & 2 & 3 & 4 & 5\end{array}$

$\begin{array}{lllll}1 & 2 & 3 & 4 & 5\end{array}$


Below are some behaviors which may expose someone to the AIDS virus. Please rate HOW LIKELY you believe EXPOSURE TO AIDS would be for the AVERAGE URI STUDENT if they engaged in the following behaviors using this 5 -point scale:

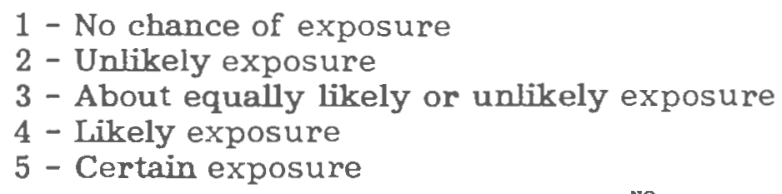

1) unprotected sex with someone who has AIDS

HO

$\downarrow$

2) unprotected sex with an IV drug user

3) unprotected sex with a prostitute

4) unprotected sex with several partners in one week

1

12

1

5) unprotected sex with several partners in six months

6) unprotected sex with someone known

7) unprotected sex with someone unknown

8) oral sex on a man without a condom

9) oral sex on a woman

10) vaginal sex using a condom

11) anal sex using a condom

12) Sharing IV needles

13) Receiving blood transfusion

14) Donating blood

15) Wet kissing

16) Being bitten by a mosquito

17) Shaking hands with an AIDS patient

CBANCB

CERTAIN
$\frac{1}{5}$

3

5

5

5

5

$\begin{array}{llllll}1 & 2 & 3 & 4 & 5\end{array}$

$\begin{array}{lllll}1 & 2 & 3 & 4 & 5\end{array}$

$\begin{array}{lllll}1 & 2 & 3 & 4 & 5\end{array}$

$\begin{array}{lllll}1 & 2 & 3 & 4 & 5\end{array}$

$\begin{array}{lllll}1 & 2 & 3 & 4 & 5\end{array}$

$\begin{array}{llllll}1 & 2 & 3 & 4 & 5\end{array}$

$\begin{array}{lllll}1 & 2 & 3 & 4 & 5\end{array}$

$\begin{array}{lllll}1 & 2 & 3 & 4 & 5\end{array}$

$\begin{array}{llllll}1 & 2 & 3 & 4 & 5\end{array}$

$\begin{array}{lllll}1 & 2 & 3 & 4 & 5\end{array}$

$\begin{array}{lllll}1 & 2 & 3 & 4 & 5\end{array}$

$\begin{array}{lllll}1 & 2 & 3 & 4 & 5\end{array}$

$\begin{array}{lllll}1 & 2 & 3 & 4 & 5\end{array}$


Below are some behaviors which may expose someone to the AIDS virus. Please rate HOW LIKELY you believe EXPOSURE TO AIDS would be for YOU if you engaged in the following behaviors using this 5 -point scale:

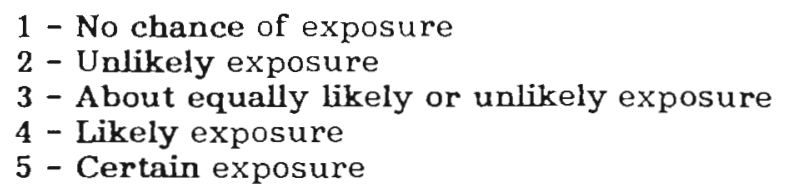

1) unprotected sex with someone who has AIDS

no

2) unprotected sex with an IV drug use

3) unprotected sex with a prostitute

1

1

4) unprotected sex with

several partners in one week

$\begin{array}{lllll}1 & 2 & 3 & 4 & 5\end{array}$

5) unprotected sex with several partners in six months

6) unprotected sex with someone known

$\begin{array}{lllll}1 & 2 & 3 & 4 & 5 \\ 1 & 2 & 3 & 4 & 5 \\ 1 & 2 & 3 & 4 & 5 \\ 1 & 2 & 3 & 4 & 5\end{array}$

8) oral sex on a man without a condom

9) oral sex on a woman

10) vaginal sex using a condom

$1 \quad 2 \quad 3 \quad 4: 5$

11) anal sex using a condom

$\begin{array}{lllll}1 & 2 & 3 & 4 & 5\end{array}$

12) Sharing IV needles

$\begin{array}{lllll}1 & 2 & 3 & 4 & 5\end{array}$

13) Receiving blood transfusion

1

14) Donating blood

$\begin{array}{llllll}1 & 2 & 3 & 4 & 5\end{array}$

15) Wet kissing

16) Being bitten by a mosquito

17) Shaking hands with an AIDS patient

$\begin{array}{lllll}1 & 2 & 3 & 4 & 5 \\ 1 & 2 & 3 & 4 & 5\end{array}$


1. How long have you been involved with your main sexual partner?

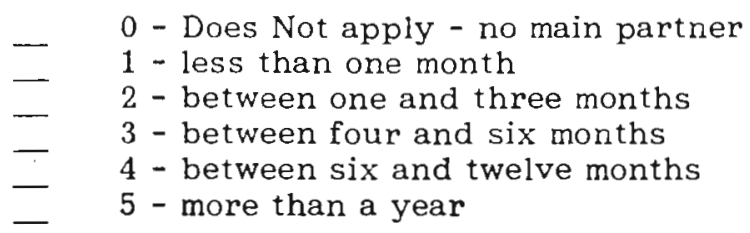

2. How far into the future do you expect to be involved with your main sexual partner?

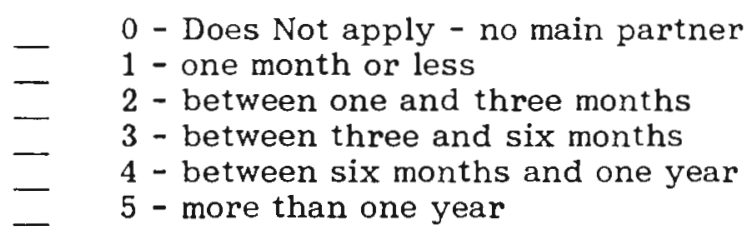

3. How exclusive would you say your main relationship is?
- $\quad 0$ - Does not apply - no main partner
- 1 - Don't know (We have no agreement about exclusiveness.)
- $\quad 2$ - Not exclusive (We allow sex with other partners.)
- 3 - Mostly exclusive (We agree we can date others, but no sex.)

4. Have you ever had an (AIDS) HIV blood test ?

$$
\begin{aligned}
& 1 \text { - NO } \\
& 2 \text { - YES }
\end{aligned}
$$

5. Has your main sexual partner ever had an (AIDS) HIV blood test ?

$$
\begin{aligned}
& 0 \text { - Does Not apply - no main partner } \\
& -1 \text { - NO } \\
& -2 \text { - YES } \\
& -3 \text { - Don't know }
\end{aligned}
$$

6. Have you ever had vaginal sex (intercourse)?

$$
\begin{aligned}
& 1 \text { - NO } \\
& -2 \text { - YES }
\end{aligned}
$$

7. Have you ever had anal sex ?

$$
\begin{aligned}
& 1 \text { - NO } \\
& -2-\text { YES }
\end{aligned}
$$

8. What do you consider yourself?

$$
\begin{aligned}
& \text { Heterosexual (Straight) } \\
& \text { - Homosexual (Gay/Lesbian) } \\
& \text { Bisexual } \\
& \text { - Not Sure - Don't know }
\end{aligned}
$$


9. Check ONE of the following which best describes your

MAIN method of preventing pregnancy:

Birth Control Pills

Condoms

— Condoms with Spermacide

- Spermacide only

- Sponge with Spermacide

— Diaphragm with Spermacide

- I.U.D.

Withdrawal

- Abstinence from intercourse

- OTHER

10. Check ALL of the following which you (or your partner) have EVER used to prevent pregnancy:

Birth Control Pills

_ Condoms

_ Condoms with Spermacide

- Spermacide only

- Sponge with Spermacide

- Diaphragm with Spermacide

I.U.D.

Withdrawal

- Abstinence from intercourse

- OTHER

11. Since you've been involved in your main relationship, how many times have you ever had sex with someone else other than your main partner?

Does not apply - no main partner

Never

- Once with one other person

- More than once with only one other person

- More than once with several other people

12. How many sexual partners have you have EVER had:

none

- 1

$-2-3$

$-4-5$

- $6-10$

- $11-20$

- more than 21

13. How many sexual partners have you had in the PAST SIX MONTHS:

none
-1
$-2-3$
$-4-5$
$-6-10$
$-11-20$
- more than 21 
14. How many sexual partners have you have had vaginal or anal sex with without condoms in the PAST SIX MONTHS:

$$
\begin{aligned}
& \text { none } \\
& =1 \\
& -2-3 \\
& =4-5 \\
& =6-10 \\
& =11-20 \\
& =\text { more than } 21
\end{aligned}
$$

15. Have you ever received oral sex from a man (his mouth on your genitals)?

1 - NO
2 - YES

16. Have you ever received oral sex from a woman (her mouth on your genitals)?

1 - NO
$2-$ YES

17. Have you ever performed oral sex on a man (your mouth on his genitals)?

1 - NO
$2-\mathrm{YES}$

18. Have you ever performed oral sex on a woman (your mouth on her genitals)?

1 - NO
$2-$ YES 
19. Circle the HOW OFTEN you have performed the following behaviors during

the PAST SIX MONTHS using this 5 -point scale:

$$
\begin{aligned}
& 1 \text { - Never } \\
& 2 \text { - Rarely } \\
& 3 \text { - Monthly } \\
& 4 \text { - Weekly } \\
& 5 \text { - Daily }
\end{aligned}
$$

had beer or wine

$\begin{array}{lllll}\text { NEVER } & \text { RARELY } & \text { MONTHLY } & \text { KEEKK,Y } & \text { DAILY } \\ \downarrow & 1 & \downarrow & \downarrow & \downarrow \\ 1 & 2 & 3 & 4 & 5\end{array}$

had hard liquor

used "illegal" drugs

$\begin{array}{lllll}1 & 2 & 3 & 4 & 5\end{array}$

used I.V. drugs

shared I.V. needles

received a blood transfusion

$$
1
$$

1

wet kissed

masturbated

mutual genital touching

had sex after drinking alcohol

had sex after using drugs

received oral sex from my partner

performed oral sex on a woman

without a latex barrier

1

performed oral sex on a woman

WITH a latex barrier

performed oral sex on a man

without condoms

$\begin{array}{lllll}1 & 2 & 3 & 4 & 5\end{array}$

$\begin{array}{lllll}1 & 2 & 3 & 4 & 5\end{array}$

$\begin{array}{lllll}1 & 2 & 3 & 4 & 5\end{array}$

performed oral sex on a man

WITH condoms

had vaginal sex without condoms

had vaginal sex WITH condoms

had anal sex without condoms

had anal sex WITH condoms

used spermacide containing

nonoxynol-9 with condoms

had sex with prostitute(s)

1

1

2

$\begin{array}{lllll}1 & 2 & 3 & 4 & 5\end{array}$

$\begin{array}{lllll}1 & 2 & 3 & 4 & 5\end{array}$

$\begin{array}{llllll}1 & 2 & 3 & 4 & 5\end{array}$

$\begin{array}{lllll}1 & 2 & 3 & 4 & 5\end{array}$

had sex with I.V. drug user(s)

$\begin{array}{lllll}1 & 2 & 3 & 4 & 5\end{array}$

$\begin{array}{lllll}1 & 2 & 3 & 4 & 5\end{array}$

$\begin{array}{lllll}1 & 2 & 3 & 4 & 5\end{array}$




\section{Survey}

1) How severe a disease is AIDS?

$$
\begin{aligned}
& 1 \text { - not at all severe } \\
& 2 \text { - slightly severe } \\
& 3 \text { - moderately severe } \\
& 4 \text { - very severe } \\
& 5 \text { - extremely severe }
\end{aligned}
$$

2) How severe a disease would AIDS be for you if you got it?

$$
\begin{aligned}
& 1 \text { - not at all severe } \\
& 2 \text { - slightly severe } \\
& 3 \text { - moderately severe } \\
& 4 \text { - very severe } \\
& 5 \text { - extremely severe }
\end{aligned}
$$

3) How susceptible are you to AIDS?

$$
\begin{aligned}
& 1 \text { - not at all susceptible } \\
& 2 \text { - slightly susceptible } \\
& 3 \text { - moderately susceptible } \\
& 4 \text { - very susceptible } \\
& -5 \text { - extremely susceptible }
\end{aligned}
$$

4) How much risk does AIDS pose for you?

$$
\begin{array}{ll}
1 \text { - }- \text { no risk at all } \\
2 \text { - slight risk } \\
3 \text { - moderate risk } \\
4 \text { - very much risk } \\
5 \text { - extreme risk }
\end{array}
$$

5) How much risk does AIDS pose for the average URI student?

$$
\begin{array}{ll}
- & 1 \text { - no risk at all } \\
- & 2 \text { - slight risk } \\
& 3 \text { - moderate risk } \\
-\quad & 4 \text { - very much risk } \\
\square & 5 \text { - extreme risk }
\end{array}
$$

6) How important to you is reducing your risk of AIDS?

$$
\begin{aligned}
& 1 \text { - not important at all } \\
& 2 \text { - slight important } \\
& 3 \text { - moderately important } \\
& 4 \text { - very important } \\
& 5 \text { - extremely important }
\end{aligned}
$$

7) How important to the average URI student is reducing AIDS risk?

$$
\begin{aligned}
& 1 \text { - not important at all } \\
& 2 \text { - }- \text { slight important } \\
& 3 \text { - moderately important } \\
& \quad 4 \text { - very important } \\
& -\quad 5 \text { - extremely important }
\end{aligned}
$$




\section{Questionnaire J}

Following is a list of statements each of which may or may not be true about you. For each statement, please circle the most appropriate response using the following 5-point scale:

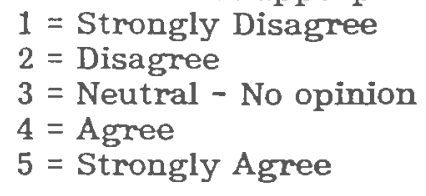

1) I always try to be considerate of the feelings of my friends.

$\begin{array}{ll}\text { STRONGLYY } & \text { STRONG } Y \\ \text { DISAGREE } & \text { ARREB } \\ 1 & 1\end{array}$

2) Nothing that happens to me makes much difference one way or the other.

$\begin{array}{lllll}1 & 2 & 3 & 4 & 5\end{array}$

3) I of ten take some responsibility for looking out for newcomers in a group.

4) I have a number of health problems.

5) In the long run, humanity will owe a lot more to the teacher than to the salesperson.

$\begin{array}{ccccc}1 & 2 & 3 & 4 & 5 \\ 1 & 2 & 3 & 4 & 5 \\ 1 & 2 & 3 & 4 & 5\end{array}$

6) I often have the feeling that I am doing something evil.

7) I am seldom ill.

8) I almost always feel sleepy and lazy.

9) My memory is as good as other people's.

10) I am not willing to give up my own privacy or pleasure in order to help other people.

11) Most of my teachers were helpful.

12) We ought to let the rest of the world solve their own problems and just look out for ourselves.

13) My life is full of interesting activities.

14) I of ten question whether life is worthwhile.

15) I am able to make correct decisions on difficult questions.

$\begin{array}{lllll}1 & 2 & 3 & 4 & 5 \\ 1 & 2 & 3 & 4 & 5 \\ 1 & 2 & 3 & 4 & 5 \\ 1 & 2 & 3 & 4 & 5 \\ 1 & 2 & 3 & 4 & 5 \\ 1 & 2 & 3 & 4 & 5\end{array}$

16) I believe people tell lies any time it is to their advantage.

$\begin{array}{lllll}1 & 2 & 3 & 4 & 5\end{array}$

$\begin{array}{lllll}1 & 2 & 3 & 4 & 5\end{array}$

$\begin{array}{lllll}1 & 2 & 3 & 4 & 5\end{array}$

17) Rarely, if ever, has the sight of food made me ill. $\begin{array}{lllllll}1 & 2 & 3 & 4 & 5\end{array}$

18) I find it difficult to concentrate. $\quad \begin{array}{llllll} & 1 & 2 & 3 & 4 & 5\end{array}$

19) I am always prepared to do what is expected of me. $\begin{array}{llllll}1 & 2 & 3 & 4 & 5\end{array}$

20) Many things make me uneasy. $\quad \begin{array}{llllll} & 1 & 2 & 3 & 4 & 5\end{array}$ 
Appendix C

Original Safer Sex Staging Algorithm

Stage

$\begin{array}{llll}\text { Question\# } & 1 & 2 & 3\end{array}$

4

7

\begin{tabular}{lccccc}
\hline Precontemplation & No & No & No & - & - \\
Contemplation & No & Yes & No & - & - \\
Preparation & No & Yes & Yes & Yes & - \\
Action & Yes & - & - & - & $2-4$ \\
Maintenance & Yes & - & - & - & 5 \\
\hline
\end{tabular}

Proposed Safer Sex Staging Algorithm

$\begin{array}{llllllll}\text { Stage } & \text { Question\# } & 1 & 2 & 3 & 4 & 7 & \text { Part6woc }\end{array}$

Precontemplation No No No -

Contemplation No Yes No

Preparation ? Yes Yes Yes $\leq 1$

Action Yes - $\quad$ - $\quad$ - $2-4$

Maintenance (A or C) Yes $\quad-\quad\left[\begin{array}{lllll} & - & 5 & 0\end{array}\right.$

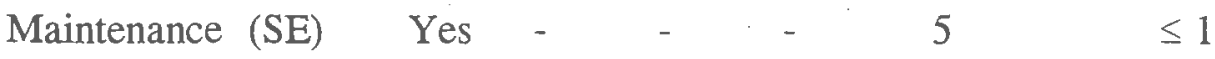

Note: Part6woc indicates the number of sexual partners in the last 6 months with whom the subject did not use condoms. 
Appendix D

Verbatim Responses to Qualitative Question:

Whether subject tried another strategy to practice safer sex

- sexually exclusive relationship with one partner who was,

prior to me, a virgin

- relationship for the last year whom I knew didn't have an HIV virus

- birth control pill

- one partner, but who hasn't been tested

- my girlfriend used the pill - I would also pull out

- birth control

- use of pill and condom

- Find low risk partners

- sexually exclusive relationship with one partner in past year, but neither of us has been tested for HIV antibodies.

- the pill

- I am in a sexually exclusive relationship with one partner for over one year

- exclusive relationship but my partner has not been tested

- condom use sometimes

- partner hasn't been tested \& birth control

- sex with one partner - usually use a condom; I take birth control pills

- exclusive relationship with one partner, but he has not been tested

- sexual exclusivity, yes, but I haven't made them get a test

- condom use with vaginal S.P. 
- my girlfriend is on pill

- exclusive relationship with partner for years

- did not have sex 


\section{BIBLIOGRAPHY}

Abraham, C., Sheeran, P., Spears, R., Abrams, D. (1992). Health beliefs and promotion of HIV-preventive intentions among teenagers: A Scottish perspective. Health Psychology, 11, 363-370.

Ahijevych, K., \& Wewers, M.E. (1992). Processes of change across five stages of smoking cessation. Addictive Behaviors, 17, 17-25.

Allen, J.R., \& Curran, J.W. (1988). Prevention of AIDS and HIV infection:

Needs and priorities for epidemiologic research. American Journal of Public Health, $\underline{78}, 381-386$.

Ankrah, E.M. (1989). AIDS: Methodological problems in studying its prevention and spread. Social Science and Medicine, 29, 265-276.

Aral, S.O., \& Holmes, K.K. (1991). Sexually transmitted diseases in the AIDS era. Scientific American, 264, 62-69.

Baldwin, J.D. \& Baldwin, J.I. (1988). Factors affecting AIDS-related sexual risk-taking among college students. The Journal of Sex Research, 25, 181-196.

Bandura, A. (1977). Self-efficacy: Toward a unifying theory of behavioral change. Psychological Review, $\underline{84}, 191-215$.

Bandura, A. (1982). Self-efficacy mechanism in human agency. American Psychologist, $\underline{37}, 122-147$.

Bandura, A. (1986). Social foundations of thought and action: A social cognitive theory. Prentice Hall, Inc.: New Jersey.

Baranowski, T. (1990). Reciprocal determinism at the Stages of behavior change: An integration of community, personal and behavioral perspectives. International Quarterly of Community Health Education, 10, 297-327. 
Becker, M.H. (Ed.) (1974). The health belief model and personal health behavior. Health Education Monograph, 2, 324-508.

Becker, M.H., \& Joseph, J.G. (1988). AIDS and behavioral change to reduce risk: A review. American Journal of Public Health, $\underline{78}, 394-410$.

Begin, A. (1989). Levels of attributions of male alcoholics, their significant others and their therapists during the course of inpatient alcohol rehabilitation. Unpublished doctoral dissertation, University of Rhode Island, Kingston, RI.

Bellis, J.M., Rossi, J.S., \& Prochaska, J.O. (1990, August) $\underline{\text { Structural }}$ invariance of the processes of change. Paper presented at the 98th annual conference of the American Psychological Association, Boston, MA.

Bellis, J.M. (1993). The transtheoretical model of change applied to psychotherapy: A psychometric assessment of related instruments. Unpublished doctoral dissertation, University of Rhode Island, Kingston, RI.

Bentler, P.M. (1989). EQS: Structural Equations Program Manual, Los Angeles, CA: BMDP Statistical Software, Inc.

Bentler, P.M. (1990). Comparative fit indexes in structural models. Psychological Bulletin, 107, 238-246.

Bentler, P.M., \& Bonett, D.G. (1980). Significance tests and goodness of fit in the analysis of covariance structures. Psychological Bulletin, $\underline{88}, 588-606$.

Betz, N.E. (1987). Use of discriminant analysis in counseling psychology research. Journal of Counseling Psychology, 34, 393-403.

Biglan, A., Metzler, C.W., Wirt, R., Ary, D., Noell, J., Ochs, L., French, C., \& Hood, D. (1990). Social and behavioral factors associated with high-risk sexual behavior among adolescents. Joumal of Behavioral Medicine, 13, 245-261. 
Birkett, N.J., Hotz, S., \& O'Hollaren, J. (1992). Dietary fat reduction: challenges in applying the stages of change model. Manuscript submitted for publication.

Blais, L.M., \& Rossi, J.S. (1990, August) Precautionary sun exposure behaviors: A comparison of early adopters and non-adopters. Paper presented at the 98th annual conference of the American Psychological Association, Boston, MA.

Bollen, K.A. (1989). Structural equations with latent variables. New York: Wiley.

Bowen, M. (1978). Family theory in clinical practice. New. York: Jason Aronson.

Brandt, A.M. (1988). AIDS in historical perspective: Four lessons from the history of sexually transmitted diseases. American Journal of Public Health, $\underline{78}$, $367-371$.

Brooks-Gunn, J., Boyer, C.B., \& Hein, K. (1988). Preventing HIV infection and AIDS in children and adolescents. American Psychologist, 43, 958-964.

Brownell, K.D., Marlatt, G.A., Lichtenstein, E., \& Wilson, G.T. (1986). Understanding and preventing relapse. American Psychologist, 41, 765-782.

Buffam, J. (1988). Substance abuse and high-risk sexual behavior: Drugs and sex -- the dark side. Journal of Psychoactive Drugs, 20, 165-168.

Burger, J.M. \& Inderbitzen, H.M. (1985). Predicting contraceptive behavior among college students: The role of communication, knowledge, sexual anxiety, and self-esteem. Archives of Sexual Behavior, 14, 343-350. 
Catania, J.A., Coates, T.J. \& Kegeles, S. (1993, March) AIDS-related behavior change among heterosexual adults: Testing the AIDS Risk Reduction Model. Paper presented at the 14th annual meeting of the Society of Behavioral Medicine in San Francisco, CA.

Catania, J.A., Coates, T.J., Stall, R., Turner, H., Peterson, J., Hearst, N., Dolcini, M., Hudes, E., Gagnon, J., Wiley, J., \& Groves, R. (1992). Prevalence of AIDS-related risk factors and condom use in the United States. Science, 258, 1101 1106.

Catania, J.A., Gibson, D.R., Chitwood, D.D., \& Coates, T.J. (1990). Methodological problems in AIDS behavioral research: Influences on measurement error and participation bias in studies of sexual behavior. Psychological Bulletin, $\underline{108}, 339-362$.

Catania, J.A., Kegeles, S.M., \& Coates, T.J. (1990). Towards an understanding of risk behavior: An AIDS Risk Reduction Model (ARRM). Health Education Quarterly, 17, 53-72.

CDC (1992). HIV/AIDS Surveillance Report, October, 1-18.

CDC (1992). HIV/AIDS Prevention Newsletter, $\underline{3}(3), 1-18$.

CDC (1992). A conceptual framework for evaluating behavior change.

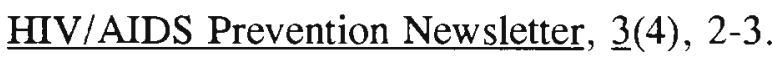

CDC (1992). Selected behaviors that increase risk for HIV infection, other sexually transmitted diseases, and unintended pregnancy among high school students - United States, 1991. Morbidity and Mortality Weekly Report, 41(50), 945-950.

Clapper, R.L. \& Lipsitt, L.P. (1991). A retrospective study of risk-taking and alcohol-mediated unprotected intercourse. Journal of Substance Abuse, $\underline{3}$, 91-96. 
Clark, M.M., Abrams, D.B., Niaura, R.S., Eaton, C.A., \& Rossi, J.S. (1991). Self-efficacy in weight management. Journal of Consulting and Clinical Psychology, 59, 739-744.

Coates, T.J. (1990). Strategies for modifying sexual behavior for primary and secondary prevention of HIV disease. Journal of Consulting and Clinical Psychology, 모, 57-69.

Cochran, S.D., \& Mays, V.M. (1989). Women and AIDS-related concerns. American Psychologist, 44, 529-535.

Comrey, A.L. (1988). Factor-Analytic methods of scale development in Personality and Clinical Psychology. Journal of Consulting and Clinical Psychology, 56, 754-761.

Condiotti, M.M., \& Lichtenstein, E. (1981). Self-efficacy and relapse in smoking cessation programs. Journal of Consulting and Clinical Psychology, $\underline{49}$, 648-658.

Crawford, J., Turtle, A., \& Kippax, S. (1990). Student-favoured strategies for AIDS avoidance. Australian Journal of Psychology, 42, 123-137.

Cummings, K.M., Jette, A.M., \& Rosenstock, I.M. (1978). Construct validation of the Health Belief Model. Health Education Monographs, $\underline{6}$, 394-405. I Curry, S.J., Kristal, A.R., \& Bowen, D.J. (1992). An application of the Stage Model of Behavior Change to Dietary Fat Reduction. Health Education Research: Theory \& Practice, 7, 95-105.

Dawson, D.A. (1986). The effects of sex education on adolescent behavior. Family Planning Perspectives, $\underline{18}, 162-170$. 
DiClemente, C.C. (1986). Self-efficacy and the addictive behaviors. Journal of Social and Clinical Psychology, 4, 302-315.

DiClemente, C.C. (1991). Motivational interviewing and the stages of behavior change. In Miller, W.R., \& Rollnick, S. (eds.) Motivational interviewing: Preparing people to change addictive behavior. New York, NY: Guilford Press. pp. 191-202.

DiClemente, C.C., \& Hughes, S. (1990). Stages of change profiles in outpatient alcoholism treatment. Journal of Substance Abuse, 2 2, 217-235.

DiClemente, C.C., Prochaska, J.O., Fairhurst, S., Velicer, W.F., Velasquez, M., \& Rossi, J.S. (1991). The process of smoking cessation: An analysis of precontemplation, contemplation and preparation stages of change. Journal of Consulting and Clinical Psychology, 59, 295-304.

DiClemente, C.C., Prochaska, J.O., \& Gilbertini, M. (1985). Self-efficacy and the stages of self-change of smoking. Cognitive Therapy and Research, $\underline{9}, 181$ 200.

DiClemente, R.J., Boyer, C.B., \& Morales, E.S. (1988). Minorities and AIDS: Knowledge, attitudes, and misconceptions among Black and Latino adolescents. American Journal of Public Health, 78, 55-57.

DiClemente, R.J., Durbin, M., Siegel, D., Krasnovsky, F., Lazarus, N., \& Comacho, T. (1992). Determinants of condom use among junior high school students in a minority, inner-city school district. Pediatrics, $\underline{89}, 197-200$. 
DiClemente, R.J., Lanier, M.M., Horan, P.F., \& Lodico, M. (1991). Comparison of AIDS knowledge, attitudes, and behaviors among incarcerated adolescents in a public school sample in San Francisco. American Journal of Public Health, $\underline{81}, 628-630$.

DiClemente, R.J., Zorn, J., \& Temoshok, L. (1986). Adolescents and AIDS: A survey of knowledge, attitudes and beliefs about AIDS in San Francisco. American Journal of Public Health, $\underline{76}$, 1443-1445.

Dixon, W.J., Brown, M.B., Engelman, L., Hill, M.A., \& Jennrich, R.I. (1988). BMDP Statistical Software Manual. Los Angeles, CA: The Regents of the University of California.

Doyle, J.A. (1989). The male experience (2nd Ed.). Dubuque, Iowa: Wm. C. Brown Publishers.

Dryfoos, J.G. (1991). Preventing high-risk behavior. American Journal of Public Health, $\underline{81}, 157-158$.

Dwyer, J.H. (1983). Statistical models for the social and behavioral sciences. New York: Oxford University Press.

Earleywine, M., \& Finn, P.R. (1991). Sensation seeking explains the relation between behavioral disinhibition and alcohol consumption. Addictive Behaviors, $\underline{16}$, 123-128.

Ekstrand, M.L., \& Coates, T.J. (1990). Maintenance of safer sexual behaviors and predictors of risky sex: The San Francisco men's health study. American Journal of Public Health, $\underline{80}$, 973-977. 
Ehrhardt, A.A., Yingling, S., Zawadzki, R., \& Martinez-Ramirez, M. (in press). Prevention of heterosexual transmission of HIV: Barriers for women. Journal of Psychology and Human Sexuality.

Elder, J.P., DeMoor, C., Young, R.L., Wildey, M.B., Molgaard, C.A., Golbeck, A.L., Sallis, J.F., \& Stern. R.A. (1990). Stages of adolescent tobacco-use acquisition. Addictive Behaviors, $\underline{15}$, 449-454.

Fawzy, F.I., Fawzy, N.W., \& Pasnau, R.O. (1991). Bereavement in AIDS. Psychiatric Medicine, 9, 469-482.

Fineburg, H.V. (1988). Education to prevent AIDS: Prospects and obstacles. Science, 239, 592-596.

Fiore-Lerner, C. (1990). The transtheoretical model of change: Self-change in adolescent delinquent behaviors. Unpublished doctoral dissertation, University of Rhode Island, Kingston, RI.

Fishbein, M. (1979). A theory of reasoned action: Some applications and implications. Nebraska Symposium on Motivation, 65-116.

Fisher, J.D. (1988). Possible effects of reference group-based social influence on AIDS-risk behavior and AIDS prevention. American Psychologist, 43, 914-920.

Fisher, J.D., \& Fisher, W.A. (1992). Changing AIDS-risk behavior. Psychological Bulletin, 111, 455-474.

Fitzgerald, T.E. (1990). Health risk reduction and psychosocial adaptation in coronary artery bypass graft surgery patients. Unpublished doctoral dissertation, University of Rhode Island, Kingston, RI. 
Fitzgerald, T.E., \& Prochaska, J.O. (1990). Nonprogressing profiles in smoking cessation: What keeps people refractory to self-change? Journal of Substance Abuse, 2 , 92-111.

Fitzgerald, T.E., Snow, M.G., \& Prochaska, J.O. (1988, July). A health behavior model of risk reduction for AIDS. Poster presented at the NIMH-VCPPP Conference on Psychological Approaches to the Treatment of AIDS, Burlington, VT.

Flavin, D.K., \& Frances, R.J. (1987). Risk-taking behavior, substance abuse disorders, and the Acquired Immune Deficiency Syndrome. Advances in Alcohol \& Substance Abuse, $\underline{6}, 23-32$.

Flora, J.A., \& Thoreson, C.E. (1989). Reducing the risk of AIDS in adolescents. American Psychologist, 43, 965-970.

Freeman, A., Cohn, D., Corby, N., \& Wood, R. (1991). Patterns of sexual behavior change among homosexual/bisexual men: Selected U.S. Sites, 1987-1990. Morbidity and Mortality Weekly Report, 40(46), 792-794.

Gladis, M.M., Michela, J.L., Walter, H.J., \& Vaughan, R.D. (1992). High school students' perceptions of AIDS risk: Realistic appraisal or motivated denial? Health Psychology, 11, 307-316.

Goggin, K.J. (1993, March). College Students' attitudes and knowledge regarding AIDS -- 1987 vs. 1991. What have they learned?. Paper presented at the fourteenth annual meeting of the Society of Behavioral Medicine, San Francisco, CA. 
Goldman, J.A., \& Harlow, L.L. (1990, August). Psychological variables mediating AIDS preventive behavior: A preliminary study. Paper presented at the 98th annual meeting of the American Psychological Association, Boston, MA.

Gottlieb, N.H., Galavotti, C., McCuan, R.S., \& McAlister, A.L. (1990). Specification of a social cognitive model predicting smoking cessation in a MexicanAmerican population: A prospective study. Cognitive Therapy and Research, $\underline{14}$, 529-542.

Greatorex, I.F., \& Packer, J.M.V. (1989). Sexual behaviour in university students: Report of a postal survey. Public Health, 103, 199-203.

Greene, G., Rossi, S., Reville, A., Reed, G. Blais, L. (1992, July).

Evaluation of an Individualized Feedback System for Reduction of Dietary Fat Intake. Paper presented at the Society for Nutritional Education, Washington, DC.

Grimley, D., Riley, G., Bellis, J.M., \& Prochaska, J.O. (in press). Accessing decision-making and contraceptive use of men and women for the prevention of pregnancy and sexually transmitted diseases. Health Education Quarterly.

Grimley, D., Riley, G.E., Prochaska, J.O, Redding, C.A., Ruggiero, L., Velicer, W.F., \& Rossi, J.S. (1992). Stages of Change Model and reproductive health in high-risk populations. Technical Report for the Centers for Disease Control Contract Grant \#CSA-92-109.

Guadagnoli, E., \& Velicer, W.F. (1988). Relation of sample size to the stability of component patterns. Psychological Bulletin, $\underline{103}, 265-275$.

Guydish, J.R., Abramowitz, A., Woods, W., Black, D.M., \& Sorensen, J.L. (1990). Changes in needle sharing behavior among intravenous drug users: San Francisco, 1986-1988. American Journal of Public Health, 무, 995-997. 
Harlow, L.L., Grimley, D., Quina, K., \& Morokoff, P. (1992, March).

Behavioral, interpersonal, and psycho-attitudinal predictors of HIV risk in women. Paper presented at the annual meeting of the Society of Behavioral Medicine, New York, NY.

Harlow, L.L., \& Minugh, P.A. (1989, June). Stages of cocaine habit acquisition: Scale assessment. Paper presented at the first annual meeting of the American Psychological Society, Alexandria, VA.

Harlow, L.L., Prochaska, J.O., Redding, C.A., Rossi, J.S., Velicer, W.F., Snow, M.G., Rhodes, F., Schnell, D.J., \& Galavotti, C. (1993). Self-efficacy for condom use in a high HIV-risk national sample. Manuscript in preparation.

Harlow, L.L., Quina, K., Morokoff, P.J., Grimley, D.M., \& Rose, J.S. (1993). HIV risk in women: A multifaceted model. Manuscript submitted for publication.

Hatcher, R.A., Stewart, F., Trussel, J., Kowal, D., Guest, F., Stewart, G.K., \& Cates. W. (1990). Contraceptive Technology: 1990-1992, 15th Revised Edition. New York, NY:Irvington Publishers, Inc.

Hingson, R.W., Strunin, L.,\& Berlin, B.M. (1989). Changes in knowledge and behaviors among adolescents: Massachusetts Statewide Surveys, 1986-88. Pediatrics, $\underline{85}, 24-29$.

Hingson, R.W., Strunin, L., Berlin, B.M., \& Heeren, T. (1990). Beliefs about AIDS, use of alcohol and drugs, and unprotected sex among Massachusetts adolescents. American Journal of Public Health, 80, 295-299.

Horn, D. (1976). A model for the study of personal choice health behavior. International Journal of Health Education, 19, 89-98. 
Horn, J.L. (1965). A rationale and test for the number of factors in factor analysis. Psychometrika, $\underline{30}, 179-185$.

Hornsby, P.P., \& Wilcox, A.J. (1989). Validity of questionnaire information on the frequency of coitus. American Journal of Epidemiology, 130, 94-99.

Jackson, D.N. (1967). Personality Research Form. Port Huron, MI: Research Psychologists Press.

Jackson, D.N. (1971). The dynamics of structured personality tests. Psychological Review, 78, 229-248.

Jackson, D.N. (1970). A sequential system for personality scale development. In C.D. Spielberger (Ed.), Current topics in clinical and community psychology (Vol. 2, pp. 61-96). New York: Academic Press.

Janis, I.L., \& Mann, L. (1977). Decision making: A psychological analysis of conflict, choice and commitment. New York: The Free Press.

Janis, I.L., \& Mann, L. (1968). A conflict theory approach to attitude and decision making. In A. Greenwald, T. Brook, and T. Ostrom (Eds.) Psychological Foundations of Attitudes. New York: Academic Press.

Janz, N.K., \& Becker, M.H. (1984). The Health Belief Model: A decade later. Health Education Quarterly, 11, 1-47.

Jöreskog, K.G., \& Sörbom, D. (1984). LISREL VI: Analysis of linear structural relationships by the method of maximum likelihood (User's guide). Mooresville, IN: Scientific Software, Inc.

Kalichman, S.C., \& Hunter, T.L. (1992). The disclosure of celebrity HIV infection: Its effects on public attitudes. American Joumal of Public Health, $\underline{82}$, 1374-1376. 
Kaplan, D. (1989). Model modification in covariance structure analysis: Application of the expected parameter change statistic. Multivariate Behavioral Research, 24, 285-305.

Kaplan, H.B. (1989). Methodological problems in the study of psychosocial influences on the AIDS process. Social Science and Medicine, 29, 277-292.

Kegeles, S.M., Adler, N.E., \& Irwin, C.E. (1988). Sexually active adolescents and condoms: Change over one year in knowledge, attitudes and use. American Journal of Public Health, 78, 460-461.

Kelly, J.A., \& Murphy, D.A. (1992). Psychological interventions with AIDS and HIV: Prevention and treatment. Journal of Consulting and Clinical Psychology, $\underline{60}, 576-585$.

Kelly, J.A., St. Lawrence, J.S., Hood, H.V., \& Brasfield, T.L. (1989). Behavioral intervention to reduce AIDS risk activities. Journal of Consulting and Clinical Psychology, 57, 60-67.

Kelly, J.A., St. Lawrence, J.S., Brasfield, T.L., Lemke, A., Amidei, T., Roffman, R.E., Hood, H.V., Smith, J.E., Kilgore, H., \& McNeill, C. (1990). Psychological factors that predict AIDS high-risk versus AIDS precautionary behavior. Journal of Consulting and Clinical Psychology, 58, 117-120.

Krauss, B.J., Siegel, K., \& Godfrey, C. (1993, March). Following their guidelines: Gay men's informal rationales for their safer sexual choices. Paper presented at the annual meeting of the Society of Behavioral Medicine, San Francisco, CA. 
Kristeller, J.L., Rossi, J.S., Ockene, J.K., Goldberg, R., \& Prochaska, J.O. (1992). Processes of change in smoking cessation: A cross-validation study in cardiac patients. Journal of Substance Abuse, 4, 263-276.

Leigh, B.C. (1990). "Venus gets in my thinking": Drinking and female sexuality in the age of AIDS. Journal of Substance Abuse, 2, 129-145.

Long, J.S. (1983). Confirmatory factor analysis: A preface to LISREL. Newbury Park, CA: Sage.

Lott, B. (1987). Women's lives: Themes and variations in gender learning. Pacific Grove, CA: Brooks/Cole Publishing.

MacCallum, R.C. (1986). Specification searches in covariance structure modeling. Psychological Bulletin, 100, 107-120.

Maiman, L.A., Becker, M.H., Kirscht, J.P., Haefner, D.P., \& Drachman, R.H. (1977). Scales for measuring Health Belief Model dimensions: A test of predictive value, internal consistency, and relationships among beliefs. Health Education Monographs, , 215-230.

Manning, D., Balson, P.M., Barenberg, N., \& Moore, T.M. (1989). Susceptibility to AIDS: What college students do and don't believe. College Health, $\underline{38}, 67-73$.

Marcus, B.H., Banspach, S.W., Lefebvre, R.C., Rossi, J.S., Carleton, R.A., \& Abrams, D.B. (1992). Using the stages of change model to increase the adoption of physical activity among community participants. American Journal of Health Promotion, $\underline{6}, 424-429$.

Marcus, B.H., Rakowski, W., \& Rossi, J.S. (1992). Assessing motivational readiness and decision making for exercise. Health Psychology, 11, 257-261. 
Marcus, B.H., Rossi, J.S., Selby, V.C., Niaura, R.S., \& Abrams, D.B. (1992). The stages and processes of exercise adoption and maintenance in a worksite sample. Health Psychology, 11, 386-395.

Marcus, B.H., Selby, V.C., Niaura, R.S., \& Rossi, J.S. (1992). Self-efficacy and the stages of exercise behavior change. Research Quarterly for Exercise and Sport, $\underline{63}, 60-66$.

Marlatt, G.A., \& Gordon, J.R. (Eds.) (1985). Relapse Prevention: Maintenance strategies in the treatment of addictive behaviors. New York: The Guilford Press.

Marsh, H.W., Balla, J.R., \& McDonald, R.P. (1988). Goodness of fit indexes in confirmatory factor analysis: The effect of sample size. Psychological Bulletin, 103, 391-410.

Martin, J.L. (1990). Drug use and unprotected anal intercourse among gay men. Health Psychology, 9, 450-465.

Martin, J.L., \& Dean, L. (1993). Effects of AIDS-related bereavement and HIV-related illness on psychosocial distress among gay men: A 7-year longitudinal study, 1985-1991. Journal of Consulting and Clinical Psychology, 61, 94-103.

Martin, R.A., Rossi, J.S., Rosenbloom, D., Monti, P.M., \& Rohsenow, D.J. (1992, November) Stages and processes of change for quitting cocaine. Paper presented at the 26th annual meeting of the Association for the Advancement of Behavior Therapy, Boston, MA.

McConnaughy, E.A., DiClemente, C.C., Prochaska, J.O. \& Velicer, W.F. (1989). Stages of change in psychotherapy: A follow-up report. Psychotherapy, 26, 494-503. 
McConnaughy, E.A., Prochaska, J.O. \& Velicer, W.F. (1983). Stages of change in psychotherapy: Measurement and sample profiles. Psychotherapy: Theory, research, and practice, 20, 368-375.

McCusker, J., Stoddard, A.M., Mayer, K.H., Zapka, J., Morrison, C., \& Saltzman, S.P. (1988). Effects of HIV antibody test knowledge on subsequent sexual behaviors in a cohort of homosexually active men. American Journal of Public Health, $\underline{78}, 462-467$.

McDermott, R.J., Hawkins, M.J., Moore, J.R., \& Cittadino, S.K. (1987). AIDS awareness and information sources among selected university students. Journal of American College Health, $\underline{35}, 222-226$.

McKusick, L., Hoff, C.C., Stall, R., \& Coates, T.J. (1991). Tailoring AIDS prevention: Differences in strategies among heterosexual and gay bar patrons in San Francisco. AIDS Education and Prevention, 3 , 1-9.

Medeiros, M.E. (1989). Predicting termination and continuation status in psychotherapy using the Transtheoretical Model. Unpublished doctoral dissertation, University of Rhode Island, Kingston, RI.

Medeiros, M.E. (1987). Predicting Attendance and Premature Termination in Psychotherapy. Unpublished doctoral dissertation, University of Rhode Island, Kingston, RI.

Migneault, J.M. (19.92). A validation study of stages of change for at risk drinking. Unpublished masters thesis, University of Rhode Island, Kingston, RI. Morokoff, P. (1986). Volunteer bias in the psychophysiological study of female sexuality. The Journal of Sex Research, 22, 35-51. 
Mott, F.L., \& Haurin, R.J. (1988). Linkages between sexual activity and alcohol and drug use among American adolescents. Family Planning Perspectives, $\underline{20}, 128-136$.

Mulaik, S.A., James, L.R., Van Alstine, J., Bennett, N., Lind, S., \& Stilwell, C.D. (1988). Evaluation of goodness-of-fit indices for structural equation models. Psychological Bulletin, 105, 430-445.

Nannis, E., Temoshok, L., Jenkins, R., Blake, S., Sharp-Breslau, E., Brown, G., Patterson, T., Jenkins, P., Coyle, C., Brandt, U., \& Johnson, C. (1993, March). Gender differences in transmission risk behavior, affect, and social support in HIV + individuals: Implications for interventions. Paper presented at the fourteenth annual meeting of the Society of Behavioral Medicine in San Francisco, CA.

Nagy, S., Hunt, B., \& Adcock, A. (1990). A comparison of AIDS and STD knowledge between sexually active alcohol consumers and abstainers. Journal of School Health, 60, 276-279.

Nicholas, D.R., \& Barke, C.R. (1988, August). Cognitive processes as predictors of exercise stage of change in older adults. Paper presented at the 96th annual meeting of the American Psychological Association, Atlanta, GA.

Nicholas, D.R., \& Barke, C.R., Blackford, M.L, \& Miller, G. (1988, April). Physical activity in older adults: The stages of change. Paper presented at the 9th annual meeting of the Society for Behavioral Medicine, Boston, MA.

Norcross, J.C., \& Prochaska, J.O. (1986a). Psychotherapist heal thyself - I. The psychological distress and self-change of psychologists, counselors, and laypersons. Psychotherapy, 23, 102-114. 
Norcross, J.C., \& Prochaska, J.O. (1986b). Psychotherapist heal thyself - II. The self-initiated and therapy facilitated change of psychological distress. Psychotherapy, 23, 345-356.

Norcross, J.C., Prochaska, J.O., \& DiClemente, C.C. (1986). Self-change of psychological distress: Layperson's vs. psychologist's coping strategies. Journal of Clinical Psychology, $\underline{42}, 834-840$.

Norcross, J.C., Prochaska, J.O., \& Hambrecht, M. (1991). Treating ourselves vs. treating our clients: A replication with alcohol abuse. $\underline{\text { Journal of }}$ Substance Abuse, 3 , 123-129.

Nutbeam, D., Catford, J.C., Smail, S.A., \& Griffiths, C. (1989). Public knowledge and attitudes to AIDS. Public Health, 103, 205-211.

O'Connell, D. (1988). Development of an observational coding system for assessing the processes of change in psychotherapy sessions. Unpublished doctoral dissertation, University of Rhode Island, Kingston, RI.

O'Connell, D., \& Velicer, W.F. (1988). A decisional balance measure and the Stages of Change Model for weight loss. The International Journal of the Addictions, 23, 729-750.

O'Reilly, K.R. \& Higgins, D.L. (1991). AIDS community demonstration projects for HIV prevention among hard-to-reach groups. Public Health Reports, $106,714-720$.

Pallonen, U.E., Fava, J.L., Salonen, J.T., \& Prochaska, J.O. (1992). Readiness for smoking change among middle-aged Finnish men. Addictive Behaviors, 17, 415-424. 
Pallonen, U.E., Murray, D.M., Schmid, L., Piri, P., \& Luepker, R.V. (1990). Patterns of self-initiated smoking cessation among young adults. Health Psychology, 9 , 418-426.

Penney, D. (1988). A comparison of psychotherapy-changers and self-changers in a naturalistic environment. Unpublished doctoral dissertation, University of Rhode Island, Kingston, RI.

Prewitt, V.R. (1989). Health beliefs and AIDS educational materials. Family and Community Health, $\underline{12}, 65-76$.

Price, J.H., Desmond, S., \& Kukulka, G. (1985). High school students' perceptions and misperceptions of AIDS. Journal of School Health, 55, 107-109.

Prochaska, J.O. (1979). Systems of Psychotherapy: A Transtheoretical Analysis. Homewood, IL: Dorsey Press.

Prochaska, J.O. (1986). Patterns of change in smoking behavior. Health Psychology, 5, 97-98.

Prochaska, J.O. (1991). Assessing how people change? Cancer, 67, 805-807. Prochaska, J.O. (in press). Common principles for progression from precontemplation to action based on twelve problem behaviors. Health Psychology.

Prochaska, J.O., \& DiClemente, C.C. (1982). Transtheoretical therapy: Toward a more integrative model of change. Psychotherapy: Theory, Research, and Practice, $19,276-278$.

Prochaska, J.O., \& DiClemente, C.C. (1983). Stages and processes of selfchange in smoking: Towards an integrative model of change. Journal of Consulting and Clinical Psychology, 51, 390-395. 
Prochaska, J.O., \& DiClemente, C.C. (1984a). The transtheoretical approach: Crossing the traditional boundaries of therapy. Homewood, IL: Dow Jones/Irwin.

Prochaska, J.O., \& DiClemente, C.C. (1984b). Self change processes, selfefficacy, and decisional balance across five stages of smoking cessation. In P.F. Anderson, L.E. Mortenson, \& L.E. Epstein (Eds.) Advance in Cancer Control. New York: Alan R. Liss, Inc.

Prochaska, J.O., \& DiClemente, C.C. (1985). Common processes of change for smoking, weight control, and psychological distress. In S. Shiffman \& T. Wills (Eds.), Coping and substance abuse (p. 345-364). New York: Academic Press.

Prochaska, J.O., \& DiClemente, C.C. (in press). Stages of change in the modification of problem behaviors. In M. Hersen, R.M. Eisler, \& P.M. Miller, (Eds.), Progress in behavior modification. Newbury Park, CA: Sage.

Prochaska J.O., DiClemente, C.C., \& Norcross, J.C. (1992a). In search of how people change: Applications to the addictive behaviors. American Psychologist, 47, $1102-1114$.

Prochaska J.O., DiClemente, C.C., \& Norcross, J.C. (1992b). In search of the structure of behavior change. In Y. Klar, J.D. Fisher, J.M. Chensky, \& A. Nadler, (Eds.), Self-change: Social psychological and clinical perspectives (pp. 87114). New York: Springer-Verlag.

Prochaska, J.O., DiClemente, C.C., Velicer, W.F., Ginpil, S., \& Norcross, J.C. (1985). Predicting change in smoking status for self-changers. Addictive Behaviors, 10, 395-406. 
Prochaska, J.O., DiClemente, C.C., Velicer, W.F., \& Rossi, J.S. (in press). Standardized, individualized, interactive and personalized self-help programs for smoking cessation. Health Psychology.

Prochaska, J.O., Harlow, L.L., Redding, C.A., Snow, M.G., Rossi, J.S., \& Velicer, W.F. (1990). Stages of Change, Self Efficacy, and Decisional Balance of condom use in a high HIV risk sample. Technical report to the Centers for Disease Control, contract grant \# 0-4115-002.

Prochaska, J.O. \& Norcross, J.C.(1983). Psychotherapists' perspectives on treating themselves and their clients for psychic distress. Professional Psychology: Research and Practice, 14, 642-655.

Prochaska, J.O., Norcross, J.C., Fowler, J.L., Follick, M.J., \& Abrams, D.B. (1992). Attendance and outcome in a work site weight control program: Processes and stages of change as process and predictor variables. Addictive Behaviors, $\underline{17}, 35-45$.

Prochaska, J.O., \& Prochaska, J.M. (in press a). A Transtheoretical Model of change for addictive behaviors. In M. Gossop \& M. Casas (Eds.) Psychological treatments of addictive behaviors. Barcelona, Spain: Cevron.

Prochaska, J.O., \& Prochaska, J.M. (in press b). Why don't continents move? In H. Arkowitz (Ed.) Why don't people change? New perspectives on resistance and noncompliance. New York: Guilford.

Prochaska, J.O., Redding, C.A., Harlow, L.L., Rossi, J.S., \& Velicer, W.F. (1993). The transtheoretical model and HIV prevention: A Review. Manuscript submitted for publication. 
Prochaska, J.O., Rossi, J.S., \& Wilcox, N. (1991). Change processes and psychotherapy outcome in integrative case research. Journal of Psychotherapy Integration, 1 , 103-120.

Prochaska, J.O., Velicer, W.F., DiClemente, C.C., \& Fava, J. (1988). Measuring processes of change: Applications to the cessation of smoking. Journal of Consulting and Clinical Psychology, 타 520-528.

Prochaska, J.O., Velicer, W.F., Guadagnoli, E., Rossi, J.S., \& DiClemente, C.C.. (1991). Patterns of change: Dynamic typology applied to smoking cessation. Multivariate Behavioral Research, 26, 83-107.

Prochaska, J.O., Velicer, W.F., Rossi, J.S., Goldstein, M.G., Marcus, B.H., Rakowski, W., Fiore, C., Harlow, L.L., Redding, C.A., Rosenbloom, D., \& Rossi, S.R. (in press). Stages of change and decisional balance for twelve problem behaviors. Health Psychology.

Rakowski, W., Dube, C.E., Marcus, B.H., Prochaska, J.O., Velicer, W.F., \& Abrams, D.B. (1992). Assessing elements of women's decisions about mammography. Health Psychology, 11, 111-118.

Redding, C.A., Rossi, J.S., Fava, J.L., Snow, M.G., Rossi, S.R., Prochaska, J.O., Velicer, W.F., \& DiClemente, C.C. (1989, April). Dynamic factors in the maintenance of smoking cessation: A naturalistic study. Paper presentation at the 10th annual meeting of the Society of Behavioral Medicine, San Francisco, CA. 
Redding, C.A., Rossi, J.S., Velicer, W.F., \& Prochaska, J.O. (1989, August). The pros and cons of safer sex: A measurement model. Paper presentation at the 97th annual convention of the American Psychological Association, New Orleans, LA.

Redding, C.A., \& Rossi, J.S.. (1993, March). The processes of safer sex adoption. Paper presentation at the 14th annual convention of the Society of Behavioral Medicine, San Francisco, CA.

Rosen, T.J., \& Shipley, R.H. (1983). A stage analysis of self-initiated smoking reductions. Addictive Behaviors, $\underline{8}, 263-272$.

Rosenbloom, D. (1991). A transtheoretical analysis of change among cocaine users. Unpublished doctoral dissertation, University of Rhode Island, Kingston, RI.

Rosenstock, I.M. (1974). The Health Belief Model and preventive health behavior. Health Education Monographs, 2, 354-386.

Rossi, J.S. (1989a). Exploring behavioral approaches to UV risk reduction. In A. Moshell \& L.W. Blankenbaker (Eds.), Sunlight, Ultraviolet Radiation, and the Skin (pp. 91-93). Bethesda, MD: National Institutes of Health.

Rossi, J.S. (1989b). The hazards of sunlight. The Health Psychologist, 11(3), $4-6$.

Rossi, J.S. (1990a, August). Radon and ultraviolet light: Emerging cancer risk factors. In J.O. Prochaska (Chair), Stages of change: Extensions to new areas of behavior change. Symposium presented at the 98 th annual convention of the American Psychological Association, Boston, MA.

Rossi, J.S. (1990b). Statistical power of psychological research: What have we gained in 20 years? Journal of Consulting and Clinical Psychology, 58, 646- 656. 
Rossi, J.S. (1992, August). Common processes of change across nine problem behaviors. Paper presented at the 100th annual convention of the American Psychological Association, Washington, DC.

Rossi, J.S, Bellis, J.M., \& Prochaska, J.O. (1993). Processes of change for smoking cessation: Measurement invariance across age, sex, geographical area, and stages of change. Manuscript in preparation.

Rossi, J.S. \& Bourgeois, P. (1993). Summary and commentary on "An Application of the Stage Model of Behavior Change to Dietary Fat Reduction" by S.J. Curry, A.R. Kristal, \& D. J. Bowen. Diabetes Spectrum, $\underline{6}, 42-44$.

Rossi, J.S., Prochaska, J.O., \& DiClemente, C.C. (1988). Processes of change in heavy and light smokers. Journal of Substance Abuse, 1, 1-9.

Rossi, S.R. (1993). Application of the Transtheoretical Model of behavior change to dietary fat reduction in a naturalistic population. Unpublished doctoral dissertation, University of Rhode Island, Kingston, RI.

Rossi, S.R., Rossi, J.S., \& Prochaska, J.O. (1990, August). A stage model for reducing dietary fat. In J.O. Prochaska (Chair), Stages of change: Extensions to new areas of behavior change. Symposium presented at the 98th annual convention of the American Psychological Association, Boston, MA.

Rossi, S.R., Rossi, J.S., Rossi-DelPrete, L.M., Prochaska, J.O., Banspach, S.W., \& Carleton, R.A. (in press). A processes of change model for weight control for participants in a community-based weight loss program. International Journal of the Addictions. 
Rugg, D.L. (1990). AIDS prevention: A public health psychology perspective. In Leviton, L.C., Hegedus, A.M., \& Kubrin, A. (eds.) Evaluating AIDS prevention: Contributions of multiple disciplines. San Francisco, CA: Josey-Bass Inc., 7-22.

Sacco, W.P., Levine, B., Reed, D.L., \& Thompson, K. (1991). Attitudes about condom use as an AIDS-relevant behavior: Their factor structure and relation to condom use. Psychological Assessment, $\underline{3}, 265-272$.

Schnell, D.J., Galavotti, C., \& O'Reilly, K.R. (in press). An evaluation of sexual behavior change using statistical and cognitive models. Statistics in Medicine.

Seidman, S.N., Mosher, W.D., \& Aral, S.O. (1992). Women with multiple sexual partners: United States, 1988. American Journal of Public Health, $\underline{82}$, 13881394.

Severn, J.J.H. (1990). College students and condoms, AIDS and attitudes. College Student Journal, 24, 296-306.

Siegel, K. (1988). Public education to prevent the spread of HIV infection.

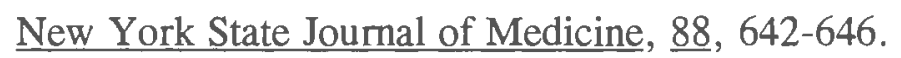

Siegel, K., Bauman, L.J., Christ, G.H., \& Krown, S. (1988). Patterns of change in sexual behavior among gay men in New York City. Archives of Sexual Behavior, 17, 481-497.

Siegel, K., \& Gibson, W.C. (1988). Barriers to the modification of sexual behavior among heterosexuals at risk for acquired immunodeficiency syndrome. $\underline{\text { New York State Journal of Medicine, }} \underline{88}, 66-70$. 
Sonstroem, R.J. (1988). Psychological Models. In R. Dishman (Ed.), Exercise Adherence, (pp. 125-154). Illinois: Human Kinetics Books.

SPSS Inc. (1988). SPSS-X User's Guide, 3rd Edition. Chicago, IL: SPSS Inc.

St. Lawrence, J.S. (1993). African-American adolescents' knowledge, healthrelated attitudes, sexual behavior, and contraceptive decisions: Implications for the prevention of adolescent HIV infection. Journal of Consulting and Clinical Psychology, 61, 104-112.

Stall, R., McKusick, L., Wiley, J., Coates, T.J., \& Ostrow, D.G. (1986). Alcohol and drug use during sexual activity and compliance with safe sex guidelines for AIDS: The AIDS Behavioral Research Project. Health Education Quarterly, 13, 359-371.

Stern, R., Prochaska, J.O., Velicer, W.F., \& Elder, J. (1987). Stages of adolescent cigarette smoking acquisition: Measurement and sample profiles. Addictive Behaviors, 12, 319-329.

Stoler, L., Cicero, J., \& Quina, K. (1990, March). Adult women's relationships and the AIDS crisis. Paper presented at the annual meeting of the Association for Women in Psychology, Tempe, AZ.

Strassberg, D.L., \& Mahoney, J.M (1988). Correlates of the contraceptive behavior of adolescents/young adults. The Journal of Sex Research, 25, 531-536.

Strunin, L. \& Hingson, R. (1987). Acquired immunodeficiency syndrome and adolescents: Knowledge, beliefs, attitudes, and behaviors. Pediatrics, 79, 825-882.

Svenson, L.W., \& Varnhagen, C.K. (1990). Knowledge, attitudes and behaviours related to AIDS among first-year university students. Canadian Journal of Public Health, $\underline{81}, 139-140$. 
Siegel, K., \& Glassman, M. (1989). Individual and aggregate level change in sexual behavior among gay men at risk for AIDS. Archives for Sexual Behavior, $\underline{18}$, $335-346$.

Siegel, K., Mesagno, F.P., Chen, J.Y., \& Christ, G. (1989). Factors distinguishing homosexual males practicing risky and safer sex. Social Science and Medicine, $\underline{28}, 561-569$.

Silvia, E.S.M., \& MacCallum, R.C. (1988). Some factors affecting the success of specification searches in covariance structure modeling. Multivariate Behavioral Research, 23, 297-326.

Snow, M.G. (1991). A transtheoretical analysis of strategies used in the recovery process from alcohol problems. Unpublished doctoral dissertation, University of Rhode Island, Kingston, RI.

Snow, M.G., Fitzgerald, T.E., \& Prochaska, J.O. (1988, November). $\underline{A}$ conceptual framework for the prevention of AIDS-related behaviors. Poster presented at the Annual Meeting of the Society of Public Health Education (SOPHE), Boston.

Snow, M.G., Prochaska, J.O., \& Rossi, J.S. (1992). Stages of change for smoking cessation among former problem drinkers: A cross-sectional analysis. Journal of Substance Abuse, 4, 107-116.

Snow, M.G., Prochaska, J.O., \& Rossi, J.S. (in press). Processes of change in AA: Maintenance factors in long-term sobriety. Journal of Studies on Alcohol.

Sonstroem, R.J. (1987, August). Stage model of exercise adoption. In D.A. Kendzierski (Chair) Exercise adoption and maintenance. Symposium conducted at annual meeting of the American Psychological Association, New York, N.Y. 
Tsoh, J.Y., Rossi, J.S., \& Prochaska, J.O. (1992, August). Effects of intention and behavior on contemplating smoking cessation. Paper presented at the 100th annual meeting of the American Psychological Association in Washington, DC.

Tucker, L.R., \& Lewis, C. (1973). A reliability coefficient for maximum likelihood factor analysis. Psychometrika, $\underline{38}, 1-10$.

Upchurch, D.M., Weisman, C.S., Shepherd, M., Brookmeyer, R., Fox, R., Celentano, D.D., Colletta, L., \& Hook, E.W. (1991). Interpartner reliability of reporting of recent sexual behaviors. American Journal of Epidemiology, 134, 11591166.

U.S. Department of Health and Human Services (1990). The health benefits of smoking cessation. U.S.D.H.H.S. Public Health Service, DHHS Publication No. (CDC) $90-8416$.

U.S. Department of Health and Human Services (1991). Healthy people 2000: National health promotion and disease prevention objectives. DHHS Pub. No. (PHS) 91-50212. Washington, DC: U.S. Government Printing Office.

Valdiserri, R.O. (1989). Preventing AIDS: The design of effective programs. Rutgers Press: New Brunswick, NJ.

Valdiserri, R.O., Lyter, D., Leviton, L.C., Callahan, C.M., Kingsley, L.A., \& Rinaldo, C.R. (1988). Variables influencing condom use in a cohort of gay and bisexual men. American Joumal of Public Health, $\underline{78}$, 801-805.

Valdiserri, R.O., Arena, V.C., Proctor, D., \& Bonati, F.A. (1989). The relationship between women's attitudes about condoms and their use: Implications for condom promotion programs. American Journal of Public Health, 79 , 499-501. 
Velicer, W.F. (1976). Determining the number of components from the matrix of partial correlations. Psychometrika, 41, 321-327.

Velicer, W.F. (1977). An empirical comparison of factor, image, and principal component patterns. Multivariate Behavioral Research, 12, 3-22.

Velicer, W.F., DiClemente, C.C., Prochaska, J.O., \& Brandenburg, N. (1985). A decisional balance measure for assessing and predicting smoking status. Journal of Personality and Social Psychology, 48, 1279-1289.

Velicer, W.F., DiClemente, C.C., Rossi, J.S., \& Prochaska, J.O. (1990). Relapse situations and self-efficacy. Addictive Behaviors, 15, 271-283.

Velicer, W.F., \& Fava, J.L. (1987). An evaluation of the effects of variable sampling on component, image, and factor analysis. Multivariate Behavioral Research, 22, 193-209.

Velicer, W.F., Hughes, S.L., Fava, J.L., Prochaska, J.O., \& DiClemente, C.C. (1993). An empirical typology of subjects within stages of change. Manuscript under review.

Velicer, W.F., \& Jackson, D.N. (1990a). Component Analysis vs. common factor analysis: Some issues in selecting an appropriate procedure. Multivariate Behavioral Research, 25, 1-28.

Velicer, W.F., \& Jackson, D.N. (1990b). Component analysis vs. common factor analysis: Some further observations. Multivariate Behavioral Research, $\underline{25}$, $95-112$.

Velicer, W.F., Peacock, A.C., \& Jackson, D.N. (1982). A comparison of component and factor patterns: A Monte Carlo Approach. Multivariate Behavioral Research, 17, 371-388. 
Velicer, W.F., Prochaska, J.O., Bellis, J.M., DiClemente, C.C., Rossi, J.S., Fava, J.L., \& Steiger, J.H. (in press). An expert system intervention for smoking cessation. Addictive Behaviors.

Velicer, W.F., Prochaska, J.O., Rossi, J.S., \& Snow, M.G. (1992). Assessing outcome in smoking cessation studies. Psychological Bulletin, 111, 23-41.

Velicer, W.F., Zwick, W., Harrop, J., \& Fava, J. (1993). Component Analysis Extended (CAX). Unpublished computer program for component analysis and the application of the Minimum Average Partial (MAP) technique.

Ventura, S.J., Taffel, S.M., \& Mosher, W.D. (1988). Estimates of pregnancies and pregnancy rates for the United States, 1976-85. American Journal of Public Health, 78, 506-511.

Weinman, M.L., Smith, P.B., \& Mumford, D.M. (1992). A comparison between 1986 and 1989 cohort of inner city adolescent females on knowledge, beliefs, and risk factors for AIDS. Journal of Adolescence, 15, 19-28.

Weinstein, N.D. (1983). Reducing unrealistic optimism about illness susceptibility. Health Psychology, 2, 11-20.

Weinstein, N.D. (1984). Why it won't happen to me: Perceptions of risk factors and susceptibility. Health Psychology, $\underline{3}, 431-457$.

Wyatt, G. (1990). Risk-taking and risk-avoiding behavior: The impact of some dispositional and situational variables. The Journal of Psychology, 124, 437- 447.

Wilcox, N.S., Prochaska, J.O., Velicer, W.F., \& DiClemente, C.C. (1985). Client characteristics as predictors of self-change in smoking cessation. Addictive Behaviors, $\underline{10}, 407-412$. 
Zeirler, S., Feingold, L., Laufer, D., Velentgas, P., Kantrowitz-Gordon, I., \& Mayer, K. (1991). Adult survivors of sexual abuse and subsequent risk of HIV infection. American Journal of Public Health, 1 , 572-575.

Zwick, W.R., \& Velicer, W.F. (1982). Variables influencing four rules for determining the number of components to retain. Multivariate Behavioral Research, 17, 253-269.

Zwick, W.R., \& Velicer, W.F. (1986). A comparison of five rules for determining the number of components to retain. Psychological Bulletin, 99, 432442 . 